\title{
Oral health promotion and tobacco use prevention in South Africa : towards an integrated educational approach
}

Citation for published version (APA):

Ayo-Yusuf, O. A. (2008). Oral health promotion and tobacco use prevention in South Africa : towards an integrated educational approach. [Doctoral Thesis, Maastricht University]. Maastricht University. https://doi.org/10.26481/dis.20081205oa

Document status and date:

Published: 01/01/2008

DOI:

10.26481/dis.20081205oa

Document Version:

Publisher's PDF, also known as Version of record

Please check the document version of this publication:

- A submitted manuscript is the version of the article upon submission and before peer-review. There can be important differences between the submitted version and the official published version of record.

People interested in the research are advised to contact the author for the final version of the publication, or visit the DOI to the publisher's website.

- The final author version and the galley proof are versions of the publication after peer review.

- The final published version features the final layout of the paper including the volume, issue and page numbers.

Link to publication

\footnotetext{
General rights rights.

- You may freely distribute the URL identifying the publication in the public portal. please follow below link for the End User Agreement:

www.umlib.nl/taverne-license

Take down policy

If you believe that this document breaches copyright please contact us at:

repository@maastrichtuniversity.nl

providing details and we will investigate your claim.
}

Copyright and moral rights for the publications made accessible in the public portal are retained by the authors and/or other copyright owners and it is a condition of accessing publications that users recognise and abide by the legal requirements associated with these

- Users may download and print one copy of any publication from the public portal for the purpose of private study or research.

- You may not further distribute the material or use it for any profit-making activity or commercial gain

If the publication is distributed under the terms of Article $25 \mathrm{fa}$ of the Dutch Copyright Act, indicated by the "Taverne" license above, 


\section{Oral Health Promotion and Tobacco Use Prevention in South Africa}

Towards an integrated educational approach

Olalekan Abdulwahab Ayo-Yusuf 



\title{
Oral Health Promotion and Tobacco Use Prevention in South Africa
}

\author{
Towards an integrated educational approach
}

\author{
DISSERTATION \\ to obtain the degree of Doctor at \\ the Maastricht University, \\ on the authority of the Rector Magnificus, \\ Prof. Dr. G.P.M.F. Mols, \\ in accordance with the decision of the Board of Deans, \\ to be defended in public \\ on Friday 5 December 2008, at 12 h00 hours
}

by

Olalekan Abdulwahab Ayo-Yusuf 


\section{Supervisor(s):}

Prof. Dr. H. W. van den Borne

Prof. Dr. S. P. Reddy, Medical Research Council, South Africa

\section{Assessment Committee:}

Prof. Dr. H. de Vries (Chairman)

Prof. Dr. J. Frencken (Radboud Universiteit, Nijmegen)

Prof. Dr. G.J. Kok

Prof. Dr. G. Majoor

Prof. Dr. N. K. de Vries

ISBN: 978-0-620-42190-4

Printed by: UP Printers, Pretoria.

Cover design by: Pixart Dynamic, Centurion, South Africa.

Cover images: American Lung Association/Life Skills Training South Africa: Grade 10

The studies presented in this dissertation were conducted at the University of Pretoria and the Maastricht Care and Public Health Research Institute (CAPHRI) and was funded by the Medical Research Council and the Cancer Association of South Africa (CANSA). The authors are also grateful to CAPHRI for financial contribution in support of my stay in Maastricht to finalize this dissertation. 


\section{Table of Contents}

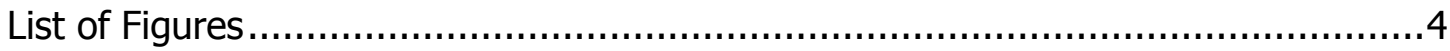

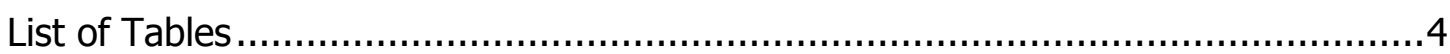

Overview of the dissertation.........................................................................

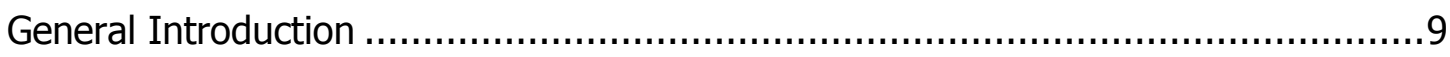

Part 1: Health Problems: Tobacco use as Common-Risk for Poor Oral and Systemic Health

\section{Chapter 1:}

Adolescents' Sense of Coherence and Smoking as Predictors of Gingivitis 37

\section{Chapter 2:}

The Association of Tooth Loss and Smoking with Hypertension in South Africa........55

\section{Chapter 3:}

The Association of Snuff Use and Smoking with Chronic Bronchitis .67

Part 2: Determinants of Oral Health-Related Risk Behaviours: Poor Oral Hygiene Care and Smoking

Chapter 4: Adolescents' Sense of Coherence and Smoking Predicts Tooth Brushing Behaviour

Chapter 5: Association of Smoking-Related Oral Health Attitude with Adolescents' Smoking Onset. 102

Part 3: Evaluating an Integrated Social Skills-Based Educational Intervention .... 113

Chapter 6: Oral Health Promotion Integrated with Smoking Prevention:

Outcomes from a Randomized Controlled Trial................................ 114

General Discussion and Conclusions ............................................. 135

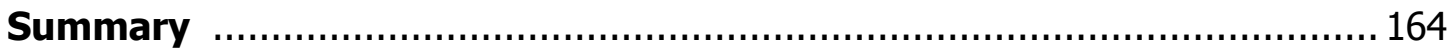

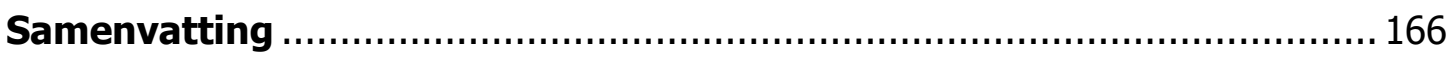

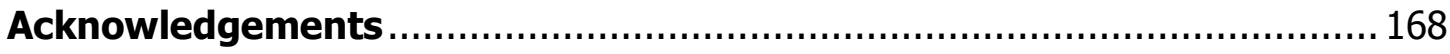

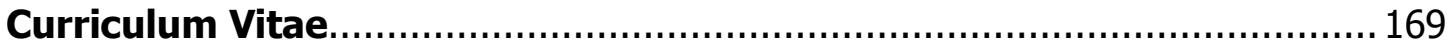




\section{List of Figures}

Figure 1: A schematic diagram providing an overview of the current dissertation............6

Figure 2: The model for planned health education interventions.............................22

Figure 3: Conceptual framework: An adapted integrated behaviour change model (Adapted from De Vries et al., 2003).................................................... 86

Figure 4: Flow diagram of recruitment of study participants (Consort figure)............. 122

Figure 5: Daily brushing prevalence by treatment group and gender ..................... 125

Figure 6: A multilevel intervention framework for integrated action: Tobacco control and oral health promotion (adapted from Reddy, 1999)........................... 149

\section{List of Tables}

Table 1: South African National Oral Health goals set for 2005 (DOH, 2001) 14

Table 2: Characteristics of participants that provided follow-up data compared to those of drop-outs. 44

Table 3: Factors associated with self-reporting of recent frequent gingival bleeding........45

Table 4: Tooth loss and hypertension by socioeconomic and health/behavioral

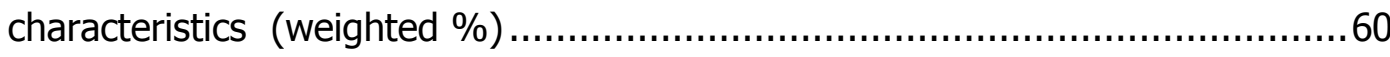

Table 5: Mean diastolic and systolic blood pressure by dental status and risk factors ......61

Table 6: Multiple logistic regression models for hypertension (BP $\geq 160 / 95 \mathrm{mmHg}$ ) ........62

Table 7: Prevalence of snuff use and chronic bronchitis relative to socio-demographic and exposure characteristics. ............................................................ 73

Table 8: Multiple logistic regression model for chronic bronchitis..............................74

Table 9: Six-item Sense of coherence (SOC) questionnaire used ..............................91

Table 10: Baseline characteristics of study participants compared to that of drop-outs who were not regularly brushing their teeth at least twice daily.

Table 11: Sequential logistic regression analysis predicting consistent twice-a-day brushing

Table 12: Characteristics of non-smokers at baseline by smoking status after

12 months. 108

Table 13: Predictive models assessing the influence of oral health attitude on smoking initiation

Table 14: The structure of the LST intervention by grade level........................... 118

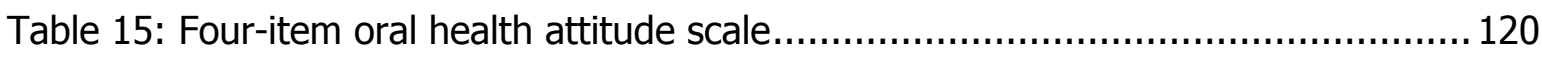

Table 16: Sample Description: Cohort and drop-outs by group assignment ..................123 
Table 17: Primary outcomes at baseline and follow-up by assigned groups 124

Table 18: Secondary outcomes at baseline and follow-up by assigned group and gender 127 
Figure 1: A schematic diagram providing an overview of the current dissertation

Social skills-based educational intervention integrating oral health promotion with smoking prevention

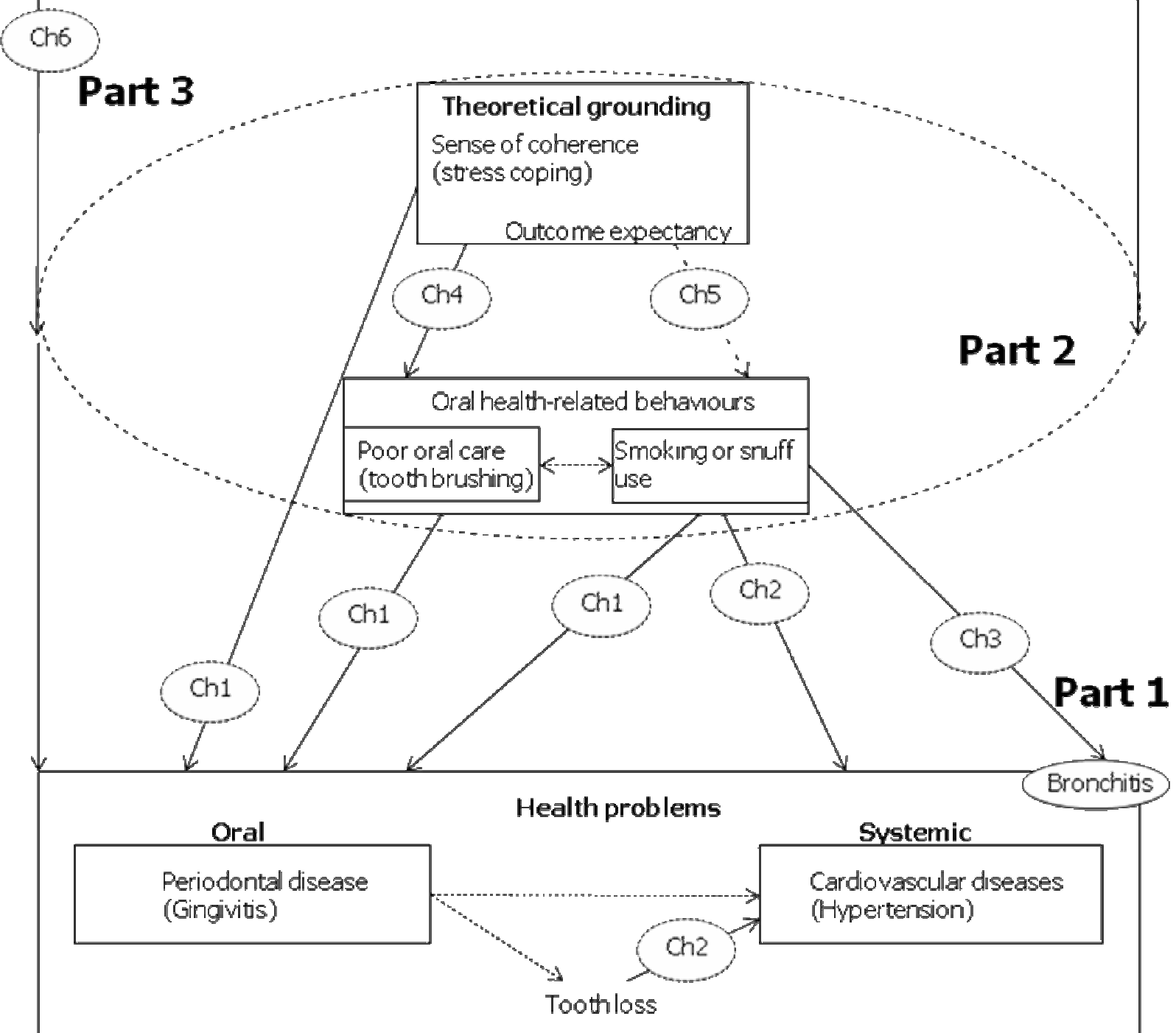

NB: Labeled pathways illustrate the areas of investigation covered by the various referenced Chapters forming parts of this dissertation ( $\mathrm{Ch}=$ Chapter). 


\section{Overview of the dissertation}

In Figure 1, an integrated overview of the main Chapters constituting the various parts of this dissertation is presented.

General introduction provides a situational analysis of oral health and tobacco control in South Africa and presents an overview of the literature on the relationship between oral health, tobacco use and general health. Next, this section of the dissertation outlines the theoretical basis for proposing the integration of oral health promotion with tobacco use prevention and, finally it summarizes the organisational framework employed in relating the different studies that are presented in this dissertation.

\section{Part 1:}

\section{Health problem: Tobacco use as common-risk for oral and systemic health}

Chapters 1, 2 and 3 cover findings from a longitudinal study of psychosocial and clinical (oral hygiene) factors associated with adolescents' poor oral health (namely 'bleeding gums' or gingivitis) (Chapter 1) and describes results from the secondary analysis of the 1998 South African Demographic and Health Survey (so far the largest of its kind in South Africa) (Chapters 2 and 3). This part of the dissertation explores the contribution of smoking and of snuff use to both oral disease and systemic disease. It also provides information on the association between the end-stage of common oral diseases (namely tooth loss) and the major systemic disease burden (hypertension) in South Africa.

\section{Part 2:}

\section{Determinants of oral health-related risk behaviours: Poor oral- self care and smoking}

Using longitudinal study designs, Chapters 4 and 5 explore the determinants of regular tooth brushing and smoking among adolescents. In particular, this part of the dissertation explores the relationship between adolescents' oral health behaviour and attitude on the one hand and, their smoking behaviour on the other. These studies in Chapter 4 and 5 were grounded mainly in the sense of coherence construct of salutogenic theory and the outcome expectancy construct of social cognitive theory, respectively. 


\section{Part 3:}

\section{Evaluating an integrated social skill-based educational intervention}

Chapter 6, reports on the findings of a randomised controlled trial evaluating the effectiveness of a smoking prevention programme in promoting oral health among adolescents.

The section on general discussion and conclusions presents a discussion of the main findings of the studies in this dissertation, describes the methodological limitations, and suggests what the implications of the findings are for future research. 


\section{General Introduction}




\section{Introduction}

Periodontal diseases and dental caries are the most prevalent oral diseases and are also the primary causes of tooth loss (Albandar, Brunelle \& Kingman, 1999). Poor oral health could adversely influence individuals' overall quality of life, self-esteem and social confidence. The perceived poor appearance of teeth and/or the presence of bad breath and pain associated with oral diseases may in fact impair social functioning, because sufferers may avoid laughing, smiling and close contact with others.

The World Health Organization (WHO) defines health not only as the absence of disease, but also as a state of complete physical, mental and social well-being (United Nations Department of Public Information, 1948). By implication, the professional discipline of dentistry, which is primarily concerned with improving facial appearance and the prevention of diseases of the soft and hard tissues of the upper jaw (including the maxillary air sinuses) and the lower jaw (including the oral cavity), is an integral part of promoting health in general. Oral diseases are largely preventable, but they still pose a significant risk to the quality of life of many people in developing countries where pain control and dental treatment are not readily available (Hunter \& Arbona, 1995). Among adults, dental problems were ranked third after gastric problems and coughing on a list of frequently mentioned health complaints in a poor peri-urban black community in Pretoria, the capital of South Africa (Westaway, 1990).

The 1999-2002 South African children's oral health survey, using the WHO (1997) community periodontal index (CPI), examined the condition of the participating children's gums and other supporting tissues (periodontium) around one representative tooth in each section of the mouth, which was divided into six equal sections or sextants (3 sextants each on the upper and lower jaw respectively). This survey demonstrated that only $15 \%$ of 15 -year-old South Africans presented with all six sextants in a state that was considered periodontally healthy; in other words, gum bleeding (CPI 1), calculus deposits (CPI 2) and/or shallow (CPI 3) and deep (CPI 4) periodontal pockets were all absent (Van Wyk, 2003). On average, each of the adolescents examined presented with only 2.5 healthy sextants (Van Wyk, 2003). This did not meet the WHO's set goal of at least 3 healthy sextants for this age category (Gjermo, 1994) for the year 2000, nor the oral health goal of 5 healthy sextants set by the South African National Department of Health (DoH) for 2005 (DoH, 2001). This situation contrasts with that found with regard to dental caries.

The 1999-2002 oral health survey showed that the set 2005 goal of having fewer than 1.5 teeth among 12-year-olds showing a caries experience (decayed, missing or filled teeth - DMFT) has already been reached. This survey demonstrated that the 12-year-olds presented with a mean DMFT of 1.1 ; and $63.1 \%$ had sound or healthy teeth (no caries experience). However, these aggregate statistics conceal the disparities in oral disease patterns observed among the children examined across the nine provinces of South Africa. Dental caries, which results from the frequent consumption of fermentable carbohydrates (sugars), was more prevalent in the more urbanized provinces of South Africa than in the rural provinces. By contrast, the reverse was true for periodontal disease, which is an 
infection primarily related to inadequate plaque control or poor oral hygiene. In particular, the highest caries severity or mean DMFT of 2.0 was observed among 12-year-olds residing in the urbanized Western Cape Province, while the lowest DMFT of 0.3 was recorded among children in the rural Limpopo Province (Van Wyk, 2003). The caries level in Limpopo province is thus even much lower than the 2010 goal of DMFT of 1 set for South Africa (DoH, 2005). On the other hand, the prevalence of the severe form of periodontal disease demonstrated by the presence of shallow and/or deep periodontal pockets among 15-year-olds was much higher in the Limpopo Province than in the Western Cape Province (11\% vs. 4.2\%).

A similar social gradient has been observed in the North American adult population, where poorer hygiene and a higher prevalence of periodontal diseases was found among blacks (who have lower socio-economic status than whites) than among whites (Albandar, 2002). It has also been noted that the prevalence of periodontal disease among adolescents tend to be associated with socio-economic class (López, Fernández \& Baelum, 2006).

Of the nine provinces in South Africa, the Limpopo Province (90\% rural) does indeed have the lowest human development index and has the highest proportion of black Africans $^{1}$ (people of African descent) (Statistics South Africa, 2001) who were historically disadvantaged by their exclusion from the mainstream economy and the educational and health care system of South Africa under the former apartheid government in South Africa. Despite the apparent decline in caries levels recently reported among South African adolescents (Van Wyk, 2003), South African adolescents, particularly those belonging to the historically disadvantaged population groups still have a significant burden of poor periodontal/gingival health.

Twice-daily brushing with fluoridated toothpaste is the universally recommended evidence-based oral self-care practice or oral health behaviour for the promotion of oral health among children and adults (Brothwell, Jutai \& Hawkins, 1998). It remains the most effective practice for the prevention of periodontal disease (Lang, Ronis \& Farghaly, 1995), caries (Nguyen et al., 2008) and subsequent tooth loss (Kressin et al., 2003). Less than daily tooth brushing has also recently been associated with an increased risk of oral and oropharyngeal cancer (Velly et al., 1998; D'Souza et al., 2007). Admittedly, oral and oropharyngeal cancer is not a common oral disease, but it is associated with a high risk of mortality.

Unlike the prevention of caries, the prevention of periodontal diseases, including the less severe form such as gingivitis (gum infection that presents as frequent bleeding gums) is influenced less by dietary control (Moynihan \& Petersen, 2004) than by adequate

\footnotetext{
1 The racially classified social groups (RCSG) used here are classified according to the system used in the population census in South Africa. The four RCSGs used in this study, namely whites (of European ancestry), blacks/Africans (of African ancestry), coloureds (mixed race) and Asian/Indians (of Asian ancestry) refer explicitly to the social conception of race (King, 1997). Of South Africa's population of 44.8 million, $79 \%$ are classified as blacks/Africans, $8.9 \%$ as coloured, $2.5 \%$ as Indians/Asians and $9.6 \%$ as whites (Statistics South Africa, 2001).
} 
plaque control related to self-care practices such as regular tooth brushing (Albandar, 2002).

The prevention of periodontal diseases therefore requires a more behavioural approach: merely making available toothbrushes and toothpaste may not be enough to guarantee their regular use by adolescents and it does not necessarily translate to improved periodontal health. A report showed 17,014 school brushing sessions across many schools in the Limpopo Province during 2000/2001 and an estimated expenditure of about R27million ( US\$4 million) on oral health services during the same period (DoH, 2002), but the children in the Limpopo Province still presented with the worst periodontal condition of any province in the 1999-2002 survey. Nevertheless, school brushing programmes have indeed been reported to be ineffective in sustaining long-term good oral hygiene/plaque control in South Africa (Maraj \& Kroon, 2004) and elsewhere (Watt, 2005). Hence, there is a need for novel approaches to oral health promotion, especially in resource-poor settings.

A recent review of global risk factors and risk indicators for periodontal diseases concluded that periodontal disease is a multi-factorial disorder, and that bacterial plaque is only the principal aetiological factor. Several other local and systemic factors have a modifying role in the pathogenesis of periodontal disease (Albandar, 2002).

Some of the less well-investigated factors that influence the onset and/or progression of periodontal disease among adolescents include stress and tobacco use, which are important factors that influence the individuals' immune response to bacterial plaque (Ballieux, 1991; Giannopoulou, Kamma \& Mombelli, 2003). Smoking was identified as the environmental factor with the most documented evidence of association with poor periodontal health among adults and it was also confirmed in a recent review to be a very important risk factor for periodontal disease (Albandar, 2002). Another systematic review also suggests that socio-economic status may be of less importance than smoking as a risk factor for periodontal disease in adulthood (Klinge \& Norlund, 2005).

Results from a large population survey among Swedish school children have shown that both smokeless tobacco (snuff) use and smoking have a significant influence on gingival health and that they affect plaque accumulation (poor oral hygiene), even after controlling for predictors such as the frequency of tooth brushing and gender differences in oral self-care (Modeer, Lavstedt \& Ahlund, 1980). Other more recent studies have also shown that smoking among adults is the second-most important risk factor for periodontitis after poor oral hygiene (Prayitno, Addy \& Wade, 1993; Amarasena, Ikeda \& Win, 2002). A little over $50 \%$ of adult periodontal disease in the United States (US) has been attributed to smoking (Tomar \& Asma, 2000) and about one-third of periodontal disease in Australia has been attributed to smoking (Do et al., 2008). According to Do et al. (2008), the hazardous effect of smoking on the gums is higher among the younger population than in the older population.

In addition to being associated with cancer and coronary disease, tobacco use among adults also plays a role in the aetiology of a number of other oral conditions - it is a primary risk factor for oropharyngeal cancer, as well as for leukoplakia (pre-cancer), impaired oral wound healing after periodontal surgery or implant placement, staining of 
teeth and restorations, bad breath, tooth loss (European Union Working Group on Tobacco and Oral Health, 1998) and the exacerbation of oral manifestations of diabetes (Grossi, 2000). Smokers have a higher prevalence of oral sites with plaque accumulation and sites that bleed upon probing than non-smokers have (Do et al, 2003). In general, the current body of evidence suggests a very strong association between smoking and periodontal disease of varying severity. Smoking has been estimated to be associated with between a 2- and 7-fold increase in the risk of periodontal disease compared to non-smoking (Albandar, 2002).

A recent review also suggests that exposure to second-hand smoke (SHS) may engender plasma nicotine concentrations that are equivalent to levels produced by tobacco smoking (Okoli, Kelly \& Hahn, 2007). The short- and long-term general health effects of SHS, including increased rates of lower respiratory illness and middle ear effusion, asthma and the development of childhood cancer are well documented (Prokhorov et al, 2006). However, the effects of SHS on the oral health of children and adolescents remain poorly defined (Billings, Berkowitz \& Watson, 2004). Nevertheless, emerging evidence suggests that SHS is associated with an increased risk of melanin pigmentation in the gingivae of children (Hanioka et al., 2004). Although dental caries is widely recognised as an infectious disease induced by diet, it can also be influenced by the susceptibility of the tooth to SHS. Previous animal and human studies have indeed demonstrated that nicotine exposure could results in disturbances in tooth development (Saad, 1990; Heikkeninen et al., 1994; Chowdhury \& Bromage, 2000). SHS may also result in pre-term low birth-weight infants (American Academy of Pediatrics, 1997; Steyn et al., 2006), who may also present with developmental defects of the tooth structure such as enamel hypoplasia, which have been associated with the promotion of the growth of caries-causing bacteria and thus increased risk for caries development (Seow, 1991; Li, Navia \& Bian, 1996). Previous epidemiological surveys conducted in developed countries have also suggested that exposure to SHS increases the risk of primary teeth caries in children (Williams, Kwan \& Parson, 2000; Aligne et al., 2003; Shenkin et al., 2004). Avşar et al. (2008) also recently demonstrated a significant association between exposure to SHS and increase primary teeth caries and an associated increase in bacterial count, decrease in salivary flow rate, buffering capacity and $\mathrm{pH}$.

Two other studies have suggested that SHS exposure may increase the risk of periodontal disease in adults (Arbes, Agústsdóttir \& Slade, 2001; Yamamoto et al., 2005). The association between SHS and periodontal disease has recently been shown to be a result of its association with the elevation of salivary biomarkers - mainly inflammatory mediators - associated with the development of adult periodontitis (Nishida et al., 2006). In addition to the effects of smoking on the immune system and reduced blood supply to the periodontum or gums (Boström, Linder \& Bergström, 1999), nicotine in tobacco has also been shown to inhibit the attachment and growth of periodontal ligament fibroblasts (James et al., 1999); and it decreases the protein content and thus irreversibly damages the cell membrane of fibroblasts (Alpar et al., 1998).

Preventing the initiation of tobacco use by youths is as fundamental to the prevention of periodontal disease and oro-pharyngeal cancer as providing fluoride and dental sealants 
to the prevention of dental caries (Sheiham \& Watt, 2000). From the epidemiological evidence presented it can be concluded that many of the national goals set for oral health in South Africa (Table 1) by 2005 (DoH, 2001) must have been influenced by both the level of improvement in oral hygiene achieved through regular tooth brushing with fluoridated toothpaste and the level of tobacco control achieved among adolescents and adults.

Table 1: South African National Oral Health goals set for 2005 (DOH, 2001)

\begin{tabular}{|l|l|}
\hline Goal & Objectives \\
\hline 1 & Age 5-6: 70\% caries-free \\
\hline 2 & Age 12: less than 1.5 DMFT (Score of 0 means sound teeth) \\
\hline 3 & $\begin{array}{l}\text { Age 15: at least } 5 \text { healthy sextants (CPI 0), the remainder scoring CPI } 1 \text { or } 2 \text { (score of } 0 \\
\text { means healthy gums) }\end{array}$ \\
\hline 4 & $\begin{array}{l}\text { Age 18: to ensure that } 60 \% \text { or more of those in this age group will retain all their teeth } \\
\text { (excluding third molars) }\end{array}$ \\
\hline 5 & $\begin{array}{l}\text { Age 35-44: no more than } 5 \% \text { edentulous; } 80 \% \text { with a minimum of } 20 \text { functional teeth. No } \\
\text { more than } 0.1 \text { sextants scoring CPI } 4 \text { (severe periodontal disease) }\end{array}$ \\
\hline 6 & $\begin{array}{l}\text { Age 65-74: no more than } 15 \% \text { edentulous; } 60 \% \text { with minimum of } 20 \text { functional teeth. No } \\
\text { more than } 0.5 \text { sextants scoring CPI } 4 \text { (severe periodontal disease) }\end{array}$ \\
\hline 7 & $\begin{array}{l}\text { The Age Standardized Incidence Rate (ASIR) of the combined figures for mouth, tongue, } \\
\text { lip and gingival cancer be } 6.9 \text { per } 100 \text { 000. The national mean in } 1989 \text { was } 6.9 \text { per } 100 \\
000 .\end{array}$ \\
\hline
\end{tabular}

*CPI=Community Periodontal Index

\section{Tobacco control in South Africa}

There is a growing body of scientific literature that implicates tobacco as the largest single preventable cause of illness and premature death (World Bank, 1999). Of the predicted 10 million annual tobacco-related deaths that may occur by $2030,70 \%$ will occur in developing countries (WHO, 2002). Of the 17 mortality risk factors recently assessed in South Africa, smoking ranked third highest after unsafe sex/sexually transmitted disease and high blood pressure (Norman et al., 2007). Smoking is already estimated to be the cause of $8 \%$ to $9 \%$ of all annual adult deaths in South Africa (Sitas et al., 2004; Groenewald et al., 2007). Tobacco control is indeed one of the most cost-effective public health interventions for the reduction of mortality from chronic diseases (Asaria et al., 2007).

Although adult tobacco consumption appears to be on the decline due to effective legislation (Steyn et al., 2002), South Africa still has one of the highest rates of tobacco consumption in Africa; nearly 1 in 4 adult South Africans smoked cigarettes during 1998 (Steyn et al., 2002). There are distinct gender and ethnic/racial differences in the prevalence and form of tobacco use among adult South Africans (Steyn et al., 2002). Cigarette smoking is most prevalent among South African coloured men and women, with prevalence rates of $49 \%$ and $39.4 \%$ respectively. The smoking rate is lowest among black Africans, with a smoking prevalence of $35 \%$ and $5.4 \%$ among men and women respectively. On the other hand, smokeless tobacco (snuff) is predominantly used by 
black Africans, with prevalence rates of $1 \%$ and $13 \%$ among men and women respectively during 1998. Less than $1 \%$ of other racial groups used smokeless tobacco (Steyn et al., 2002). Similarly, gender, ethnic/racial and geographical differences in the prevalence and form of tobacco use has also been recently reported among South African adolescents (Reddy et al. 2003).

The first and as yet the only South African Youth Risk Behaviour (YRBS) survey (conducted in 2002) showed that the national past-month smoking prevalence rate was $21.1 \%$. The highest rate was observed in the Western Cape Province (37.7\%) and among coloured youths (39.5\%), while the lowest rate was observed in the Limpopo Province (14\%) and among black African youths (17.3\%) (Reddy et al., 2003). On the other hand, the prevalence of adolescent smokeless tobacco use was the highest in the Limpopo Province (14.4\%) and among black African youths (11.3\%). The prevalence of smokeless tobacco in the Western Cape Province $(7.8 \%)$ and among coloured youths $(7.5 \%)$ was, however, below the estimated national prevalence average of $10.5 \%$. Except for the Western Cape Province where there was no gender difference, smoking rates were significantly higher among males than females in all other provinces. There were, however, no significant gender differences in smokeless tobacco use rates.

Another $25 \%$ of non-smokers in South Africa are exposed to SHS in their homes (Steyn et al., 2002). In South Africa, women and children are the most vulnerable to SHS exposure (Steyn et al., 2002; Steyn et al., 2006). A recent study suggests that about $57 \%$ of South African pregnant women who do not use tobacco are exposed to SHS by a household member (HHM) (Steyn et al., 2006). The WHO estimated that 700 million or almost half of the children in the world are exposed to SHS (WHO, 1999). Similarly, the most recent South African global youth tobacco survey showed that $43.6 \%$ of 13 - to $15-$ year-old South African adolescents are exposed to SHS (Swart et al., 2004). Smoking by HHMs, even where mothers do not smoke has an enormous adverse impact on the health of children, and it increases the use and cost of health services (Lam, Leung \& Ho, 2001).

Smoking quit rates are still very low, particularly among non-white South African smokers (Steyn et al., 2002). Due to the lack of consistent associations between snuff and major diseases (particularly in the developed nations), snuff is promoted as a reducedharm tobacco product and it has been advocated that it be offered to smokers who cannot quit (Kozlowski et al., 2001; Stratton et al., 2001). Other researchers have expressed concerns about the unintended consequences of such a harm-reduction strategy, which may include providing a gateway to adolescent smoking (Tomar, 2002; 2003; Severson, Forrester \& Biglan, 2007) and/or establishing dual tobacco product use (Henningfield, Rose \& Giovino, 2002). Although in South Africa, snuff use, which includes the nasal use of both moist and dry snuff, may be different from the pattern of use in developed nations (Critchley \& Unal, 2003; Ayo-Yusuf, Swart \& Pickworth, 2004), snuff use is perceived by some South African adolescents as a safer alternative to cigarette smoking (Peltzer, 2003).

Whereas the health consequences of smoking are well documented, apart from the reported effects of oral snuff use on periodontal disease (Offenbacher \& Weathers, 1985; Fisher, Taylor \& Tilashalski, 2005), only limited information is available on the general health effects of smokeless tobacco or snuff use, particularly in South Africa. Nevertheless, 
the majority of black South African women who use tobacco products do so in the form of snuff, with the national prevalence previously mentioned to be estimated at $13.2 \%$ during 1998 as compared to a smoking prevalence of $5.3 \%$ in the same population (Steyn et al., 2002). Therefore, without an evidence base to support such a harm reduction approach in South Africa, it remains important to continue to develop effective tobacco prevention programmes to reduce the initiation of use of all forms of tobacco products.

In recognition of the threat tobacco use poses to health and social development and consistent with the WHO Framework Convention on Tobacco Control (WHO, 2005), a remarkably consistent tobacco control (TC) policy has been followed in South Africa (SA) over the past 10 years. Notable are the strong legislative actions set within the Tobacco Products Control (TPC) Act of 1993 (TPC Act 83 of 1993), followed by the TPC amendment Act of 1999 (TPC Act 12 of 1999), which included a partial ban on smoking in public places. Smoking prevalence decreased from 35\% in 1995 (Reddy, Meyer-Weitz \& Yach, 1996) to 25\% in 1998 (Steyn et al., 2002). Between 1993 and 2000, per capita cigarette consumption in South Africa decreased by about 40\% (Van Walbeek, 2002). This significant decrease has been ascribed to a consistent annual increase in the real retail prices of cigarettes, especially since 1994, which is in support of the objectives of the legislation. However, most of the decrease in the per capita cigarette consumption has been explained by a reduction in the average number of cigarettes consumed by smokers, and only to a lesser degree by an actual reduction in smoking prevalence (Van Walbeek, 2002). This trend was also confirmed in a study by Ayo-Yusuf (2005), which indicated that the average annual decrease of 4\% in smoking prevalence recorded between 1998 and 2003 compares favourably with what would be expected in high-income countries that follow tax increases similar to those followed in South Africa, but this compares less favourably with an average annual decrease rate of 8.8\% earlier observed between 1995 and 1998, which is in line with what is expected as a response to price increases in lowincome and middle-income populations (Levy, Chaloupka \& Gitchell, 2004) such as those in South Africa. This finding, taken together with the fact that the most recent Global Youth Tobacco Survey (GYTS) conducted in South Africa (Swart et al., 2004), suggests that the decline in adolescent smoking was not statistically significant, emphasizes the need for continued efforts directed at smoking reduction among South African adolescents through the development of novel approaches to adolescent smoking prevention.

\section{The case for integrating oral health promotion with adolescent tobacco use prevention}

Given the economic crisis in health care in South Africa, and the demands on limited resources, there is unlikely to be an increase in the allocation of money to dental care in the foreseeable future, and thus there is a strong need to embrace a common-risks or integrated strategy. Within the nationally adopted health-promoting school initiative (Swart \& Reddy, 1999) and in line with the proposed national (DoH, 1997; DoH, 2001), regional (Myburg, Hobdell \& Lallo, 1998) and international oral health prevention strategies (Petersen, 2003), there is a need to design and evaluate integrative approaches 
to oral health promotion in South Africa. Such an integrative approach would also give effect to the recent resolution of the World Health Assembly on oral health taken in May 2007 (WHO, 2007).

The effectiveness of traditional school-based dental health education based on the dissemination of information has been challenged in recent times and a common-risk factor approach to oral health promotion is now favoured (Watt, 2002). This approach addresses risk factors (such as tobacco use, stress, diet) or protective factors (such as adequate coping) common to many chronic conditions within the context of the wider socio-environmental milieu and promises to have much greater impact on public health when measured in terms of improved quality of life (Sheiham \& Watt, 2000). Similarly, addressing risk behaviours in concert can maximise the efficacy of interventions, because changing one behaviour can serve as a gateway for change in other behaviours (Emmons et al., 1994). Albandar and Rams (2002) recently suggested that the fact that dental health education programmes have been relatively ineffective in making sustained changes in oral hygiene behaviours (such as regular tooth brushing) may be partly related to a failure to incorporate in these programmes any social context factors (such as bad breath and social functioning) and other factors such as loss of function and aesthetics (for example due to stained teeth) and the general health impact of periodontal diseases.

There is indeed growing evidence implicating periodontal disease as a risk factor for pre-term low- birth-weight infants (Offenbacher et al., 1996; Scannapieco, Bush \& Paju, 2003), poor diabetic control (Aldridge et al., 1996) and cardiovascular disease (Beck et al., 1996; Joshipura et al., 1996). Recent studies also suggest that tooth loss or edentulousness, which may result from dental caries and periodontal disease, is associated with increased mortality from cardiovascular disease (Cabrera et al., 2005; Tu et al., 2007), increased risk of oral and oropharyngeal cancer (Rosenquist et al., 2005), gastric cancer (Abnet et al., 2005), oesophageal cancer (Abnet et al., 2001) and pancreatic cancer (Stolzenberg-Solomon et al., 2003) and even death (Abnet et al., 2005). Tobacco use is also a risk factor for periodontal diseases (Johnson \& Slach, 2001; Bergström, 2004), cardiovascular diseases and the aforementioned cancers. Cardiovascular diseases account for the largest proportion of deaths attributed to smoking in South Africa (Groenewald et al., 2007). In the majority of South Africans, hypertension is the single most important risk factor for cardiovascular disease (Steyn et al., 2002; Alberts et al., 2005; Connor et al., 2005), but a number of factors, including tobacco use, have been associated with the development of hypertension among both South African men and women, irrespective of their race/ethnicity (Alberts et al., 2005; Connor et al., 2005).

Although little is known of the association between poor oral health and systemic health in South Africa, from the epidemiological evidence available elsewhere, it is conceivable that behavioural interventions that address important risk factors common to both oral diseases (and tooth loss) and systemic diseases would have a significant public health impact in South Africa. Such behavioural interventions would typically include promoting healthy dietary habits (reducing frequent daily sugar intake), improving oral hygiene (through regular tooth brushing) and preventing tobacco use. However for reasons previously alluded to (such as the greater burden of periodontal disease in the 
adolescent population under study), the current dissertation focuses on tobacco use as common risk factor for periodontal disease, edentulousness (tooth loss) and poor systemic health (refer to Figure 1). Poor oral health is therefore operationalised in this dissertation as the presence of periodontal disease (gingivitis) and its end-stage, namely tooth loss (edentulousness). While the long-term consequences of untreated oral diseases (notably tooth loss) are more commonly experienced in adulthood, the prevention of the oral diseases and eventual tooth loss is best instituted in the early stages of life through the promotion of regular tooth brushing with fluoridated toothpaste and the prevention of tobacco use in adolescence.

\section{Psychological determinants of tooth brushing and smoking behaviour in adolescents}

Oral health behaviours central to the promotion of oral health include limiting frequent sugar intake to less than four times daily (Moynihan \& Petersen, 2004), brushing twice or more often daily and making regular dental visits (at least once a year) for routine professional care (Levine, 2004). Regular tooth brushing remains the most important aspect of the control of periodontal disease, which has been identified as the oral disease priority among adolescents in the Limpopo Province, who in turn are the recipients of the intervention reported on in the this dissertation. The observed decline in dental caries in developed countries (Bratthall, Hänsel-Petersson \& Sundberg, 1996) and more recently in South Africa (Van Wyk, Louw \& Du Plessis, 2004) has also been mainly associated with the increased availability of fluoridated toothpaste for use with toothbrushes. Therefore, it can be reasonable to expect that interventions to promote regular tooth brushing behaviour would have a preventive impact on the two most common oral diseases.

Research has shown that oral health behaviour such as regular tooth brushing with fluoridated toothpaste, like many other health risk behaviours, is influenced by the psychosocial predisposition of the individual and the structural conditions in the environment. It has moreover been argued that structural properties in the social environment such as social class and ethnic group affiliation have diminished in strength as causes of dental disease while lifestyle factors seem to have increased in importance (Källestål, Dahlgren \& Stenlund, 2000). A number of lifestyle variables, such as smoking, bedtime and movie watching have been associated with tooth brushing among adolescents (Macgregor, Balding \& Regis, 1996).

Tooth brushing behaviour has also been increasingly associated with indicators of selfconcept, such as self-esteem (Macgregor \& Balding, 1991; Regis, Macgregor \& Balding, 1994; Macgregor, Regis \& Balding, 1997; Källestål et al., 2000). It has been reported that weak life-control among young people is generally associated with unhealthy living habits, mental health problems, poor school success and marginalisation (Pietila et al., 1994). A recent study across 25 European countries suggests that school performance, perceived health and/or happiness and self-esteem are significant predictors for recommended tooth brushing frequency among 109061 children studied (Honkala et al., 2003). The findings that associate tooth brushing frequency with adolescents' life circumstances and personal 
resource such as self-esteem have also been recently replicated in a less developed country (Honkala, Honkala \& Al-Sahli, 2007).

It has been suggested that people who are low on coping or personal resources such as self-esteem, mastery, resilience or social support may turn to substance use because they see it as the only means available to deal with stress (Wills, McNamara \& Vaccaro, 1995). Stress has been associated with children living in poverty and their engaging in health risk behaviours such as smoking (Wills et al., 1995). Therefore, the influence of low socio-economic status on periodontal disease may also be partly mediated through higher levels of stress and/or low coping with life stresses.

There is growing evidence that stress directly influences periodontal disease occurrence (Kurer et al., 1995; Klages, Weber \& Wehbein, 2005; Deinzer et al., 1999) and that it may also be associated with irregular tooth brushing and thus inadequate plaque control, which increases the risk of periodontal disease (Deinzer et al., 2005). The effect of stress on plaque control has been shown to be worse among smokers than among nonsmokers (Monteiro da Silva et al., 1998; Johannsen et al., 2005). Inadequate stress-coping behaviours have actually been directly associated with periodontal disease (Genco et al., 1998; Wimmer et al., 2002). The ability to cope effectively with the continued stresses of life therefore also seems to be a very important common protective factor with regards to periodontal health and systemic health.

An increasingly popular psychosocial construct, Antonovsky's theory of Sense of Coherence (SOC), seeks to explain the relationship between coping with life stresses and maintaining health (Antonovsky, 1993; Geyser, 1997). According to this theory of salutogenesis, people have internal and external resources (general resistance resources) that they can use in the face of stressful situations, and thus to maintain health. Sense of coherence measures the ability to effectively use these general resistance resources. Other related measures of personal resources include locus of control, hardiness and resilience. However, unlike the SOC, the measurements of these other personal resources may be culturally bound, as they tend to test specific coping strategies that may not be crosscultural. SOC, which does not measure a specific coping style, has been argued to be cross-culturally applicable (Antonovsky, 1987). McSherry and Holm (1994) have also suggested the existence of pathways that connect SOC with the concepts of cognitive appraisal, perceived social support, self-efficacy and self-statements or attributions. The stronger a person's SOC is, the better he/she is able to cope adequately, as he/she is able to find appropriate solutions in the face of challenges (mastery orientation). Such individuals perceive their world as comprehensible, manageable and meaningful. The SOC has been associated with health outcomes (Eriksson \& Lindström, 2006), and has recently received significant empirical research support as a determinant of oral health behaviour in adults (Savolainen et al., 2004; Savolainen et al., 2005) and adolescents (Freire, Sheiham \& Hardy, 2001; Freire, Hardy \& Sheiham, 2002). Because SOC focuses attention on factors responsible for creating and maintaining good health (salutogenesis), rather than on health risk factors, SOC holds some promise in explaining the relationship between oral health and the general health of individuals. 
Several behavioural models that have been successfully applied in explaining smoking behaviour have also been used in explaining oral health behaviour (Hollister \& Anema, 2004), yet most of the oral health promotion interventions have not been based on any theoretical framework (Brown, 1994; Kay \& Locker, 1996). The social cognitive theory (Bandura, 1986), the theory of planned behaviour (Ajzen, 1991), stages of change theory (Proshaska \& Velicer, 1997), the integrated behaviour change-model (De Vries et al., 2003) and more recently sense of coherence (SOC) (Glanz, Maskarinec \& Carlin, 2005) have been successfully applied in explaining adolescent smoking behaviour. The traditional school-based smoking prevention approaches that relied on disseminating information about the adverse consequences of smoking either alone, or in combination with fear arousal methods, have been found to be ineffective (Hansen, 1992; Thomas, 2002).

Recognising the importance of the psychosocial factors that have been associated with the initiation of tobacco use in South Africa (Rocha-Silva, De Miranda \& Erasmus, 1996; Panday, Reddy \& Bergström, 2002; Peltzer, 2003) and elsewhere (Tyas \& Pederson, 1998; Wills et al., 2001), contemporary prevention studies have evaluated the effectiveness of broader approaches designed to inoculate teenagers against pressure to use tobacco from peers and advertisements in the media, and to teach generic life skills (such as coping effectively with stress) and specific life skills for resisting such influences. Implementing a tobacco prevention programme based on teaching social skills may also provide a unique opportunity to incorporate a social and aesthetic context to oral hygiene promotion. It is pertinent that a previous qualitative study among adolescents found that adolescents tended to mention smoking as a cause of discoloured teeth rather than as a cause of periodontal disease or cancer. These adolescents generally thought it was unacceptable that their peers should suffer from the image-related consequences of poor oral health, such as poor oral hygiene and mal-odour (Stokes, Ashcroft \& Platt, 2006). These social and aesthetic contexts of oral health conceptions among adolescents informed the design of the adopted educational programme used in this dissertation.

One of the programmes using a social skills approach to smoking prevention is Life Skills Training (LST), which has been consistently found to be effective in the US in reducing 30-day smoking prevalence by up to $60 \%$ (Botvin, Eng \& Williams, 1980; Botvin et al., 1990; Botvin et al., 1995). LST, like most of the other tobacco use prevention strategies involving adolescents to date, has so far been undertaken mainly in developed nations; and its universal applicability is yet to be established, especially in view of the potential differences that may exist in susceptibility to social influences and the level of social skills of adolescents of similar ages across different societies.

In summary, there are no organized national oral health promotion interventions in South Africa, possibly because oral health may not rank high on the list of priority health problems. Furthermore, past interventions have been found to be relatively ineffective, probably because most have not been developed on the basis of any theoretical framework. However, there is fairly good evidence to suggest that the psychosocial predisposition of adolescents, such as their ability to cope with stress, may be a commonrisk factor for poor periodontal health and the adoption of a health risk behaviour such as tobacco use. Tobacco use, in turn, is also an important risk factor for both periodontal 
disease and the majority of chronic disease burdens (cardiovascular and respiratory diseases) in South Africa (Norman et al., 2007). Dietary interventions to reduce excess body mass index (BMI) may be just as important as smoking as a common-risk factor for poor oral and systemic health, but periodontal disease was identified among the Limpopo Province's adolescent population as a priority oral health problem more strongly associated with poor oral hygiene, stress and smoking than diet. Furthermore, smoking ranks higher (third out of 17) than BMI (fifth of 17) in the list of important risk factors associated with premature death in South Africa (Norman et al., 2007). Also, being underweight $(12.1 \%)$ was identified as a more prevalent nutritional condition among adolescents in the Limpopo Province than being obese (3.8\%) (Reddy et al., 2003). Furthermore, a recently published report of a large-scale study in the US found no evidence of an association between being overweight and dental caries prevalence among the children studied in the US (Macek \& Mitola, 2006).

Prioritizing a reduction in tobacco use over dietary change as an outcome, this dissertation therefore evaluated the feasibility of integrating adolescent oral health promotion (the promotion of gingival health through regular tooth brushing behaviour), with the prevention of tobacco use among adolescents in a largely rural province of South Africa.

The studies presented in this dissertation were not conducted as one single project, but were informed by the available data and the level of research funding available to the researcher. However, the presentation of the relation of the studies in the dissertation to one another was to a large extent guided by the intervention planning approach of Green and Kreuter (1991).

\section{Organisational framework for planning health education interventions}

Several studies suggest that the most effective health promotion interventions are those that are developed and implemented using a systematic and planned approach (Green \& Kreuter, 1991; Kok, Van den Borne \& Mullen, 1997; Bartholomew et al., 2006). The model for planned health education interventions identifies five phases in the planning process (Figure 2).

The first phase in the development of a health education intervention is to identify a relevant problem (epidemiological analysis) caused by human behaviour (Part 1 of the current dissertation). The main physical health problems identified in the present dissertation are periodontal disease as represented by gingivitis (gum bleeding), hypertension and chronic bronchitis. In the second phase, the relevant behaviour or behaviours that cause the problem should be identified. Still in the first part of the current dissertation, the identified modifiable oral health-related risk behaviours that were associated with this oral health problem - periodontal disease - were poor plaque control and tobacco smoking. Smoking has also been associated with the end-stage of this oral disease (that is, complete tooth loss). 
Figure 2: The model for planned health education interventions

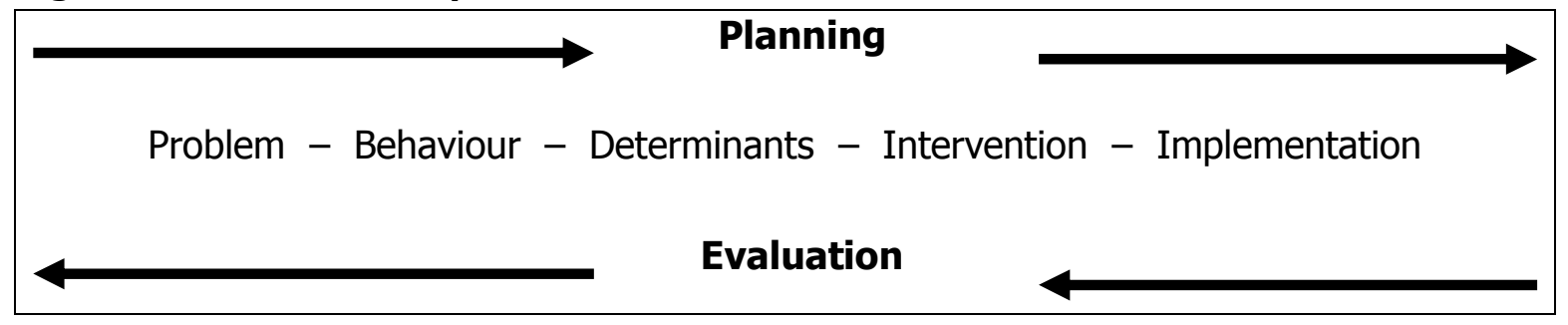

Both smoking and smokeless tobacco use were identified as important behaviours associated poor systemic health. It was concluded that it is important in the long term to prevent children (as a priority group) from starting to use any form of tobacco and to encourage them to adopt regular tooth brushing habits in order to prevent these oral and systemic health problems.

During the third phase, important determinants of the behaviours that cause the problem should be examined. Part 2 of this dissertation therefore describes the determinants of smoking and regular tooth brushing mainly among historically disadvantaged South African adolescents living in a resource-poor setting. Smoking and the poor plaque control that can result from irregular tooth brushing are behaviours that have been identified in this dissertation and in the literature as significant risk factors for periodontal disease (Albandar, 2002; Amarasena et al., 2002; Do et al., 2003), which can in turn result in tooth loss and some systemic health problems in adulthood as demonstrated in Part 1 of this dissertation.

In studying the determinants of tooth brushing behaviour, we used the central constructs of the salutogenic theory (SOC) (Antonovsky, 1993), integrated with the constructs of the integrated change model (De Vries et al., 2003). The outcome expectancy construct of the social cognitive theory (Bandura, 1986) was deemed useful in exploring the determinants of smoking onset that could be related to adolescents' concerns about the consequences of smoking for their oral health and ensuing social functioning. In this study it was hypothesize that these concerns could motivate adolescents to take the precaution of not starting to smoke. Furthermore, the results from a qualitative study conducted among a sample of the adolescents that participated in the smoking determinant study reported on in this dissertation suggested that the interviewed adolescents that were current smokers had a low SOC and ineffective coping skills, and reportedly used substances to cope with life stresses (O'Hara, 2008). The intervention developed in the current study, which was also informed by the salutogenic theory, was therefore also aimed at teaching the adolescents skills to cope with life stresses.

The fourth phase in the planning model is the actual development of the intervention, which is based on the results of the preceding phases. The next phase in the model is the implementation of the intervention, which is followed by the evaluation of the intervention. Part 3 of this dissertation deals with the impact evaluation of the implementation of an integrative school-based educational intervention for smoking prevention and oral health promotion (that is, encouraging frequent tooth brushing and preventing the onset of periodontal disease). The two-year intervention evaluated - training in social skills - was not only directed at preventing smoking uptake, but was also designed to encourage the 
participants to adopt healthy eating habits (limited sugar intake), frequent tooth brushing with fluoridated toothpaste and making a visit to a dentist at least once a year.

However, the choice of oral health-related outcomes to be evaluated was, among other factors previously mentioned, informed by the fact that the evaluation of oral health promotion needs to be appropriate, not only to the nature of the intervention, but also to the time scales involved (Watt et al., 2001). In particular, considering that dietary changes will not alter periodontal disease or even caries scores in the short term, and that the prevention of plaque-induced periodontal disease was identified a priority in the population studied, both tooth brushing behaviour and the most prevalent periodontal disease in adolescents - gingivitis - were selected as outcome measures of changes in oral health behaviour and oral health respectively. Indeed, the effect of improved tooth brushing habits or plaque control should be reflected in the short term in reduced prevalence of gingivitis (gum bleeding), but it has been suggested that even the maximum reduction in sugar intake may not be able to prevent the development of gingivitis (Gaengler et al., 1986). The only cohort study on nutrition and caries among South African children also failed to demonstrate a significant association between micronutrient intake and dental caries development (Mackeown, Cleaton-Jones \& Fatti, 2003). Furthermore, according to the criteria set by the Swedish council on technology assessment in health care, a threeyear follow-up would be necessary to demonstrate the effectiveness of interventions on the reduction of caries in permanent teeth (Bratthall et al., 2003).

The general discussion and conclusion section of this dissertation presents a discussion of the main findings of the various studies, describes the methodological limitations, and suggests the implications of the findings for future research. 


\section{References}

Abnet, C.C., Kamanger, F., Dawsey, S.M., Stolzenberg-Solomon, R.Z, Albanes, D. and Pietinen, P. (2005). Tooth loss is associated with increased risk of gastric non-cardia adenocarcinoma in a cohort of Finnish smokers. Scandinavian Journal of Gastroenterology, 40: 681-687.

Abnet, C.C., Qiao, Y.L., Mark, S.D., Dong, Z.W., Taylor, P.R. and Dawsey, S.M. (2001). Prospective study of tooth loss and incident esophageal and gastric cancers in China. Cancer Causes \& Control, 12: 847-854.

Ajzen, I. (1991). The Theory of Planned Behaviour. Organisational Behaviour and Human Decision Processes, 50: 179-211.

Albandar, J.M. (2002). Global risk factors and risk indicators for periodontal diseases. Periodontology 2000, 29: 177-206.

Albandar, J.M. and Rams, T.E. (2002). Global epidemiology of periodontal diseases: an overview. Periodontology 2000, 29: 1-10.

Albandar, J.M. Brunelle, J.A., and Kingman, A. (1999). Destructive periodontal disease in adults 30 years of age and older in the United States, 1988-1994. Journal of Periodontology, 70: 1329.

Alberts, M., Urdal, P., Steyn, K., Stensvold, I., Tverdal, A., Nel, J.H. et al. (2005). Prevalence of cardiovascular diseases and associated risk factors in a rural black population of South Africa. European Journal of Cardiovascular Prevention \& Rehabilitation, 12: 347-354.

Aldridge, J.P., Lester, V., Watts T.L.P., Collins, A., Viberti, G. and Wilson, R.F. (1996). Single-blind studies of the effects of improved periodontal health on metabolic control in type 2 diabetes mellitus. Journal of Periodontology, 67: 166-176.

Aligne, C.A., Moss, M.E., Auinger, P. and Weitzman, M. (2003). Association of paediatric dental caries with passive smoking. Journal of American Medical Association, 289: 1258-1264.

Alpar, B., Leyhausen, G., Sapotnick, A., Gunay, H. and Geurtsen, W. (1998). Nicotine-induced alterations in human primary periodontal ligament and gingival fibroblast cultures. Clinical Oral Investigations, 2: 40-46.

Amarasena, N., Ikeda, N. and Win, K.K. (2002). Tobacco use and oral hygiene as risk indicators for periodontitis. Community Dentistry \& Oral Epidemiology, 30: 115-123.

American Academy of Pediatrics. (1997). Environmental tobacco smoke: a hazard to children. Pediatrics, 99: 639-642.

Antonovsky, A. (1993). The structure and properties of the sense of coherence scale. Social Science \& Medicine, 36: 725-733. 
Arbes S.J. Jr., Agústsdóttir, H. and Slade, G.D. (2001). Environmental tobacco smoke and periodontal disease in the United States. American Journal of Public Health, 91: 253-257.

Asaria, P., Chisholm, D., Mathers, C., Ezzati, M. and Beaglehole, R. (2007). Chronic disease prevention: health effects and financial costs of strategies to reduce salt intake and control tobacco use. Lancet, 370: 2044-2053.

Avşar, A., Darka, O., Topalğlu, B. and Bek, Y. (2008). Association of passive smoking with caries and related salivary biomarkers in young children. Archives of Oral Biology, 53: 969-974.

Ayo-Yusuf, O.A. (2005). Re-emergence of traditional tobacco products' usage in South Africa: an unintended consequence of existing tobacco control policy. African Journal of Drug and Alcohol Studies, 4: 32-43.

Ayo-Yusuf, O.A., Swart, T.J.P. and Pickworth, W.B. (2004). Nicotine delivery capacities of smokeless tobacco products and implications for control of tobacco dependence in South Africa. Tobacco Control, 13: 186-189.

Ballieux, R.E. (1991). Impact of stress on the immune response. Journal of Clinical Periodontology, 18: $427-430$.

Bandura, A. (1986). Social foundations of thoughts and action. Englewood Cliffs, NJ: Prentice Hall.

Bartholomew, L.K., Parcel, G.S., Kok, G. and Gottlieb, N.H. (2006). Planning health promotion programs: an intervention mapping approach (2nd Ed). New York: John Wiley \& Sons.

Beck, J., Garcia, R., Heiss, G., Vokonas, P.S. and Offenbacher, S. (1996). Periodontal disease and cardiovascular disease. Journal of Periodontology, 67: 1123-1137.

Bergström, J. (2004). Tobacco smoking and chronic destructive periodontal disease. Odontology, 92: $1-8$.

Billings, R.J., Berkowitz, R.J. and Watson G. (2004). Teeth. Pediatrics, 113: 1120-1127.

Boström, L., Linder, L.E. and Bergström, J. (1999). Smoking and crevicular fluid levels of IL-6 and TNF-a in periodontal disease. Journal of Clinical Periodontology, 26: 352-357.

Botvin, G.J., Baker, E., Dusenbury, L., Botvin, E.M. and Diaz, T. (1995). Long-term follow-up results of a randomised drug abuse prevention trial in a white middle-class population. Journal of the American Medical Association, 273: 1106-1112.

Botvin, G.J., Baker, E., Filazzola, A.D. and Botvin, E.M. (1990). A cognitive-behaviour approach to substance abuse prevention: One-year follow-up. Addictive Behaviors, 15: 47-63.

Botvin, G.J., Eng, A. and Williams, C.L. (1980). Preventing the onset of cigarette smoking through life skills training. Preventive Medicine, 9: 135-143. 
Bratthall, D., Hänsel-Petersson, G. and Sundberg, H. (1996). "Reasons for the caries decline: what do the experts believe?" European Journal of Oral Sciences 104: 416-422.

Bratthall, D., Petersen, P.E., Stjernswärd, R.J. and Brown, J. (2003). Oral and craniofacial diseases and disorders. In: Disease control priorities in developing countries. pp 723-736. Geneva: World Health Organisation.

Brothwell, D. J., Jutai, D. K. and Hawkins, R. J. (1998). An update of mechanical oral hygiene practices: evidence-based recommendations for disease prevention. Journal of the Canadian Dental Association, 64: 295-306.

Brown, L.F. (1994). Research in dental health education and health promotion: a review of the literature. Health Education Quarterly, 21: 83-102.

Cabrera, C., Hakeberg, M., Ahlqwist, M., Wedel, H., Björkelunde, C., Bengtsson, C., et al. (2005). Can the relationship between tooth loss and chronic disease be explained by socio-economic status? A 24-year follow-up from the population of women in Gothenburg, Sweden. European Journal of Epidemiology, 20: 229-236.

Chowdhury, I.G. and Bromage, T.G. (2000) Effects of foetal exposure to nicotine on dental development of laboratory rat. The Anatomical Record, 258: 397-405.

Connor, M., Rheeder, P., Bryer, A., Meredith, M., Beukes, M., Dubb, A., et al. (2005). The South African stroke risk in general practice study. South African Medical Journal, 95: 334-338.

Critchley, J.A. and Unal, B. (2003). Health effects associated with smokeless tobacco: a systematic review. Thorax, 58: 435-443.

Deinzer, R., Forster P., Fuck, L., Herforth, A., Stiller-Winkler, R. and Idel, H. (1999). Increase in crevicular interleukin $1 \beta$ under academic stress at experimental gingivitis sites and at sites with perfect oral hygiene. Journal of Clinical Periodontology, 26: 1-8.

Deinzer, R., Granrath, N., Spahl, M., Linz, S., Waschul, B. and Herforth, A. (2005). Stress, oral health behaviour and clinical outcome. British Journal of Health Psychology, 10: 269-283.

Department of Health (DoH). (1997). White paper for the transformation of the health system in South Africa. Notice 667 of 1997. Government Gazette No. 17910. Pretoria: Government Printer.

Department of Health (DoH. (2001). South African oral health policy - revised draft. Pretoria: Oral Health Directorate.

Department of Health (DoH). (2002). Report on Oral Health in South Africa 2000/2001. Oral Health Directorate. Internal report. Unpublished.

Department of Health (DoH). (2005). South African national oral health strategy. Oral Health Directorate, Pretoria. Available at http://www.doh.gov.za/docs/index.html 
De Vries, H., Mudde, A., Leijs, I., Charlton, A., Vartiainen, E., Buijs, G., et al. (2003). The European Smoking Prevention Framework Approach (EFSA): an example of integral prevention. Health Education Research, 18: 611-626.

Do, L.G., Slade, G.D, Roberts-Thomson K.F. and Sanders, A.E. (2008). Smoking-attributable periodontal disease in the Australian adult population. Journal of Clinical Periodontology, 35: 398-404.

Do, G.L., Spencer, A.J., Robert-Thompson, K., Ha, H.D. (2003). Smoking as a risk indicator for periodontal disease in the middle-aged Vietnamese population. Community Dentistry \& Oral Epidemiology, 31: 437-436.

D'Souza, G., Kreimer, A.R., Viscidi, R., Pawlita, M., Fakhry, C., Koch, W.M., et al. (2007). Casecontrol study of human papillomavirus and oropharyngeal cancer. The New England Journal of Medicine, 356: 1944-1956.

Emmons, K.E., Marcus, B.H., Linnan, L., Rossi, J.S. and Abrams, D.B. (1994). Mechanisms in multiple risk factor interventions: smoking, physical activity, and dietary fat intake among manufacturing workers. Preventive Medicine, 23: 481-489.

Eriksson, M. and Lindström, B. (2006). Antonovsky's sense of coherence scale and the relation with health: a systematic review. Journal of Epidemiology \& Community Health, 60: 376-381.

European Union Working Group on Tobacco and Oral Health. Meeting report. (1998). Oral Diseases, 4: 484-467.

Fisher, M.A., Taylor, G.W. and Tilashalski, K.R. (2005). Smokeless tobacco and severe active periodontal disease, NHANES III. Journal of Dental Research, 84: 705-710.

Freire, M.C.M., Sheiham, A. and Hardy, R. (2001). Adolescents' sense of coherence, oral health status, and oral health-related behaviours. Community Dentistry \& Oral Epidemiology, 29: 204-212.

Freire, M.C.M., Hardy, R. and Sheiham, A. (2002). Mothers' sense of coherence and their adolescent children's oral health status and behaviours. Community Dental Health, 19: 2431.

Gaengler, P., Pfister, W., Sproessig, M. and Mirgorod, M. (1986). The effects of carbohydratereduced diet on development of gingivitis. Clinical Preventive Dentistry, 8: 17-23.

Genco, R.J, Ho, A.W., Grossi, S.G., Dunford, R.G. and Tedesco, L.A. (1999). Relationship of stress, distress and inadequate coping behaviours to periodontal disease. Journal of Periodontology, 70: 711-723.

Geyser, S. (1997). Some conceptual considerations on the sense of coherence. Social Science \& Medicine, 44: 1771-1779. 
Giannopoulou, C., Kamma, J.J. and Mombelli, A. (2003). Effect of inflammation, smoking and stress on the gingival crevicular fluid cytokine level. Journal of Clinical Periodontology, 30: 145-153.

Gjermo, P. (1994). Goals for periodontal health and acceptable levels of disease. In. A. Feandsen (Ed). Public health aspects of periodontal disease. Chicago: Quintessence.

Glanz, K., Maskarinec, G. and Carlin, L. (2005). Ethnicity, sense of coherence, and tobacco use among adolescents. Annals of Behavioural Medicine, 29: 192-199.

Green, L. and Kreuter, M. (1991). Health promotion planning: An educational and environmental approach. Mountain View, CA: Mayfield.

Groenewald, P., Vos, T., Norman, R., Laubscher, R., Van Walbeek, C., Saloojee, Y., et al. (2007). Estimating the burden of disease attributable to smoking in South Africa in 2000. South African Medical Journal, 97: 674-681.

Grossi, S. (2000). Smoking and stress: common denominator for periodontal disease, heart disease and diabetes mellitus. Compendium of Continuing Education in Dentistry, 30: 31-39.

Hanioka, T., Tanaka, K., Ojima, M. and Yuuki, K. (2005). Association of melanin pigmentation in the gingiva of children with parents who smoke. Pediatrics, 116: e186-e190.

Hansen, W.B. (1992). School-based substance abuse prevention: A review of the state-of-the-art in curriculum, 1980-1990. Health Education Research, 7: 403-430.

Heikkeninen, T., Alvesalo, L., Osborne, R.H. and Tienari, J. (1994). Maternal smoking and tooth formation in the foetus. II. Tooth crown size in the permanent dentition. Early Human Development, 40: 73-86.

Henningfield, J.E., Rose, C.A. and Giovino, G.A. (2002). Brave new world of tobacco disease prevention. Promoting dual tobacco-product use? American Journal of Preventive Medicine, 23: 226-228.

Hollister, M.C. and Anema, M.G. (2004). Health behaviour models and oral health: a review. Journal of Dental Hygiene, 78: 1-8.

Honkala, S., Honkala, E. and Al-Sahli, N. (2007). Do life- or school-satisfaction and self-esteem indicators explain the oral hygiene habits of schoolchildren? Community Dentistry \& Oral Epidemiology, 35: 337-47.

Honkala, S., Honkala, E., Tynjälä, J., Kannas, L. and Åstrøm, A. (2003). Explaining tooth brushing behaviour - a cross-country study. Journal of Dental Research, 82(C, Abstract \#90), 625.

Hunter, J.M. and Arbona, S.I. (1995). The tooth as a marker of developing world quality of life: a field study in Guatemala. Social Science \& Medicine, 41: 1217-1240. 
James, J.A., Sayers, N.M., Drucker, D.B. and Hull, P.S. (1999). Effects of tobacco products on the attachment and growth of periodontal ligament fibroblasts. Journal of Periodontology, 70: 518-525.

Johannsen, A., Asberg, M., Soder, P. and Soder, B. (2005). Anxiety, gingival inflammation and periodontal disease in non-smokers and smokers - an epidemiological study. Journal of Clinical Periodontology, 32: 488-491.

Johnson, G.K. and Slach, N.A. (2001). Impact of tobacco use on periodontal status. Journal of Dental Education, 65: 313-321.

Joshipura, K.J., Rimm, E.B., Douglass, C.W., Trichopoulos, D., Ascherio, A. and Willett, W.C. (1996). Poor oral health and coronary heart disease. Journal of Dental Research, 75: 16311636.

Källestål, C., Dahlgren, L. and Stenlund, H. (2000). Oral health behaviour and self-esteem in Swedish children. Social Science \& Medicine, 51: 1841-1849.

Kay, L. and Locker, D. (1996). Is dental health education effective? A systematic review of current evidence. Community Dentistry \& Oral Epidemiology, 24: 231-235.

King, G. (1997). The "race" concept in smoking: a review of the research on African Americans. Social Science and Medicine, 45: 1075-1087.

Klages, U., Weber, A.G. and Wehrbein, H. (2005). Approximal plaque and gingival sulcus bleeding in routine dental care patients: relations to life stress, somatization and depression. Journal of Clinical Periodontology, 32: 575-582.

Klinge, B. and Norlund, A. (2005). A socio-economic perspective on periodontal diseases: a systematic review. Journal of Clinical Periodontology, 32: 314-325.

Kok, G., Van den Borne, B. and Mullen, P. (1997). Effectiveness of health education and health promotion: meta-analyses of effect-studies and determinants of effectiveness. Patient Education and Counselling, 30: 19-27.

Kozlowski, L.T., Strasser, A.A., Giovino, G.A., Erickson, P.A. and Terza, J.V. (2001). Applying the risk/use equilibrium: use medical nicotine now for harm reduction. Tobacco Control, 10: 201203.

Kressin, N.R., Boehmer, U., Nuun, M.E. and Spiro III, A. (2003). Increased preventive practices lead to greater tooth retention. Journal of Dental Research, 82: 223-227.

Kurer, J.R., Watts, T.L., Weinman, J. and Gower, D.B. (1995). Psychological mood of regular dental attenders in relation to oral hygiene behaviour and gingival health. Journal of Clinical Periodontology, 22: 52-55.

Lam, T., Leung, G.M. and Ho, L. (2001). The effects of environmental tobacco smoke on health services utilization in the first eighteen months of life. Pediatrics, 107: 1-6. 
Lang, W.P., Ronis, D.L. and Farghaly, M.M. (1995). Preventive behaviours as correlates of periodontal health status. Journal of Public Health Dentistry, 55: 10-17.

Levine, R. (2004). The scientific basis of oral health education. Community Dental Health, 21: 131133.

Levy, D.T., Chaloupka, F. and Gitchell, J. (2004). The effects of tobacco control policies on smoking rates: a tobacco control scorecard. Journal of Public Health Management Practice, 10: 338353.

Li, Y., Navia, J.M., and Bian, J.Y. (1996). Caries experience in deciduous dentition of rural Chinese children 3-5 years old in relation to the presence or absence of enamel hypoplasia.. Caries Research, 30: 8-15.

López, R., Fernández, O. and Baelum, V. (2006). Social gradient in periodontal diseases among adolescents. Community Dentistry \& Oral Epidemiology, 34: 184-196.

Macek, M.D. and Mitola, D.J. (2006). Exploring the association between overweight and dental caries among US children. Paediatric Dentistry, 28: 375-380.

Macgregor, I.D.M. and Balding, J.W. (1991). Self-esteem as a predictor of tooth brushing behaviour in young adolescents. Journal of Clinical Periodontology, 18: 312-326.

Macgregor, I.D.M, Balding, J. and Regis, D. (1996). Tooth brushing schedule, motivation and 'lifestyle' behaviours in 7,770 young adolescents. Community Dental Health, 13: 232-237

Macgregor, I.D.M., Regis, D. and Balding, J.W. (1997). Self-concept and dental health behaviours in adolescents. Journal of Clinical Periodontology, 24: 335-339.

Mackeown, J.M., Cleaton-Jones, P.E. and Fatti, P. (2003). Caries and micronutrient intake among urban South African children: a cohort study. Community Dentistry \& Oral Epidemiology, 31: 213-220.

Maraj, E. and Kroon, J. (2004). The impact of a school dental service on the periodontal health and hygiene status of 6-year-old Sowetan learners. South African Dental Journal, 59: 374-6, 378.

McSherry, W.C. and Holm, J.E. (1994). Sense of coherence: its effects on psychological and physiological processes prior to, during, and after a stressful situation. Journal of Clinical Psychology, 50: 476-487.

Modeer, T., Lavstedt, S. and Ahlund, C. (1980). Relation between tobacco consumption and oral health in Swedish schoolchildren. Acta Odontologica Scandinavica, 38: 223-227.

Monteiro da Silva, A.M., Newman, H.N., Oakley, D.A. and O'Leary, R. (1998). Psychosocial factors, dental plaque levels and smoking in periodontitis patients. Journal of clinical Periodontology, 25: 517-523. 
Moynihan, P. and Petersen, P.E. (2004). Diet, nutrition and the prevention of dental diseases. Public Health Nutrition, 7: 201-226.

Myburg, N.G., Hobdell, M.H. and Lallo, R. (2004). African countries propose a regional oral health strategy: The Darker report from 1998. Oral Diseases, 10: 129-137.

Nguyen, L., Hakkinen, U., Knuuttila, M. and Järvelin M. (2008). Should we brush twice a day? Determinants of dental health among young adults in Finland. Health Economics, 17: 267286.

Nishida, N., Yamamoto, Y., Tanaka, M., Maeda, K., Kataoka, K., Nakayama, K. et al. (2006). Association between passive smoking and salivary markers related to periodontitis. Journal of Clinical Periodontology, 33: 717-723.

Norman, R., Bradshaw, D., Schneider, M., Joubert, J., Groenewald, P., Lewin, S. et al. (2007). A comparative risk assessment for South Africa in 2000: towards promoting and preventing disease. South African Medical Journal, 97: 637-641.

Offenbacher, S. and Weathers, D.R. (1985). Effects of smokeless tobacco on the periodontal, mucosal and caries of adolescent males. Journal of Oral Pathology, 14: 169-181.

Offenbacher, S., Katz, V., Fertik G., Collins, J., Boyd, D., Maynor, G., McKaig, R. and Beck, J. (1996). Periodontal infection as a possible risk factor for pre-term low birth weight. Journal of Periodontology, 67: 1103-1113.

O'Hara, O.R. (2008). The association of adolescent smoking with stress and coping in Pretoria high schools: a qualitative study. MPH thesis. Johannesburg: University of Witwatersrand.

Okoli, C.T., Kelly, T. and Hahn, E.J. (2007). Second-hand smoke and nicotine exposure: a brief review. Addictive Behaviors, 32: 1977-1988.

Panday, S., Reddy, P. and Bergström, E. (2002). The determinants of smoking behaviour among adolescents in South Africa. Scandinavian Journal of Public Health, 30: 1-7.

Peltzer, K. (2003). Smokeless tobacco and cigarette use among black secondary school students in South Africa. Substance Use \& Misuse, 38: 1003-1016.

Petersen, P.E. (2003). The world oral health report 2003: continuous improvement of oral health in the 21st century - the approach of the WHO global oral health programme. Community Dentistry \& Oral Epidemiology, 31: 3-24.

Pietila, A.M. (1994). Factors associated with life control in young men. Journal of Advanced Nursing, 20: 491-499.

Prayitno, S.W., Addy, M. and Wade, W.G. (1993). Does gingivitis lead to periodontitis in young adults? Lancet, 342: 471-472. 
Prochaska, J.O. and Velicer, W.F. (1997). The trans-theoretical model of health behaviour change. American Journal of Health Promotion, 12: 38-48.

Prokhorov, A.V., Winickoff, J.P., Ahluwalia, J.S., Ossip-Klein, D., Tanski, S., Lando, H.A., et al. (2006). Youth tobacco use: a global perspective for child health care clinicians. Pediatrics, 118: e890-e903.

Reddy, P., Meyer-Weitz, A. and Yach, D. (1996). Smoking status, knowledge of health effects and attitudes towards tobacco control in South Africa. South African Medical Journal, 86: 13891393.

Reddy, S.P., Panday, S., Swart, D., Jinabhai, C.C., Amosun, S.L., James, S. et al. (2003). Umthnte Uhhaba Usamila- The South African Youth Behaviour Survey 2002. Cape Town: South African Medical Research Council.

Regis, D., Macgregor, I.D. and Balding, J.W. (1994). Differential prediction of dental health behaviour by self-esteem and health locus of control in young adolescents. Journal of Clinical Periodontology, 21: 7-12.

Republic of South Africa. Tobacco Products Control Act. (1993). Regulations relating to the labelling, advertising, and sale of tobacco products. Government Gazette No. 2063, 1994, Pretoria: Government Printer.

Republic of South Africa. Tobacco Products Amendment Act. (1999) Act No 12, 1999. Government Gazette 1999. No. 406 (19962). Pretoria: Government printer.

Rocha-Silva, L., De Miranda, S. and Erasmus, R. (1996). Alcohol, tobacco, and other drug use among black youth. Pretoria: HSRC.

Rosenquist, K., Wennerberg, J., Schildt, E., Bladström, A., Hansson, B.G. and Andersson, G. (2005). Oral status, oral infections and some lifestyle factors as risk factors for oral and oropharyngeal squamous cell carcinoma: A population-based case-control study in Southern Sweden. Acta Oto-laryngologica, 125: 1327-36.

Saad, A.Y. (1990). Postnatal effects of nicotine on incisor development of albino mouse. Journal of Oral Pathology and Medicine, 19: 426-429.

Savolainen, J., Knuuttila, M., Suominen-Taipale, L., Martelin, T., Nordlad, A., Niskanen, M. et al. (2004). A strong sense of coherence promotes regular dental attendance in adults. Community Dental Health, 21: 271-276.

Savolainen, J.J., Suominen-Taipale, A.L., Uutela, A.K., Martelin, T.P., Niskanen, M.C. and Knuuttila, M.L. (2005). Sense of coherence as a determinant of tooth brushing frequency and level of oral hygiene. Journal of Periodontology, 76: 1006-1012.

Scannapieco, F.A., Bush, R.B. and Paju, S. (2003). Periodontal disease as a risk factor for adverse pregnancy outcomes. A systematic review. Annals of Periodontology, 8: 70-78. 
Seow, W.K. (1991). Enamel hypoplasia in the primary dentition: A review. Journal of Children Dentistry, 58: 441-452.

Severson, H.H., Forrester, K.K. and Biglan, A. (2007). Use of smokeless tobacco is a risk factor for cigarette smoking. Nicotine \& Tobacco Research, 9: 1331-1337.

Sheiham, A. and Watt, R.G. (2000). The common risk factor approach: A rational basis for promoting oral health. Community Dentistry \& Oral Epidemiology, 28: 399-406.

Shenkin, J.D., Broffitt, B., Levy, S.M., Warren, J.J. (2004). The association between environmental tobacco smoke and primary tooth caries. Journal of Public Health Dentistry, 64: 184-186.

Sitas, F., Bradshaw, D., Kielkowski, D., Bah, S. and Peto, R. (2004). Tobacco attributable deaths in South Africa. Tobacco Control, 13: 396-399.

Statistics South Africa. (2001). Census in brief. Pretoria: Government Printer.

Steyn, K., Bradshaw, D., Norman, R., Laubscher, R. and Saloojee, Y. (2002). Tobacco use in South Africans during 1998: The first demographic and health survey. Journal of Cardiovascular Risk, 9: 161-170.

Steyn, K., De Wet, T., Saloojee, Y., Nel, H. and Yach, D. (2006). The influence of maternal cigarette smoking, snuff use and passive smoking on pregnancy outcomes: the birth to ten study. Paediatric and Perinatal Epidemiology, 20: 90-99.

Stokes, E., Ashcroft, A. and Platt, M.J. (2006). Determining Liverpool adolescents' beliefs and attitudes in relation to oral health. Health Education Research, 21: 195-205.

Stolzenberg-Solomon, R.Z., Dodd, K.W., Blaser, M.J., Virtamo, J., Taylor, P.R. and Albanes, D. (2003). Tooth loss, pancreatic cancer, and Helicobacter pylori. American Journal of Clinical Nutrition, 78: 176-181.

Stratton, K., Shetty, P., Wallace, R. and Bondurant, S (2001). Clearing the smoke: assessing the science base for tobacco harm reduction. Washington, DC: National Academy of Sciences, National Academy Press.

Swart, D. and Reddy, P. (1999). Establishing network for health promoting schools in South Africa. Journal of School Health, 69: 47-50.

Swart, D., Reddy, P., Panday, S., Phillip, J.L., Naidoo N. and Ngobeni, N. (2004). The 2002 Global Youth Tobacco Survey (GYTS): The 2nd GYTS in South Africa - A comparison between GYTS (SA) 1999 and GYTS (SA) 2002. Cape Town: South African Medical Research Council.

Thomas, R. (2002). School-based programmes for preventing smoking. Cochrane Database Systematic Review, 4, CD001293.

Tomar, S.L. (2002). Snuff use and smoking in U.S. men; implications for harm reduction. American Journal of Preventive Medicine, 23: 143-149. 
Tomar, S.L. (2003). Is use of smokeless tobacco a risk factor for cigarette smoking? The US experience. Nicotine \& Tobacco Research, 5: 561-569.

Tomar, S.L. and Asma, S. (2000). Smoking attributable periodontitis in the United States: findings from NHANES III. National Health and Nutrition Examination Survey. Journal of Periodontology, 71: 743-751.

Tu, Y.K., Galobardes, B., Smith, G.D., McCarron, P., Jeffreys, M. and Gilthorpe, M.S. (2007). Association between tooth loss and mortality patterns in the Glasgow Alumni Cohort. Heart, 93: $1022-1023$.

Tyas, S.L. and Pederson, L.L. (1998). Psychosocial factors related to adolescent smoking: a critical review of the literature. Tobacco Control, 7: 409-420.

United Nations Department of Public Information. (1948). The universal declaration of human rights. URL: http://www.unhchr.ch/udhr/miscinfo/carta.htm. Accessed April 27, 2008.

Van Walbeek, C. (2002). Recent trends in smoking prevalence in South Africa - some evidence from AMPS Data. South African Medical Journal, 92: 468-472.

Van Wyk, P.J. (2003). National Children's Oral Health Survey South Africa, 1999-2002. Pretoria: UPrinters.

Van Wyk, P.J., Louw, A.J., and Du Plessis J.B. (2004) Caries status and treatment needs in South Africa: Report of the 1999-2002 national children's oral health survey South African Dental Journal, 59: 238-242.

Velly, A.M., Franco, E.L., Schlecht, N., Pintos, J., Kowalski, L.P. and Oliveira, B.V. (1998). Relationship between dental factors and risk of upper aerodigestive tract cancer. Oral Oncology, 34: 284-291.

Watt, R., Fuller, S., Harnett, R., Treasure, E. and Stillman-Lowe, C. (2001). Oral health promotion evaluation - time for development. Community Dentistry \& Oral Epidemiology, 29: 161-166.

Watt, R.G. (2002). Emerging theories into the social determinants of health: implications for oral health promotion. Community Dentistry \& Oral Epidemiology, 30: 241-247.

Watt, R.G. (2005). Strategies and approaches in oral disease prevention and health promotion. Bulletin of the World Health Organisation, 83: 711-718.

Westaway, M.S. (1990). Health complaints, remedies and medical assistance in a peri-urban area. South African Medical Journal, 77: 34-36.

Williams, S.A., Kwan, S.Y.L. and Parson, S. (2000) Parental smoking practices and caries experience in pre-school children. Caries Research, 34: 117-122. 
Wills, T.A., McNamara, G. and Vaccaro, D. (1995). Parental education related to adolescent stresscoping and substance use: development of a mediational model. Health Psychology, 14: 464-478.

Wills, T.A., Sandy, J.M., Yaeger, A.M., Cleary, S.D. and Shinar, O. (2001). Coping dimensions, life stress, and adolescent substance use: a latent growth analysis. Journal of Abnormal Psychology, 110: 309-323.

Wimmer, G., Janda, M., Wieselmann-Penkner, K., Jakse, N., Polansky, R. and Pertl, C. (2002). Coping with stress: its influence on periodontal disease. Journal of Periodontology, 73: 13431351.

World Bank. (1999). Global trends in tobacco use. In Curbing the epidemic: governments and the economics of tobacco control. Washington, DC: The World Bank.

World Health Organisation (1997). Oral health surveys: basic methods. (4th ed.). Geneva: World Health Organisation.

World Health Organization (WHO), Division of Non-communicable Diseases, Tobacco Free Initiative. (1999). International consultation on environmental tobacco smoke (ETS) and child health. Consultation report. WHO technical document WHO/NCD/TFI/99.10.

World Health Organisation. (2002). Reducing risks, promoting healthy life. In The World Health Report 2002. Geneva, Switzerland: World Health Organisation.

World Health Organisation. (2005). WHO Framework Convention on Tobacco Control. Geneva, Switzerland: World Health Organisation.

World Health Organisation (2007). 'Africa to take the lead in integrating oral health into chronic disease programmes.' Press Release. URL: http://www.afro.who.int/press/2007/pr20070925.html (Last accessed date 13 February 2008).

Yamamoto, Y., Nishida, N., Tanaka, M., Hayashi, N., Matsuse, R., Nakayama, K. et al. (2005). Association between passive and active smoking evaluated by salivary cotinine and periodontitis. Journal of Clinical Periodontology, 32: 1041-1016. 


\section{Part 1:}

\section{Health Problems: Tobacco use as Common- Risk for Poor Oral and Systemic Health}




\section{Chapter 1:}

\section{Adolescents' Sense of Coherence and Smoking as Predictors of Gingivitis}

Accepted for publication as: Ayo-Yusuf, O.A., Reddy, P.S. \& Van den Borne, BW. Adolescents' sense of coherence and smoking as longitudinal predictors of self-reported gingivitis. Journal of Clinical Periodontology. 


\section{Abstract}

Objective: This study sought to determine the influence of sense of coherence (SOC) and smoking on self-reported gingival health of a cohort of rural black South African adolescents.

Methods: This 18-month study involved a three-wave survey of a representative sample of 8th-graders from 11 randomly selected high schools in the Limpopo province, South Africa ( $n=970)$. Using a generalized estimating equation model, we prospectively examined the correlates of recent or persistent gingivitis, defined as self-reporting frequent gingival bleeding (GB). Explanatory variables included baseline socio-economic status, age, gender, plaque levels, tooth brushing frequency, smoking and snuff use status and SOC levels.

Results: Among our sample, $74.6 \%$ reported experiencing gingivitis at some point during follow-up, while $41.9 \%$ reported recent frequent GB at the last survey. Factors that were positively associated with recent or persistent gingivitis include living in poor households (odds ratio $[O R]=1.49 ; p<0.01)$, having higher plaque levels $(O R=1.18 ; p=0.04)$ and smoking regularly $(O R=1.57 ; p=0.04)$. Self-reporting gingivitis was negatively associated with being female $(O R=0.76 ; p=0.02)$ and having a higher $S O C(O R=0.96 ; p<0.001)$.

Conclusions: Adolescent smoking and SOC levels are independent predictors of selfreported gingivitis. Therefore, in addition to plaque control, smoking prevention and teaching stress-coping skills may be important interventions for promoting adolescents' gingival health.

Keywords: Adolescents; Gingivitis; Self-reporting; Smoking; Sense of Coherence; South Africa; Stress-coping. 


\section{Introduction}

Experiencing 'bleeding gums' when brushing one's teeth is the most common symptom of plaque-induced gingivitis. Self-reported gum or gingival bleeding has been shown to be a good measure of service demand for periodontal care (Rayant \& Sheiham, 1980) and has been suggested as a useful measure for monitoring gingival health among adolescents in developing countries where the costs of clinical oral surveys may be prohibitive (Taani \& Alhaija, 2003). A previous adolescent study finding suggests that self-reported bleeding gums may be explained by the same factors that are associated with clinical gingival health status (Kallio \& Murtomaa, 1997).

Gingivitis is a reversible condition that does not always progress to periodontitis, but it is usually the early phase of the inflammatory process leading to severe periodontal disease and eventual tooth loss (Prayitno et al., 1993; Albandar et al., 1998). Gingivitis is the most common periodontal disease in adolescents; therefore the control of gingivitis in this population may have a significant impact on public health, as it may result in a lower prevalence of destructive periodontitis in adulthood. This is also particularly important because periodontal disease, traditionally recognized as a risk factor for tooth loss and impaired oral functioning, has recently also been implicated in adverse reproductive health outcomes (Offenbacher et al., 1996; Herrera et al., 2007), poor diabetic control (Aldridge et al., 1995), and an increased risk of cardiovascular disease (Beck et al., 1996; Joshipura et al., 1996) and cancer (Michaud et al., 2008).

Periodontal disease is a multi-factorial disorder. Bacterial plaque is the principal aetiological factor; and several other local and systemic factors have a modifying role in its pathogenesis (Albandar, 2002). For instance, studies among adolescents have demonstrated that periodontal disease may be more prevalent among and have a greater impact on the oral health-related quality of life of adolescents in a lower socio-economic class than on that of adolescents in a higher socio-economic class (Lopez et al., 2006; Lopez \& Baelum, 2007). In the United States, ethnic minorities, especially blacks, are more likely than whites to present with periodontal disease (Albandar, 2002). The ethnic/racial differences which have also been reported in South Africa (Van Wyk et al., 1994) have been suggested by some researchers to originate in microbiological, immunological or genetic factors related to ethnic background (Kornman \& Di Giovine, 1998; Armitage et al., 2000). However, other researchers have argued that these ethnic differences may be related to underlying ethnic differences in socio-economic status, which have in turn been associated with lifestyle risk factors such as smoking (Norlund, 2005), stress and ineffective coping with life stresses (Wills et al., 1995).

There is growing evidence that stress directly influences periodontal disease occurrence (Deinzer et al., 1999; Klages et al., 2005) and may also be associated with irregular tooth brushing and thus with inadequate plaque control (Deinzer et al., 2005). Inadequate stress-coping behaviour has in fact been directly associated with periodontal disease (Genco et al., 1999; Wimmer et al., 2002). These observations have drawn public oral health researchers' interest to an increasingly popular psychosocial construct Antonovsky's theory of Sense of Coherence (SOC), which seeks to explain the relationship 
between coping with life stresses and maintaining health (Antonovsky, 1993; Watt, 2002). The stronger a person's SOC is, the better he/she is able to cope adequately - he/she is able to find appropriate solutions in the face of challenges (mastery orientation). People with a strong SOC perceive their world as comprehensible, manageable and meaningful. SOC has been associated with health outcomes (Eriksson \& Lindström, 2006) and has recently received significant empirical research support as a determinant of tooth brushing behaviour in adults (Savolainen et al., 2005) and adolescents (Ayo-Yusuf et al., in press). SOC has also recently been associated with adolescent smoking (Glanz et al., 2005).

Smoking is the environmental factor for which there is well-documented evidence of association with poor periodontal health in adults (Albandar, 2002; Do et al., 2003). For instance, several studies have demonstrated that the inflammatory response of the gingiva to a given amount of supragingival plaque appeared to be altered or depressed in smokers, compared to the gingiva of non-smokers (Bergström \& Preber, 1986, Calsina et al., 2002). This suppressive effect of smoking on the inflammatory response of the gingiva has been suggested to be dependent on the intensity of smoking (Dietrich et al., 2004). However, very few of these studies have been conducted among adolescents who commonly display a lower smoking intensity than adults. The few studies of the effect of smoking on gingival health that have been done on adolescents, mainly in developed countries, have produced inconsistent results (Modeer et al., 1980; Romao \& Wennström, 2007). Furthermore, the few studies that have been done on adolescents have either been limited to cross-sectional designs (Modeer et al., 1980; Romao \& Wennström, 2007) which do not take into account the natural time-related variation in gingival status that occurs irrespective of the level of oral hygiene (Smith \& Geegan, 1991) - or employed analytical methods that do not adequately model highly correlated data such as repeated measurements of gingival health of the same subjects over time.

A recent study using a multilevel modeling method, which does adequately model correlated data, suggests that some subjects tend to have gingivae that consistently bleed after mechanical manipulation such as probing (Müller \& Stadermann, 2006). These authors suggested that their observation of a greater significant serial correlation of bleeding gums on probing at subject level (compared to at tooth level) might be related to differences in coping with stress. Regular smoking has also been suggested as a coping response to stress especially among people from a low socioeconomic class (Wills et al., 1995; Byrne et al., 1995). The present study therefore sought to determine the independent roles of rural adolescents' sense of coherence and smoking in predicting transitions in self-reported gingival health, using a multilevel model namely - generalized estimating equation (GEE) method.

\section{Methods}

\section{Study population and sample design}

This longitudinal study was conducted in the rural Limpopo province of South Africa between April 2005 and October 2006. The participants in this study were $8^{\text {th }}$-graders from 11 randomly selected public high schools. A detailed description of the sampling strategy has previously been provided by Ayo-Yusuf et al. (in press). Briefly, a two-stage sampling 
technique was used to produce a provincially representative sample of $8^{\text {th }}$-graders. All the $8^{\text {th }}$-graders in the selected schools were eligible to participate in the study. Participation in the study required the informed consent of the participants, as well as that of their parents. After providing informed consent, the participants completed a pre-tested self-administered questionnaire during class time at baseline (T1), after 12 months (T2) and again after 18 months (T3). The study protocol was approved by the University of Pretoria's Ethics Committee (22/2005).

\section{Measures and definitions}

\section{Socio-demographic features}

The study participants provided information about their age, gender, ethnicity (black African and others), estimated household income and the type of dwelling they lived in (formal housing - a brick house/flat; or informal housing - huts/tents or a non-brick house). The type of dwelling (Wichman et al., 2008) and the subjective measure of household income indicated served as two proxy measures for the socio-economic status of the participating adolescents. Because some adolescents may not be able to state their households' total earnings accurately, the respondents were instructed to choose from a range of options of what they estimated was their households' total monthly earnings to be. On the basis of data from the report on income poverty that was derived from an analysis of the 2005 South African general household survey findings (Leatte, 2006), we categorised the respondents into those that live in 'poor' households (that is, selected estimated monthly earnings; 0 - R1500) and that did not.

The current study was limited to those who identified themselves as black Africans ( $n=970 ; 95 \%$ of the total sample). This therefore imposed inherent control for potential genetic variations that have been noted as potential modifying factors for the development of periodontal disease (Albandar, 2002).

\section{Tobacco use status}

Using items previously employed in national and international youth tobacco surveys (Swart et al., 2004), the respondents themselves were categorised as daily/regular smokers if they indicated that they had smoked at least one cigarette (even a puff) within the 24 hours preceding the survey and had also indicated smoking in the last week and in the last 30 days preceding the date of the survey. A similar approach was used to define regular oral smokeless tobacco/snuff users, but the question enquired whether the respondents had used snuff at least once within the referenced periods.

\section{Sense of coherence (SOC)}

The original 13-item short version of Antonovsky's 7-point Likert-type SOC scale was included in the original questionnaire (Freire et al., 2001). However, results of factor analysis reported in a previous paper showed six items of the original SOC scale to be an internally consistent (Cronbach alpha $=0.63$ ) measure of SOC in the current adolescent population sample (Ayo-Yusuf et al., in press). Because this compared favourably with the Cronbach alpha (0.64) reported for a 17-item scale (factor-analysed from the original 29- 
item long version of the SOC scale) used in another study of adolescents (Antonovsky \& Sagy, 2001), the six-item SOC scale was used in the current study (score range 0 - 42).

\section{Tooth brushing frequency}

To measure brushing frequency, respondents were asked the following question: 'In the past month (30 days), how often have you been brushing/cleaning your teeth?' Guided by the findings from the pilot test, the response options provided were: (1) 'I did not always clean daily'; (2) 'Always once daily'; (3) 'Most days once, but some days twice daily'; (4) 'Most days twice, but sometimes once'; and (5) 'Always brush at least twice daily'. Respondents who indicated brushing always at least twice were classified as having 'twicea-day' or regular brushing behaviour (Ayo-Yusuf et al., in press).

\section{Self-reported gum bleeding (gingivitis)}

For this main outcome measure, respondents were asked how frequently they had experienced bleeding gums while brushing in the three months prior to the survey dates. Those who indicated that their gums always or often bled were categorised as having frequent gingival bleeding or gingivitis and those who reported that their gums never bled or seldom bled were categorised as not having gingivitis (Ayo-Yusuf et al., in press).

\section{Oral hygiene status}

An objective measure of plaque control using the patient hygiene performance (PHP) index as previously described (Podshadley \& Harley, 1968; Maraj \& Kroon, 2004) was used to document patient oral hygiene (the mean range was 0 to 5 ; a higher mean plaque score represented poorer oral hygiene). Because the frequency distribution of the plaque scores was compatible with a normal distribution, we did not transform the scores, so they were used as a continuous variable, as was also done in a previous study in South Africa (Maraj \& Kroon, 2004). All six trained examiners who conducted the oral screening on consenting participants $(n=910)$ were blinded to the completed questionnaires. The interexaminer agreement on plaque scoring was considered good with a Kappa coefficient ranging between 0.72 and 0.88 . No repeat examinations were conducted, as this was not feasible, considering that the plaque deposit is likely to be altered with repeated tooth staining with the plaque-disclosing agents used as part of the measurement protocol. Each participant was provided with a toothbrush and toothpaste after his/her oral examination.

\section{Past dental visit}

Based on a question on past dental visits, the sample was divided into two groups namely those who self-reported that they had never visited a dentist before and those who had made at least one or more past dental visits.

\section{Data analysis}

All those who provided data on this measure of gingival health at baseline and consented to an oral examination were included in our analysis. The main outcome measure was therefore a self-report of recent frequent bleeding gums (Coded 1) compared to a report of no recent frequent bleeding gums (Coded 0 ). Descriptive and multivariate analyses 
were conducted to assess the rates and correlates of reporting bleeding gums at the last follow-up stage. For bivariate analyses, the option 'svy' for survey data in Stata (Stata Corporation, College Station, Texas, USA) was used to account for the fact that the study participants were nested within schools (the primary sampling unit). The chi-square test and t-tests were used to compare the characteristics of the study cohort with those of drop-outs. Drop-outs were defined as learners with baseline data (T1), but no data at either of the follow-up stages (T2 or T3).

For the multivariate modelling, all the subjects for whom at least one set of follow-up measurement on gingival health was available were included in the analysis. The analysis included fitting generalized estimating equation (GEE) models with the logit link function for analysis of the correlated data, in order to determine factors associated with recent frequent bleeding gums. This was done to take into account the fact that this repeated measure of gingival health was nested within the same subjects (random effect). Missing data was also addressed by means of the GEE estimating mechanism, which uses all the available pairs method to estimate the missing data from dropouts or intermittent missings. At first step, we used the GEE univariate analysis to determine factors associated with recent frequent bleeding gums. In order to adjust for potential confounding, all variables that were $p<0.15$ in GEE univariate analyses were entered in a multivariate logistic GEE model using a stepwise approach (Müller et al., 2002). This involved the inclusion of the socio-demographic variables in one block followed by the sequential inclusion of tooth brushing frequency, plaque score, smoking status and SOC. This therefore allowed us to examine whether or not the effect of the preceding variables was mediated by the effect of the succeeding variables (Baron \& Kenny, 1986). The participants' age and the time from the baseline to the follow-ups were always used as covariates in the multivariate analysis. All group differences were considered significant when $\mathrm{p}<0.05$.

\section{Results}

\section{Baseline characteristics of the study population and drop out analysis}

The study participants were between 12 and 19 years old, with a mean (SD) age of 14.4 (SD 1.5 ) years. Only $22.8 \%$ of our study participants had ever visited a dental professional; and $37.4 \%$ reported frequent bleeding gums at the baseline time. An analysis of those lost to follow-up (drop-outs) showed that there were no significant differences between the baselines social or behavioural characteristics of the participants that provided at least one follow-up measurement and the characteristics of those who were lost to the follow-up (see Table 2). 
Table 2: Characteristics of participants that provided follow-up data compared to those of drop-outs

\begin{tabular}{|c|c|c|c|}
\hline Baseline characteristics & $\begin{array}{c}\text { Participants } \\
\text { followed up on } \\
\%(N=845)\end{array}$ & $\begin{array}{l}\text { Drop-outs } \\
\%(\mathbf{N}=\mathbf{1 2 5})\end{array}$ & p-value \\
\hline Lives in informal housing structure & $13.1 \%(n=109)$ & $16.4 \%(n=30)$ & 0.37 \\
\hline Lives in poor household & $71.7 \%(n=599)$ & $69.5 \%(n=82)$ & 0.72 \\
\hline Female & $52.8 \%(n=445)$ & $52.4 \%(n=65)$ & 0.93 \\
\hline Late adolescence (15-19 years) & $41.2 \%(n=344)$ & $44.3 \%(54)$ & 0.57 \\
\hline Ever visited a dentist before & $22.9 \%(n=191)$ & $20.2 \%(n=25)$ & 0.57 \\
\hline Brushes at least twice daily & $26.8 \%(n=225)$ & $28.5 \%(n=35)$ & 0.79 \\
\hline Daily/regular smoker & $7.0 \%(n=59)$ & $5.8 \%(n=7)$ & 0.70 \\
\hline Daily/regular oral snuff use & $1.0 \%(n=8)$ & $1.7 \%(n=2)$ & $0.33 *$ \\
\hline \multirow[t]{2}{*}{ Recent frequent gum bleeding } & $37.4 \%(n=313)$ & $35.8 \%(n=44)$ & 0.68 \\
\hline & \multicolumn{2}{|c|}{ Mean (SD) } & \\
\hline Total SOC-6 score (range 0 - 42) & $26.3(7.2)$ & $25.3(7.3)$ & 0.17 \\
\hline Age (range $12-19$ years) & $14.4(1.5)$ & $14.7(2.0)$ & 0.09 \\
\hline Mean Plaque score (range $0-5$ ) & $2.84(0.70)$ & $2.81(0.66)$ & 0.69 \\
\hline
\end{tabular}

The total sample contributed to 2505 observations, with a median number of 3 follow-up visits, and 845 (87.1\%) participants completing at least two surveys. Among our sample of eligible adolescents (those who had completed an oral examination and the questionnaire at the baseline time), $74.6 \%$ reported experiencing gingivitis at some point during the 18month follow-up surveys, while $41.9 \%$ reported experiencing gingivitis at the last survey.

In univariate GEE, as compared to baseline, the odds of reporting gingival bleeding was higher at T2 (after 12 months) than at T3 (after 18 months), but this difference was attenuated in the final multivariate model after adjusting for potential confounders (see Table 3). Except for tooth brushing frequency, all the factors found to be associated with reporting recent or persistent frequent bleeding gums in univariate GEE remained independently associated with this outcome in multivariate GEE (see Table 3). The influence of twice-daily brushing lost statistical significance after we had controlled for mean plaque levels. On the other hand, the influence of the mean plaque score on recent frequent bleeding gums only reached statistical significance after we had controlled for the SOC level. Furthermore, the influence of smoking and socio-economic status on selfreported gingival health was slightly attenuated (but remained significant) after we had controlled for SOC level. 
In the final model, the factors that were positively associated with recent frequent bleeding gums included living in a poor household (odds ratio [OR] $=1.49 ; p<0.01$ ), increasing plaque levels (odds ratio $[\mathrm{OR}]=1.18 ; \mathrm{p}=0.04)$ and regular smoking $(\mathrm{OR}=$ 1.57; $p=0.04)$. Reporting recent frequent bleeding gums was found to be negatively associated with being female $(O R=0.76 ; p=0.02)$ and higher levels of $S O C(O R=0.96$; $\mathrm{p}<0.001)$.

Table 3: Factors associated with self-reporting of recent frequent gingival bleeding

\begin{tabular}{|c|c|c|c|c|}
\hline \multirow[b]{2}{*}{ Characteristics } & \multicolumn{2}{|l|}{ Univariate GEE } & \multicolumn{2}{|c|}{ Multivariate GEE* } \\
\hline & OR (95\% CI) & p-value & OR (95\% CI) & p-value \\
\hline \multicolumn{5}{|l|}{ Time } \\
\hline Baseline vs. 12 months & $1.52(1.24-1.88)$ & $<0.001$ & $1.49(1.19-1.85)$ & $<0.001$ \\
\hline vs. 18 months & $1.40(1.23-1.74)$ & $<0.01$ & $1.46(1.17-1.83)$ & $<0.01$ \\
\hline $\begin{array}{c}\text { Poor household resident } \\
\text { Yes vs. No }\end{array}$ & $1.59(1.26-2.02)$ & $<0.001$ & $1.49(1.17-1.89)$ & $<0.01$ \\
\hline $\begin{array}{l}\text { Gender } \\
\quad \text { Female vs. male }\end{array}$ & $0.79(0.64-0.98)$ & 0.03 & $0.76(0.61-0.95)$ & 0.02 \\
\hline
\end{tabular}

Never visited a dentist before

Yes vs. No

$0.99(0.77-1.27) \quad 0.91$

Brushes at least twice daily

Yes vs. No

$0.78(0.61-0.99) \quad 0.04$

$0.79(0.62-1.00) \quad 0.06$

Plaque score

(per unit change)

$1.15(0.99-1.34) \quad 0.08 \quad 1.18(1.01-1.39) \quad 0.04$

Regular oral snuff user

Yes vs. No

$1.68(0.60-4.75) \quad 0.32$

\section{Regular smoker}

Yes vs. No

$1.74(1.16-2.61) \quad 0.01$

$1.57(1.02-2.39)$

0.04

SOC total score

(per unit change)

$0.96(0.95-0.98) \quad<0.001$

$0.96(0.95-0.98)$

$<0.001$

Note: Model included all study participants that provided complete data on all explanatory variables $(n=863)$. $\mathrm{GEE}=$ Generalized Estimating Equation; OR = Odds Ratio; CI = Confidence Interval.

*In addition to the above variables, the multivariate models included age as covariates. 


\section{Discussion}

This study is the first study to examine the longitudinal course of self-reported gingival health among South African adolescents. In the present study, at some point during the 18month follow-up period, three-quarters of the study participants reported having experienced gingivitis. Recent frequent bleeding gums were less likely to be reported among those with a higher SOC at the baseline time, but were more prevalent among those with poorer oral hygiene, those smoking regularly and those living in poor households.

In contrast to findings by Lopez et al. (2001), never having made a dental visit was not significantly associated with reporting frequent bleeding gums. The lack of a significant association between dental service utilization and gingival health in this study may be related to the fact that the utilization of dental services was generally low and (as illustrated in a previous study) even when these adolescents do make a visit to the dentist, it is often visit to alleviate particular symptoms (Ayo-Yusuf et al., in press). This notwithstanding, our finding of a lack of association between dental attendance and self-reported periodontal health corroborates findings from other studies (Do et al., 2003; Pattussi et al., 2007).

Our findings were also consistent with previous studies in that our findings indicated that the adolescents reporting poor gingival health were less likely to be females (Albandar, 2002), and more likely to be living in lower income households (Kallio \& Murtomaa, 1997; Lopez et al., 2006). As expected, the influence of twice-daily brushing lost significance after we had controlled for plaque levels, thus confirming that the effect of regular brushing on reducing the likelihood of reporting gingivitis was perfectly mediated by the level of plaque control achieved. Also, consistent with the literature, a number of characteristics were found to be independently and positively associated with reporting recent frequent bleeding gums in the current study, including higher plaque levels and regular smoking (Müller \& Stadermann, 2006).

The fact that baseline plaque levels only became significant after controlling for SOC levels suggests that SOC provided the context for the relevance of plaque levels. This finding supports the view that the influence of stress on periodontal health may be partly related to the fact that people who are not coping adequately with stress are also those more likely to neglect regular tooth brushing and thus experience inadequate plaque control, which then directly influences periodontal or gingival health (Savolainen et al., 2005; Deinzer et al., 2005). It is also conceivable that plaque would have a greater adverse effect on the gingival health of people whose immune system is already compromised, as may be the case in the presence of stress (Ballieux, 1991; Giannopoulou et al., 2003), which may in turn result from a low SOC. Given a stress-induced compromise of the immune response, it was not surprising to find that the final predictor model demonstrated an independent or a direct influence of SOC on gingival health, irrespective of oral hygiene status. This study's finding therefore corroborates findings from previous studies on the direct influence of inadequate stress-coping behaviour on periodontal disease (Genco et al., 1999; Wimmer et al., 2002).

The fact that a higher SOC was protective against poor gingival health is indeed consistent with the salutogenic theory (Antonovsky, 1993). In contrast to our findings, a 
previous study showed no association between adolescents' SOC and gingival health measured by bleeding on probing (Freire et al., 2001). The differences in the findings may be related to the fact that the study by Freire et al. (2001) was a cross-sectional study, while the current study used a longitudinal approach. Considering that SOC develops throughout life and in particular that it is only tentative in childhood (Antonovsky, 1993), it is less likely that one will find an association between concurrent measures of adolescents' SOC and their current oral health status.

The difference between the findings of the current study and those of a recent study of Swedish adolescents (Ramao \& Wennstrom, 2007) that failed to demonstrate a significant association between smoking and measures of gingival health may also be related to the differences in the study design used and/or differences in the population studied. For instance, while this study showed that only $26.8 \%$ of the participating adolescents brushed twice daily, a previous study of a Swedish adolescent cohort suggest as high as $84.6 \%$ of Swedish adolescents reported brushing twice daily (Källestål et al., 1990). This difference in the level of plaque control may influence the amount of calculus build-up, which has been shown to reduce or reverse the suppressive effect of smoking on gingival bleeding, particularly among light smokers (Dietrich et al., 2004). Furthermore, given that the suppressive effect of smoking on gingival bleeding is dose-dependent, the difference in the findings in this study and those that have reported a suppressive or no significant effect of smoking on gingival bleeding may also be related to the fact that South African adolescents are mostly light smokers (most smoke six to ten cigarettes per week) (Swart et al., 2004; Panday et al., 2007).

There was evidence to suggest that the influence of smoking on adolescents' gingival health may only be partly mediated through the adolescents' SOC, as the inclusion of SOC resulted in only a small attenuation of the effect of smoking, although smoking remained significantly associated with the self-reporting of frequent gingival bleeding. Nevertheless, considering that a high SOC has been associated with a lower risk for adolescent smoking (Glanz et al., 2005), taken together, our study findings suggest that a high SOC, and by implication a greater ability to cope with stress, may be a common salutogenic factor promoting smoking abstinence and gingival health.

Consistent with the findings of another study (Montén et al., 2006), the current study has failed to demonstrate an association between the oral application of snuff and frequent gingival bleeding. This is finding did, however, contrast with that of a previous study that showed a significant association between oral snuff use and gingivitis among adolescents (Modeer et al., 1980). Given that only a few $(n=8)$ of the current study's participants were regular oral snuff users, the lack of association may also be related to the reduced statistical power to detect a difference even if there was one (that is, a Type 2 error). Considering that snuff use has been associated with higher mortality from all causes (Gupta \& Mehta, 2000; Henley et al., 2005), notwithstanding the findings in the current study, efforts need to be directed at preventing all forms of tobacco use among adolescents.

The findings of this study should be considered in relation to its methodological strengths and limitations. A major limitation of this study is the reliance on self-reported 
tobacco use and self-reported gingival health, which may create potential reporting bias. However, adolescent self-reports of tobacco use have been generally found to be reliable (Post et al., 2005). Furthermore, the self-reporting of household income could also be considered fairly reliable, considering that the $72 \%$ obtained for those living in poor households in this study was similar to the fact that $71 \%$ of children in the Limpopo Province have been estimated to be living with unemployed parents (Leatte, 2006).

Self-reporting of gingivitis may not have sufficient validity for screening individuals, but it has been demonstrated to be a useful method for monitoring the gingival health of adolescent populations (Kallio \& Murtomaa, 1997; Taani \& Alhaija, 2003). The alternative clinical diagnostic protocol (using probes to elicit the presence of bleeding gums on mechanical manipulation) was not carried out, as it was considered invasive and our pilot test suggested this would result in a high refusal rate. The high prevalence of HIV infection in South Africa (Department of Health, 2005) and low literacy did pose an additional challenge with regard to convincing potential participants about infection control that would guarantee the safety of the procedure. In addition, intra- and inter-examiner variations in BOP measurements are also by themselves potential sources of measurement errors (Kallio, 1996). If anything, the use of self-reporting is more likely to have led to an underestimation than an overestimation of the associations reported in the current study. However, it should be noted that self-ratings of oral health have been suggested to be influenced by social class (Pattussi et al., 2007); therefore the findings in this study may not be generalized to all adolescent populations.

Notwithstanding these limitations, a major strength of this study is that it involved a relatively large representative sample of adolescents in a resource-poor setting where access to regular care is not likely to have affected the 'natural history' of periodontal disease (Baelum \& Scheutz, 2002). Furthermore, we have used a longitudinal design with the GEE method, which limits the chance of sample bias (due to missing data) that may be encountered with longitudinal studies (Lee et al., 2007).

In conclusion, the findings of the current study that identify smoking and poor oral hygiene as important modifiable risk factors for poor gingival health suggest that promoting regular tooth brushing may not be enough to prevent periodontal disease, but that the integration of smoking prevention with an oral health promotion initiative may have a greater public health impact. In addition, considering the important role of socioeconomic status and SOC as determinants of gingival health, this study's findings suggest that poverty alleviation initiatives and psychological and/or educational interventions such as classroom teaching of stress-coping skills can play a role in promoting gingival health among adolescents.

\section{Clinical relevance}

Consistent with good clinical practice that encourages patients to play a more active role in their health, we examined over an 18-month period the predictors of self-reported gum bleeding or gingivitis among rural adolescents. This study's findings suggest that at some point during the 18-month follow-up period, three-quarters of the study participants had experienced gingivitis. Self-reporting recent frequent bleeding gums was less likely among 
those with higher sense of coherence - a measure of stress-coping, but was more prevalent among those who smoked and had poorer oral hygiene. Smoking cessation and stress management may be useful additions to clinical periodontal care.

\section{Acknowledgements}

This study was supported by grants received from the Medical Research Council and the Cancer Association of South Africa. The authors are grateful to Colgate and GlaxoSmithKline for donating the toothbrushes and toothpaste given to all study participants. The authors are also grateful to the oral hygienists and dentists in the employment of the Limpopo province who participated in the clinical oral examination. 


\section{References}

Albandar, J.M. (2002). Global risk factors and risk indicators for periodontal diseases. Periodontology 2000, 29: 177-206.

Albandar, J.M., Kingman, A., Brown, L.J. \& Löe, H. (1998). Gingival inflammation and sub-gingival calculus as determinants of disease progression in early-onset periodontitis. Journal of Clinical Periodontology, 25: 231-237.

Aldridge, J.P., Lester, V., Watts, T.L, Collins, A., Viberti, G. \& Wilson, R.F. (1995). Single-blind studies of the effects of improved periodontal health on metabolic control in type 1 diabetes mellitus. Journal of Clinical Periodontology, 22: 271-275.

Antonovsky, A. (1993). The structure and properties of the sense of coherence scale. Social Science \& Medicine, 36: 725-733.

Antonovsky, H. \& Sagy, S. (1986). The development of a sense of coherence and its impact on responses to stress situations. Journal of Social Psychology, 126: 213-225.

Armitage, G.C., Wu, Y., Wang, H.Y., Sorrell, J., Di Giovine, F.S. \& Duff, G.W. (2000). Low prevalence of a periodontitis-associated intrleukin-1 composite genotype in individuals of Chinese heritage. Journal of Periodontology, 71: 164-171.

Ayo-Yusuf, O.A, Reddy, P.S. \& Van den Borne, B.W. (in press). Longitudinal association of adolescents' sense of coherence with tooth brushing using an integrated-behaviour change model. Community Dentistry and Oral Epidemiology.

Baelum, V. \& Scheutz, F. (2002). Periodontal diseases in Africa. Periodontology 2000, 29: 79-103.

Ballieux, R.E. (1991). Impact of stress on the immune response. Journal of Clinical Periodontology, 18: $427-430$.

Baron, R.M. \& Kenny, D.A. (1986). The moderator-mediator variable distinction in social psychological research: Conceptual, strategic, and statistical considerations. Journal of Personality and Social Psychology, 51: 173-182.

Beck, J., Garcia, R., Heiss, G., Vokonas, P.S. and Offenbacher, S. (1996). Periodontal disease and cardiovascular disease. Journal of Periodontology, 67: 1123-1137.

Bergström, J. \& Preber, H. (1986) The influence of cigarette smoking on the development of experimental gingivitis. Journal of Periodontal Research, 21, 668-676.

Byrne, D.G., Byrne, A.E. \& Reinhart, M.I. (1995) Personality, stress and the decision to commence cigarette smoking in adolescence. Journal of Psychosomatic Research, 39: 53-62.

Calsina, G., Ramon, J-M. \& Echeverria, J-J. (2002). Effects of smoking on periodontal tissues. Journal of Clinical Periodontology, 29, 771-776. 
Deinzer, R., Forster P., Fuck, L., Herforth, A., Stiller-Winkler, R. \& Idel, H. (1999). Increase in crevicular interleukin $1 \beta$ under academic stress at experimental gingivitis sites and at sites with perfect oral hygiene. Journal of Clinical Periodontology, 26: 1-8.

Deinzer, R., Granrath, N., Spahl, M., Linz, S., Waschul, B. \& Herforth, A. (2005). Stress, oral health behaviour and clinical outcome. British Journal of Health Psychology, 10: 269-283.

Department of Health (2005). National HIV and Syphilis sero-prevalence survey of women attending public antenatal clinics in South Africa. Pretoria: Government printer.

Dietrich, T., Bernimoulin, J.P. \& Glynn, R.J. (2004). The effect of cigarette smoking on gingival bleeding. Journal of Periodontology, 75, 16-22.

Do, L.G., Spencer, A.J., Roberts-Thomson K.F. \& Ha, H.D. (2003). Smoking as a risk indicator for periodontal disease in the middle-aged Vietnamese population. Community Dentistry and Oral Epidemiology, 31: 437-446.

Eriksson, M. \& Lindström, B. (2006). Antonovsky's sense of coherence scale and the relation with health: a systematic review. Journal of Epidemiology and Community Health, 60: 376-381.

Freire, M.C.M., Sheiham, A. \& Hardy, R. (2001). Adolescents' sense of coherence, oral health status, and oral health-related behaviours. Community Dentistry and Oral Epidemiology, 29: 204-212.

Genco, R.J, Ho, A.W., Grossi, S.G., Dunford, R.G. \& Tedesco, L.A. (1999). Relationship of stress, distress and inadequate coping behaviours to periodontal disease. Journal of Periodontology, 70: 711-723.

Giannopoulou, C., Kamma, J.J. \& Mombelli, A. (2003). Effect of inflammation, smoking and stress on gingival crevicular fluid cytokine level. Journal of Clinical Periodontology, 30, 145-153.

Glanz, K., Maskarinec, G. \& Carlin, L. (2005). Ethnicity, sense of coherence, and tobacco use among adolescents. Annals of Behavioral Medicine, 29: 192-199.

Gupta, P.C. \& Mehta, H.C. (2000). Cohort study of all-cause mortality among tobacco users in Mumbai, India. Bulletin of the World Health Organization, 78: 877-883.

Henley, S.J., Thun, M.J., Connell, C. \& Calle E.E. (2005). Two large prospective studies of mortality among men who use snuff or chewing tobacco (United States). Cancer Causes and Control, 16: 347-358.

Herrera, J.A., Parra, B., Herrera, E., Botero, J.E., Arce, R.M., Contreras, A. \& López-Jaramillo, P. (2007). Periodontal disease severity is related to high levels of C-reactive proteins in preeclampsia. Journal of Hypertension, 25: 1459-1464. 
Joshipura, K.J., Rimm, E.B., Douglass, C.W., Trichopoulos, D., Ascherio, A. \& Willett, W.C. (1996). Poor oral health and coronary heart disease. Journal of Dental Research, 75: 1631-1636.

Källestål, C., Mattson, L. \& Holm, A.K. (1990). Periodontal conditions in a group of Swedish adolescents. (I). A descriptive epidemiologic study. Journal of Clinical Periodontology, 17: 601-608.

Kallio, P. (1996). Self-assessed bleeding in monitoring gingival health among adolescents. Community Dentistry and Oral Epidemiology, 24: 128-132.

Kallio, P. \& Murtomaa, H. (1997). Determinants of self-assessed gingival health among adolescents. Acta Odontologica Scandinavica, 55: 106-110.

Klages, U., Weber, A.G. \& Wehrbein, H. (2005). Approximal plaque and gingival sulcus bleeding in routine dental care patients: relations to life stress, somatization and depression. Journal of Clinical Periodontology, 32: 575-582.

Kornman, K.S., \& Di Giovine, F.S. (1998). Genetic variations in cytokine expression: a risk factor for severity of adult periodontitis. Annals of Periodontology, 3, 327-338.

Lee, J., Herzog, T.A., Meade, C.D., Webb, M.S. \& Brandon, T.H. (2007). The use of GEE for analysing longitudinal binomial data: A primer using data from a tobacco intervention. Addictive Behaviors, 32: 187-193.

Leatte, A. (2006). Income poverty in South Africa. URL: http://www.ci.org.za/depts/ci/pubs/pdf/general/gauge2006/gauge2006 incomepoverty.pdf (last Accessed 26/05/2008).

López, R., Fernández, O., Jara, G. \& Baelum, V. (2001). Epidemiology of clinical attachment loss in adolescents. Journal of Periodontology, 72: 1666-1674.

López, R., Fernández, O. \& Baelum, V. (2006). Social gradient in periodontal diseases among adolescents. Community Dentistry and Oral Epidemiology, 34: 184-196.

López, R. \& Baelum, V. (2007). Oral health impact of periodontal diseases in adolescents. Journal of Dental Research, 86: 1105-1109.

Maraj, E. \& Kroon, J. (2004). The impact of a school dental service on the periodontal health and hygiene status of 6-year-old Sowetan learners. South African Dental Journal, 59: 374-6, 378.

Michaud, D.S., Liu, Y., Meyer, M., Giovannucci, E. \& Joshipura, K. (2008). Periodontal disease, tooth loss, and cancer risk in male health professionals: a prospective cohort study. Lancet Oncology, 9: 550-558.

Modeer, T., Lavstedt, S. \& Ahlund, C. (1980). Relation between tobacco consumption and oral health in Swedish schoolchildren. Acta Odontologica Scandinavica, 38: 223-227. 
Montén, U., Wennström, J.L. and Ramberg, P. (2006). Periodontal conditions in male adolescents using smokeless tobacco (moist snuff). Journal of clinical Periodontology, 33: 863-868.

Müller, H.P. \& Stadermann, S. (2006). Multivariate multilevel models for repeated measures in the study of smoking effects on the association between plaque and gingival bleeding. Clinical Oral Investigations, 10: 311-316.

Müller, H.P., Stadermann, S. and Heinecke, A. (2002). Longitudinal association between plaque and gingival bleeding in smokers and non-smokers. Journal of Clinical Periodontology, 29: 287294.

Norland, K.B. (2005). A socio-economic perspective on periodontal diseases: a systematic review. Journal of Clinical Periodontology, 32: 314-325.

Offenbacher, S., Katz, V., Fertik G., Collins, J., Boyd, D., Maynor, G., McKaig, R. \& Beck, J. (1996). Periodontal infection as a possible risk factor for pre-term low birth weight. Journal of Periodontology, 67: 1103-1113.

Panday, S., Reddy, S.P., Ruiter, R.A., Bergstrom, E., \& de Vries, H. (2007). Nicotine dependence and withdrawal symptoms among occasional smokers. Journal of Adolescent Health, 40,144-150.

Pattussi, M.P., Olinto, M.T.A., Hardy, R. \& Sheiham, A. (2007). Clinical, social and psychosocial factors associated with self-rated oral health in Brazilian adolescents. Community Dentistry and Oral Epidemiology, 35: 377-386.

Podshadley, A.G. \& Haley, J. (1968). A method for evaluating oral hygiene performance. Public Health Report, 83: 259.

Post A, Gilljam, H., Rosendahl, I., Meurling, L., Bremberg, S. \& Galanti, M.R. (2005). Validity of self reports in a cohort of Swedish adolescent smokers and smokeless tobacco (snus) users. Tobacco control, 14: 114-117.

Prayitno, S.W., Addy, M. \& Wade, W.G. (1993). Does gingivitis lead to periodontitis in young adults? Lancet, 342: 471-472.

Rayant, G.A., \& Sheiham, A. (1980). An analysis of factors affecting compliance with tooth-cleaning recommendation. Journal of Clinical Periodontology, 7: 289-299.

Romao, C. \& Wennström, J.L. (2007). Periodontal conditions in a Swedish city population of adolescents: a comparison between smokers and never-smokers. Oral Health \& Preventive Dentistry, 5: 105-112.

Savolainen, J.J., Suominen-Taipale, A.L., Uutela, A.K., Martelin, T.P., Niskanen, M.C. \& Knuuttila, M.L. (2005). Sense of coherence as a determinant of tooth brushing frequency and level of oral hygiene. Journal of Periodontology, 76: 1006-1012. 
Smith, Q.T. \& Geegan, S.J. (1991). Repeated measurement of crevicular fluid parameters at different sites. Journal of Clinical Periodontology, 18: 171-176.

Swart, D., Reddy, S.P., Panday, S., Philip, J.L., Naidoo, N. \& Ngobeni, N. (2004). The 2002 Global Youth Tobacco Survey (GYTS): The $2^{\text {nd }}$ GYTS in South Africa (SA) - A comparison between GYTS (SA) 1999 and GYTS (SA) 2002. Cape Town: South African Medical Research Council.

Taani, D.Q., \& Alhaija D.S. (2003). Self-assessed bleeding as an indicator of gingival health among 12-14-year-old children. Journal of Oral Rehabilitation, 30: 78-81.

Van Wyk, P.J. (1994). National Oral Health Survey, South Africa 1988/89. Pretoria. Government Printers.

Watt, R.G. (2002). Emerging theories into the social determinants of health: implications for health promotion. Community Dentistry and Oral Epidemiology, 30: 241-247.

Wichmann, J., Wolvaardt, J. E., Maritz, C., \& Voyi, K. V. (2008). Association between children's household living conditions and eczema in the Polokwane area, South Africa. Health \& Place, 14: 323-335.

Wills, T.A., McNamara, G. \& Vaccaro, D. (1995). Parental education related to adolescent stresscoping and substance use: development of a mediational model. Health Psychology, 14: 464-478.

Wimmer, G., Janda, M., Wieselmann-Penkner, K., Jakse, N., Polansky, R. \& Pertl, C. (2002). Coping with stress: its influence on periodontal disease. Journal of Periodontology, 73: 1343-1351. 


\section{Chapter 2:}

\section{The Association of Tooth Loss and Smoking with Hypertension in South Africa}

Published as: Ayo-Yusuf OA, Ayo-Yusf IJ. Association of Tooth Loss with Hypertension. South African Medical Journa/2008; 98: 381-385. 


\section{Abstract}

Objective: Hypertension may result from changes in dietary quality and nutrient intake. We therefore sought to determine the epidemiological association between tooth loss and hypertension in South African adults.

Methods: This is a secondary data analysis of a cross-sectional survey of a nationally representative sample of adults aged 25-70 years who participated in the South African Demographic and Health Survey during 1998 ( $N=9$ 098). The primary data were collected using a validated questionnaire, which included information on past experience of tooth loss (partial or complete), use of dental services, tobacco use and other known risk factors for hypertension. Hypertension was defined as having a measured average blood pressure (BP) $\geq 160 / 95 \mathrm{mmHg}$ and/or taking antihypertensive medication.

Results: The prevalence of hypertension, any tooth loss and complete edentulousness were $18.1 \%, 72.2 \%$ and $9.4 \%$ respectively. Tooth loss was more common among overweight/obese respondents than among those with a normal body mass index $(76.7 \%$ v. $66.7 \% ; p<0.01)$. Compared with the fully dentate respondents, the completely edentulous respondents had mean systolic and diastolic BPs that was respectively 12 $\mathrm{mmHg}$ and $5 \mathrm{mmHg}$ higher. After adjusting for known risk factors for hypertension in a multiple logistic regression model, being completely edentulous remained significantly associated with hypertension (odds ratio 1.35, 95\% confidence interval 1.02-1.78). The estimated population-attributable fraction of hypertension resulting from complete edentulousness was $10 \%$.

Conclusions: The findings suggest that complete edentulousness is a risk indicator for hypertension in South Africa and highlights the importance of primary care practitioner involvement in oral health promotion. 


\section{Introduction}

Vascular disease is a leading cause of death in developed countries and an increasingly important cause of morbidity and mortality in developing countries, including South Africa. ${ }^{1-2}$ Risk factors for vascular diseases in developing countries include smoking, diabetes mellitus, obesity, dyslipidaemia and hypertension. ${ }^{3-4}$ Studies in developed countries have suggested an association between tooth loss - an end-stage of dental and periodontal disease - and an increased risk of coronary heart disease and cerebrovascular disease. ${ }^{5-6}$ Others have failed to demonstrate any significant independent association. ${ }^{7}$

The link between tooth loss and risk of vascular disease is based on the premise that local chronic bacterial infection in the oral cavity that precedes tooth loss may influence systemic levels of inflammatory mediators. This may contribute to endothelial dysfunction, carotid artery plaque formation ${ }^{8}$ or deterioration of the anti-atherogenic potency of highdensity lipoproteins. ${ }^{9}$ Another mechanism postulated is that tooth loss may affect dietary quality and nutrient intake, leading to an increased risk of vascular diseases. ${ }^{10}$ Others have suggested that the relationship between tooth loss and vascular diseases can mainly be explained by confounding factors, particularly those relating to personal health behaviour and practices. ${ }^{7}$

Studies to date have been in developed countries, and except for one, ${ }^{11}$ no earlier studies have explored the link with hypertension. The only study demonstrating an association between tooth loss and hypertension was restricted to postmenopausal women. ${ }^{11}$ Given that tooth loss may lead to dietary pattern change that may be associated with hypertension, especially among black subjects, ${ }^{12}$ hypertension might be an important risk factor linking tooth loss and vascular diseases in South Africa. We therefore sought to determine the association between tooth loss and hypertension, using a nationally representative adult sample of South Africans.

\section{Methods}

\section{Data source and study design}

The data were obtained from individuals aged 25 - 70 years who participated in the first South African Demographic and Health Survey (SADHS), a nationally representative, crosssectional household survey conducted between February and September 1998. The 1998 SADHS used a stratified, two-staged, probability sample design. The methods used to ensure standardised data collection and interviews and consent procedures have been published. ${ }^{13}$

\section{Cardiovascular disease risk factor assessment and definitions}

The questionnaire was administered by trained and standardised fieldworkers. It included questions on the respondents' personal and family medical history, and their use of chronic medications. Interviewers listed medication containers. Other information on lifestyle and habits that was recorded included the respondents' history of tobacco and/or alcohol use and an estimation of discretionary salt usage. The respondents' smoking status and intensity were stratified according to the reported average number of cigarettes 
smoked per day. Fieldworkers assessed anthropometric measurements and blood pressure (BP) using methods previously detailed. ${ }^{13}$ Wealth index - a measure of socio-economic status - was derived from a composite score of a list of household items (working refrigerator, television, car, washing machine, electricity) owned by the respondents. The reliability of the scale derived was considered very satisfactory as reflected by a high internal consistency of response to scale items (Cronbach $a=0.83$ ). The index scores were then ranked to classify the respondents into three socio-economic categories.

Hypertension was defined using the then South African hypertension guidelines (a cut-off point of $160 / 95 \mathrm{mmHg}$ and/or being on antihypertensive medication were used). ${ }^{13}$ This is higher than the usual cut-off point of $140 / 90 \mathrm{mmHg}$, but it was used in the risk estimation in this study in order to avoid over-diagnosis and misclassification of hypertensive respondents, given that all the triplicate BP measurements were taken on one occasion. This cut-off also provided some understanding of policy implications for the findings, locally. 'Dyslipidaemia' was defined as having a past history of diagnoses of high cholesterol or being on current medication for high cholesterol. Similarly, diabetes mellitus was defined as having a past history of diagnoses by health professionals of diabetes or blood sugar problems.

\section{Dental status assessment}

A person with tooth loss was defined as someone who responded in the affirmative to the question 'Have you lost any of your natural teeth?' If the respondent answered in the negative, he/she was classified as fully dentate. Partially edentulous participants were those who had lost natural teeth, but also responded in the affirmative to the question 'Do you have any of your natural teeth?'; otherwise the respondent was classified as completely edentulous. Participants were asked what they usually did to look after their teeth. Those indicating that they would visit the dentist were categorised as making preventive dental visits. Those answering 'Yes' to the question 'Do you usually brush/clean your mouth every day?' were categorised as brushing daily. The latter two responses were applied in data analysis as variables of preventive health behaviour and oral hygiene practice respectively.

\section{Statistical analysis}

Statistical analyses were done using STATA release 8 (Stata Corp., Texas, USA), with appropriate weights and design effects to produce unbiased standard errors (SE). Group differences were assessed using chi-square statistics and $t$-test or ANOVA for categorical and continuous variables respectively. Statistical comparisons were done between fully dentate and partially or completely edentulous respondents with regard to known vascular disease risk factors and oral hygiene behaviour (daily brushing/cleaning and preventive dental visits). Multiple logistic regression models were constructed to determine any independent association between different categories of dental status with hypertension, while adjusting for the influence of the covariates that have been identified in the literature as risk factors for hypertension and/or tooth loss. All models controlled for the age and gender of the participants regardless of the level of significance obtained in the 
bivariate analysis. Odd ratios (OR) with a 95\% confidence interval (CI) were used in estimating the effect sizes. The level of statistical significance was set at $5 \%$.

To illustrate the potential public health impact of tooth loss as a modifiable risk factor, population-attributable fraction or risk was calculated based on the assumptions that the associations are causal and that the prevalence odds ratios in the adjusted models approximate the true relative risks. ${ }^{14}$

\section{Results}

A total of 9098 records matched the age selection criteria. Of the respondents $60.6 \%$ $(\mathrm{N}=5$ 470) were female and 75\% ( $\mathrm{N}=6$ 824) identified themselves as black Africans, $72.1 \%(\mathrm{~N}=6560)$ reported that they had lost at least one tooth, and $9.4 \%(\mathrm{~N}=851)$ had experienced total tooth loss (were completely edentulous). Using the cut-off point of $160 / 95 \mathrm{mmHg}, 18.1 \%$ of the respondents could be classified as hypertensive.

Respondents who were overweight/obese were more likely to be hypertensive and were also significantly more likely to have lost at least a tooth (Table 4). Alcohol and tobacco use were associated with tooth loss and hypertension, albeit not at a significant level when the measure of hypertension was at the cut-off point of $160 / 95 \mathrm{mmHg}$. Irrespective of the measure of hypertension, affluent respondents were the most likely to be hypertensive and to have lost at least a tooth, but were less likely to be completely edentulous.

The mean diastolic BP increased with an increasing level of tooth loss. Compared with the fully dentate respondents, the completely edentulous respondents presented with mean systolic and diastolic BPs that were $12 \mathrm{mmHg}$ and $5 \mathrm{mmHg}$ higher respectively (Table 5). After controlling for potential confounders and known risk factors, complete edentulousness but not partial edentulousness remained significantly associated with hypertension (Table 6).

The estimated population-attributable fraction of hypertension resulting from complete edentulousness was $10 \%$. 
Table 4: Tooth loss and hypertension by socioeconomic and health/behavioral characteristics (weighted \%)

\begin{tabular}{|c|c|c|c|}
\hline Characteristics & Tooth loss & $B P \geq 140 / 90$ & $B P \geq 160 / 95$ \\
\hline Prevalence $(95 \% \mathrm{CI})$ & $72.2(70.9-73.5)$ & $28.9(27.7-30.0)$ & $18.1(17.1-19.1)$ \\
\hline Mean age (yrs) (SD) & $45.5(12.7)$ & $50.1(12.2)$ & $51.9(11.5)$ \\
\hline \multicolumn{4}{|l|}{ Wealth index $(\mathrm{N}=9068)$} \\
\hline Poorest & 64.9 & 25.9 & 15.0 \\
\hline Middle & 70.7 & 28.0 & 16.2 \\
\hline \multirow[t]{2}{*}{ Wealthiest } & 79.3 & 31.9 & 22.7 \\
\hline & $p<0.001$ & $p<0.001$ & $p<0.001$ \\
\hline \multicolumn{4}{|l|}{ Level of education $(\mathrm{N}=9046)$} \\
\hline None & 72.3 & 36.2 & 23.3 \\
\hline $1-7$ years schooling & 74.2 & 30.6 & 19.0 \\
\hline $8-12$ years schooling & 71.8 & 26.4 & 16.6 \\
\hline \multirow[t]{2}{*}{$>12$ years schooling } & 65.4 & 20.0 & 12.4 \\
\hline & $p<0.01$ & $p<0.001$ & $p<0.001$ \\
\hline \multicolumn{4}{|l|}{ Lifestyle/habits } \\
\hline \multicolumn{4}{|l|}{ Brushes/cleans daily $(\mathrm{N}=8 \mathrm{711})$} \\
\hline No & 73.2 & 36.4 & 24.2 \\
\hline Yes & 71.7 & 28.3 & 17.8 \\
\hline & $p=0.59$ & $p<0.01$ & $p<0.01$ \\
\hline \multicolumn{4}{|l|}{ Regular dental visits $(\mathrm{N}=8711)$} \\
\hline No & 66.2 & 28.3 & 18.0 \\
\hline Yes & 83.2 & 25.9 & 16.2 \\
\hline & $p<0.001$ & $p=0.21$ & $p=0.61$ \\
\hline \multicolumn{4}{|l|}{ Ever used tobacco $(\mathrm{N}=9088)$} \\
\hline No & 68.6 & 27.1 & 17.4 \\
\hline Yes & 77.2 & 31.3 & 19.1 \\
\hline & $p<0.001$ & $p<0.01$ & $p=0.10$ \\
\hline \multicolumn{4}{|l|}{ Body mass index $\left(\mathrm{kg} / \mathrm{m}^{2}\right)(\mathrm{N}=8616)$} \\
\hline Underweight $(<18.5)$ & 72.4 & 18.5 & 9.8 \\
\hline Normal $(18.5-<25)$ & 66.7 & 23.1 & 12.7 \\
\hline \multirow[t]{2}{*}{ Overweight/obese $(\geq 25)$} & 76.7 & 34.6 & 23.3 \\
\hline & $p<0.001$ & $p<0.001$ & $p<0.01$ \\
\hline \multicolumn{4}{|l|}{ Salt intake in food $(\mathrm{N}=9088)$} \\
\hline Not salted & 73.4 & 26.9 & 15.7 \\
\hline Lightly salted & 72.0 & 28.6 & 17.9 \\
\hline Very salty & 72.7 & 41.1 & 31.3 \\
\hline & $p=0.65$ & $p<0.001$ & $p<0.001$ \\
\hline \multicolumn{4}{|l|}{ Ever used alcohol $(\mathrm{N}=9$ 088) } \\
\hline No & 70.8 & 27.1 & 17.5 \\
\hline Yes & 74.0 & 31.1 & 19.0 \\
\hline & $p<0.01$ & $p<0.01$ & $p=0.12$ \\
\hline
\end{tabular}


Table 5: Mean diastolic and systolic blood pressure by dental status and risk factors

Mean systolic pressure $(\mathbf{m m H g})$

Mean (SE) p-value
Mean diastolic pressure $(\mathbf{m m H g})$

Mean (SE)

p-value

Dental status

Fully dentate (no tooth

$119(0.39)$

$76(0.25)$

loss)

Partially edentulous

$124(0.29)$

$79(0.17)$

Completely edentulous

$131(0.82)$

$81(0.43)$

$p<0.001$

$p<0.001$

Diabetes $(\mathrm{N}=9$ 059)

$\begin{array}{ll}\text { No } & 123(0.23) \\ \text { Yes } & 133(1.33)\end{array}$

$78(0.14)$

$81(0.66)$

$p<0.001$

$p<0.001$

Dyslipidaemia ( $N=8983)$

$\begin{array}{ll}\text { No } & 123(0.23) \\ \text { Yes } & 130(1.83)\end{array}$

$81(1.01)$

$p<0.001$

$\mathrm{SE}=$ standard error of the mean. 
Table 6: Multiple logistic regression models for hypertension (BP $\geq 160 / 95 \mathrm{mmHg}$ )

\begin{tabular}{|c|c|c|c|}
\hline & & $\begin{array}{l}\text { Age-adjusted } \\
\text { OR }(95 \% \mathrm{CI})\end{array}$ & $\begin{array}{c}\text { Fully adjusted* } \\
\text { OR }(95 \% \mathrm{CI})\end{array}$ \\
\hline \multirow[t]{3}{*}{ Tooth loss } & None & 1 & 1 \\
\hline & Partial & $1.42(1.19-1.69)$ & $1.18(0.98-1.42)$ \\
\hline & Complete & $2.02(1.57-2.60)$ & $1.35(1.02-1.78)$ \\
\hline \multirow[t]{4}{*}{ BMI category $\left(\mathrm{kg} / \mathrm{m}^{2}\right)$} & $<18.5$ & 1 & 1 \\
\hline & $18.5-<25$ & $1.48(1.05-2.09)$ & $1.44(1.02-2.05)$ \\
\hline & $25-30$ & $2.24(1.58-3.16)$ & $2.04(1.42-2.92)$ \\
\hline & $>30$ & $3.46(2.45-4.88)$ & $3.15(2.20-4.53)$ \\
\hline \multirow[t]{4}{*}{ Level of education } & No school education & 1 & 1 \\
\hline & 1 - 7 yrs (primary) & $1.27(1.04-1.54)$ & $1.11(0.90-1.36)$ \\
\hline & 8 - 12 yrs (secondary) & $1.52(1.23-1.88)$ & $1.04(0.83-1.30)$ \\
\hline & $>12$ yrs (tertiary) & $1.11(0.82-1.49)$ & $0.64(0.45-0.93)$ \\
\hline \multirow[t]{3}{*}{ Wealth Index } & Poorest & 1 & 1 \\
\hline & Middle & $1.34(1.11-1.61)$ & $1.19(0.98-1.45)$ \\
\hline & Richest & $1.83(1.53-2.21)$ & $1.38(1.10-1.73)$ \\
\hline \multirow[t]{3}{*}{ Added salt in food } & Not salted & 1 & 1 \\
\hline & Lightly salted & $1.07(0.86-1.33)$ & $1.01(0.80-1.27)$ \\
\hline & Very salty & $1.81(1.29-2.54)$ & $1.48(1.02-2.15)$ \\
\hline \multirow[t]{2}{*}{ Diabetes } & No & 1 & 1 \\
\hline & Yes & $3.10(2.88-4.05)$ & $2.35(1.80-3.08)$ \\
\hline \multirow[t]{2}{*}{ Current drinking } & No & 1 & 1 \\
\hline & Yes & $1.02(0.88-1.18)$ & $1.32(1.11-1.58)$ \\
\hline \multirow[t]{4}{*}{ Smoke category } & Never smoked/quitted & 1 & 1 \\
\hline & $1-10 \mathrm{cpd}$ & $1.07(0.85-1.36)$ & $1.10(0.84-1.44)$ \\
\hline & $11-20 \mathrm{cpd}$ & $1.34(0.98-1.83)$ & $1.16(0.81-1.67)$ \\
\hline & $>20 \mathrm{cpd}$ & $2.14(1.44-3.17)$ & $1.61(1.02-2.54)$ \\
\hline \multirow[t]{2}{*}{ Family history of high BP } & No & 1 & 1 \\
\hline & Yes & $1.81(1.56-2.09)$ & $1.57(1.34-1.84)$ \\
\hline
\end{tabular}

*The final multivariate model also controlled for participants' age and lifetime duration of smoking. $\mathrm{OR}=$ odds ratio; $\mathrm{CI}=$ confidence interval; $\mathrm{cpd}$ - cigarettes per day. 


\section{Discussion}

As far as we could ascertain, this study is the first to demonstrate an association between hypertension and tooth loss in a general population. It has shown that total tooth loss or complete edentulousness, but not partial edentulousness, is a risk factor for developing hypertension. This finding may be attributable to dietary changes that could be associated with being completely edentulous, ${ }^{15}$ which may result in an increased risk of vascular disease. An association between vitamin $\mathrm{C}$ and folate levels and cardiovascular disease has been shown. ${ }^{10}$. The apparently graded response observed between the dental status and mean BP of the respondents in our study supports the view that nutrition or dietary pattern changes could account for the association observed between tooth loss and hypertension. Conceivably, completely edentulous subjects may not be able to consume foods as nutritious as that consumed by dentate or partially dentate subjects.

This study has confirmed the key reported traditional lifestyle factors associated with high BP in Africa. ${ }^{3}$ It confirmed the potential benefit that could be derived from dietary approaches to hypertension reduction, such as salt restriction, at a population level. ${ }^{12} \mathrm{~A}$ significant association between traditional risk factors for vascular disease, such as smoking, and an increased risk of tooth loss, was consistent with the literature. ${ }^{7}$ Being overweight or obese was associated with an increased risk of tooth loss. Given that periodontal disease is a leading cause of tooth loss in developing countries, the findings are consistent with a study that found increased upper body weight to be associated with an increased risk of periodontal disease. ${ }^{16}$ It is hypothesised that this association results from possible diminished blood flow in the periodontal blood vessels and compromise of the local host immune response in the presence of visceral fat. ${ }^{16}$ The observed relationship between body mass index and tooth loss may partly account for the observed gross attenuation of the association between hypertension and tooth loss after adjustment for several traditional risk factors. Therefore, the findings support views that the association between tooth loss and cardiovascular disease may be related to shared risk or confounding factors. ${ }^{7}$

However, the fact that total tooth loss remained significantly associated with hypertension after controlling for confounding factors supports the view that the link between tooth loss and heart disease may be related to an increased risk of hypertension. This is further supported in that total tooth loss was associated with a significant increase of $5 \mathrm{mmHg}$ in mean diastolic blood pressure (DBP). A prolonged lower DBP of $5 \mathrm{mmHg}$ has been associated with an at least $34 \%$ lower risk of a stroke and at least $21 \%$ lower risk of coronary heart disease. ${ }^{17}$ These figures are consistent with findings from a study of periodontal disease and tooth loss as risk factors for strokes. ${ }^{5}$

The major design limitations of this study were its cross-sectional approach and its reliance on self-reporting. Although the cross-sectional nature did not allow for the establishment of the temporal order of events, considering that the mean age of those who reported tooth loss was 5 years less than that of the respondents who reported hypertension, it is likely that tooth loss preceded hypertension in the current cohort. Furthermore, given that this was a cross-sectional study, edentulousness can only be 
considered a risk indicator. Consequently, edentulousness needs to be confirmed as a true risk factor in longitudinal studies that take into account the temporal order of events. Another limitation was that the level of partial tooth loss was not graded, so the 'partially edentulous' category may have lost significance as it represented too wide a range of subjects. Lastly, it may be possible that residual confounders not measured, so not adjusted for in the current model, may explain the relationship observed. Despite these limitations, this study provides, for the first time in a large national representative sample, useful information on tooth loss as a risk indicator for hypertension, while controlling for multiple risk factors.

In conclusion, this study illustrates that total tooth loss is a risk indicator for established hypertension and confirms that some traditional risk factors associated with an increase in blood pressure are also associated with the increased likelihood of tooth loss. Since the study findings suggest that 1 in 10 South African hypertensive adults could be hypertension-free if total tooth loss were eliminated, priority should be given to public health interventions to reduce tooth loss. For instance, at a primary health care level, preventive messages directed at reducing hypertension should also include how to reduce factors that may increase the risk of tooth loss, such as excessive drinking, smoking and poor oral hygiene. The importance of these factors should be emphasised in oral health promotion programmes.

\section{Acknowledgements}

Data for this study was obtained with permission from the National Department of Health through the South African Data Archives (SADA) housed at the South African National Research Foundation (NRF). The SADHS was funded by the South African National Department of Health under the co-ordination of the Medical Research Council, South Africa. 


\section{References}

1. Murray CJL, Lopez AD. Mortality by cause for eight regions of the world: Global burden of disease study. Lancet 1997; 349: 1269-1276.

2. Bradshaw D, Schneider M, Dorrington R, Bourne DE, Laubscher R. South African cause-of-death profile in transition - 1996 and future trends. S Afr Med J 2002; 92: 618-623.

3. Kaufman J, Barkey N. Hypertension in Africa: an overview of prevalence rates and causal risk factors. Ethn Dis 1993; 3: suppl, S83-101.

4. Connor $\mathrm{M}$, Rheeder $\mathrm{P}$, Bryer $\mathrm{A}$, et al. The South African stroke risk in general practice study. $S$ Afr Med J 2005; 95: 334-338.

5. Joshipura KJ, Hisn-Chia Hung, Rimm EB, Willett C, Ascherio A. Periodontal disease, tooth loss, and incidence of ischemic stroke. Stroke 2003; 34: 47-52.

6. Okoro CA, Balluz LS, Eke PI, et al. Tooth loss and heart disease. Am J Prev Med 2005; 29 (5S1): 50-56.

7. Hujoel PP, Drangsholt M, Spiekerman C, DeRouen TA. Periodontitis-systemic disease associations in the presence of smoking - causal or coincidental? Periodontal 2002; 30: 51-60.

8. Desvarieux M, Demmer RT, Rundek $\mathrm{T}$, et al. Relationship between periodontal disease, tooth loss, and carotid artery plaque: the oral infections and vascular disease epidemiology study (INVEST). Stroke 2003; 34: 2120-2125.

9. Pussinen $\mathrm{PJ}$, Jauhiainen $\mathrm{M}$, Vilkuna-Rautiainen $\mathrm{T}$, et al. Periodontitis decreases the antiatherogenic potency of high density lipoprotein. J Lipid Res 2004; 45: 139-147.

10. Lowe G, Woodward M, Rumley A, Morrison C, Tunstall-Pedoe H, Stephen K. Total tooth loss and prevalent cardiovascular disease in men and women: possible roles of citrus fruit consumption, Vitamin C, and inflammatory and thrombotic variables. $J$ Clin Epidemiol 2003: 56: 694-700.

11. Taguchi A, Sanada M, Suei $Y$, et al. Tooth loss is associated with an increased risk of hypertension in postmenopausal women. Hypertension 2004; 43:1297-1300.

12. Svetkey LP, Simons-Morton D, Vollmer WM, Appel L, Conlin PR, Ryan DH. Effects of dietary patterns on blood pressure subgroup analysis of the dietary approaches to stop hypertension (DASH) randomized clinical trial. Arch. Intern Med 1999; 159: 285-293.

13. Steyn K, Gaziano TA, Bradshaw D, Laubscher R, Fourie J. Hypertension in South African Adults: results from the demographic and health survey, 1998. J Hypertens 2001; 19: 1717-1725.

14. Kabn HA, Sempos CT. Statistical Methods in Epidemiology. New York: Oxford University Press, 1989: 1-292. 
15. Nowjack-Raymer RE, Sheiham A. Association of edentulism and diet and nutrition in US adults. $J$ Dent Res 2003; 82: 123-126.

16. Saito T, Shimazaki Y, Koga T, Tsuzuki M, Ohshima A. relationship between upper body obesity and periodontitis. J Dent Res 2001; 80: 1631-1636.

17. MacMahon S, Peto R, Cutler J, et al. Blood pressure, stroke, and coronary heart disease. Part 1: Prolonged differences in blood pressure: prospective observational studies corrected for the regression dilution bias. Lancet 1990; 335: 765 -774. 


\section{Chapter 3:}

\section{The Association of Snuff Use and Smoking with Chronic Bronchitis}

Published as: OA Ayo-Yusuf, PS Reddy, BW van den Borne. Association of snuff use with chronic bronchitis among South African women: implications for tobacco harm reduction. Tobacco Control 2008; 17: 99-104. 


\section{Abstract}

Objective: Nasal use of snuff is the predominant form of tobacco use among black South African women. This study examines the association between snuff use and chronic bronchitis (CB) among black South African women.

Design: The study investigates a nationally representative sample of 4,464 black women $\geq 25$ years old who participated in the 1998 South African Demographic and Health Survey. Data on participants' tobacco use patterns, medical history and other relevant factors were obtained through an interviewer-administered questionnaire. Peak expiratory flow rates (PEFR) were also measured. Data analysis included chi-square statistics, t-tests and multiple logistic regression analysis.

Outcome measure: $\mathrm{CB}$, defined as reporting a productive cough for $\geq 3$ months/year for at least two successive years.

Results: The prevalence of current snuff use was $16.1 \%(n=719)$. Compared to nonusers of snuff, snuff users were not only more likely to present with a history of tuberculosis (TB) $(23.3 \%$ vs. $15.9 \%$; $p=0.06)$, but they were also more likely to present with CB $(5.3 \%$ vs. $2.8 \% ; \mathrm{p}<0.01)$ and a lower PEFR $(275 \mathrm{~L} / \mathrm{min}$ vs. $293 \mathrm{~L} / \mathrm{min} ; \mathrm{p}<0.01)$. Significant determinants of CB included snuff use $>8$ times/day (OR 2.86, 95\% CI 1.17, 7.02), a history of TB (OR 7.23, 95\% CI 4.02, 13.03), current smoking (OR 2.84, 95\% CI $1.60,5.04)$ and exposure to smoky cooking fuels (OR $1.98,95 \%$ CI $1.32,2.96)$.

Conclusions: These data suggest that snuff use, in the form predominantly used in South Africa, increases the risk of CB. This challenges the idea that snuff may be a much less harmful alternative to smoking in South Africa. 


\section{Introduction}

Both cigarette smoking and smokeless tobacco (SLT) or snuff use are common in South Africa, with an estimated national prevalence of $24.6 \%$ and $6.7 \%$ respectively in $1998 .^{1}$ Unlike in most western countries, about $80 \%$ of snuff is taken nasally in South Africa. While fewer than $1 \%$ of South African men use snuff, among black South African women, snuff is the predominant form of tobacco use, with a prevalence of $13.2 \%$ among women in 1998 , compared to the $5.3 \%$ prevalence of smoking among women. ${ }^{1}$ Of particular concern is a recent report of the WHO global youth tobacco survey, which suggests that in 2002 the prevalence of snuff use amongst South African adolescents was $14.5 \% .^{2}$

There are traditional homemade and a limited range of commercial/industrialised SLT products on the South African market. The nicotine delivery potentials of the popular SLT products have been previously published. ${ }^{3}$ Snuff, available as fine powdered tobacco, is much less expensive than cigarettes in South Africa; a can of snuff typically costs R3,00 (US $\$ 0.40$ ) compared to R14,00 (US $\$ 2$ ) for a pack of cigarettes. The concentration of free base nicotine available for absorption by the users of South African SLT products previously tested was comparable and sometimes greater than that obtainable from commercial filtered cigarettes, depending on the heaviness of use. The most popular traditional and industrialised products on the South African market, typically with a moisture content of about $40 \%,{ }^{3}$ are used both by oral and nasal application. The route of delivery therefore does not appear to be product-specific in South Africa, but may be dependent on cultural preferences as suggested by a recent study finding. ${ }^{4}$

Most of the existing literature on the health effects of snuff comes from western nations, particularly Sweden, where most users are Caucasian male snuff dippers. Since consistent association between snuff and major diseases is lacking (particularly in developed nations), snuff is widely considered to be considerably less harmful than cigarettes and snuff is therefore promoted as a reduced-harm product. ${ }^{5}$ Although the snuff products commonly used in South Africa may differ from those used in such western countries, ${ }^{6}$ in South Africa too, snuff use is perceived by some South African adolescents to be a safer alternative to cigarettes. ${ }^{7}$ New Zealand is currently considering allowing the sale of nasal snuff as part of a harm reduction strategy. The strategy has been proposed by some members of the public health community. ${ }^{8}$ Nasal snuff is also reported to be making its way back onto the English market as a result of the impending ban on public smoking. ${ }^{9}$

In fact, long-term use of certain types of snuff has been associated with adverse reproductive outcomes ${ }^{10}$ and the development of oro-pharyngeal and upper respiratory tract cancers. ${ }^{10-13}$ The results of recent large-scale studies have suggested that compared to non-use of any tobacco product, snuff use is associated with an increased risk of pancreatic cancer, ${ }^{14}$ higher mortality from all causes, ${ }^{15-16}$ and an increased risk of lung cancer mortality ${ }^{17}$ and lung cancer incidence among elderly American women. ${ }^{18}$ Snuff use and chronic bronchitis (CB) have also previously been reported as strong risk factors for lung cancer in a Moroccan population, ${ }^{19}$ but the association between snuff use and $\mathrm{CB}$ has not been previously reported. 
None of the reviews of the earlier literature on the health effects of oral ${ }^{6}$ or nasal ${ }^{20}$ use of snuff has explored a link between snuff use and $\mathrm{CB}$, despite the fact that even during nasal application snuff dust can conceivably be inhaled, and snuff has been suggested as a source of bacteria in $\mathrm{CB} .{ }^{21} \mathrm{~A}$ more recent study has also questioned the microbiological safety of some finished snuff products on the South African market. ${ }^{22}$ The majority of users in South Africa use snuff with high nicotine-delivery capabilities, ${ }^{3}$ and nicotine has been suggested to be a potent bronchial gland stimulant. ${ }^{23}$ This study therefore sought to determine the association between snuff use and CB among black South African women.

\section{Method}

\section{Data source and study design}

Data for this study were obtained from black African women aged 25 years and older ( $N=4,464$ ) who participated in the first (and so far the largest publicly available) South African Demographic and Health Survey (SADHS), a nationally representative, crosssectional household questionnaire survey conducted between February and September 1998. Questionnaires were prepared in all 11 of South Africa's official languages and back translation was used to check for consistency of meaning. The 1998 SADHS used a stratified, two-stage probability sample design. The methods used to standardize data collection, and the interview and consent procedures have been previously published. ${ }^{1,24}$ The protocol for the SADHS was approved by the ethics committee of the South African Medical Research Council.

\section{CB risk-factor assessment and definitions}

The questionnaire was administered by trained fieldworkers. It inquired into sociodemographic characteristics and past medical history, including a past history of tuberculosis (TB) infection. An asset index, which is a measure of socioeconomic status, was derived from a composite score of five household items (electricity, television, telephone, refrigerator and washing machine) owned by respondents as identified in a factor analysis for inclusion. The respondents answered "yes" (code 1) or "no" (code 0 ) to each of the listed household items on the questionnaire. The scale can be considered to be very reliable, because it has a Cronbach alpha score of 0.80 . The scores that were obtained were then ranked to classify the respondents into three socioeconomic categories.

Respondents who answered "yes" to the question "have you ever smoked tobacco?" were categorized as "ever" smokers. Those who said that they had never smoked but that they may have used snuff were classified as "never" smokers. "Ever" smokers were further categorized as "current regular smokers" if they said that they currently smoke daily or occasionally, and as "ex-smokers" if they said that they had previously smoked daily, but did not smoke at all at the time of the interview. Respondents who said they currently take snuff were asked about average daily frequency of snuff use. There was no question on the past history of snuff use in the 1998 SADHS. Other exposure and personal history variables included occupational exposure to dust/fumes/strong smells, domestic fuel exposure and domestic and work exposure to secondhand smoke. 
Data on the symptomatology of $\mathrm{CB}$ were based on a series of four standardized questions on chronic productive coughing, adapted from the internationally used British Medical Research Council Questionnaire. ${ }^{25-26} \mathrm{CB}$ was defined as presenting with a history of a complex of symptoms including a chronic cough with phlegm every day for at least three months of the year for at least two successive years. As part of an effort to internally validate the questionnaire diagnosis of $\mathrm{CB}$, each participant's peak expiratory flow rate (PEFR) was tested at his/her home using a Tru-Zone mini-peak flow meter (Trudell Medical International, London, Ontario, Canada).

\section{Statistical analysis}

All statistical analyses were done using STATA Release 8 (Stata Corporation, College Station, Texas, USA) with appropriate weight adjustments made for selection probabilities and the SADHS's complex sample design. Data were summarized as prevalence rates (\%) with $95 \%$ confidence intervals (CI). Statistical comparisons were made between the PEFR and $\mathrm{CB}$ prevalence among current and non-current snuff users. Group differences were assessed using chi-square statistics and independent sample t-tests. Multiple logistic regression models were constructed to determine the independent association between different intensities of snuff use and CB prevalence, while controlling for the influence of age, smoking duration and other covariates identified in both published literature ${ }^{24}$ and our bivariate analysis as being significantly associated with snuff use and CB. Guided by the previously reported frequency of snuff use, ${ }^{27}$ for the purpose of analyses, respondents were categorized as those who do not currently use snuff, those who use 1-8 times/day and those who use $>8$ times/day. As there were too few women snuff users currently smoking $(n=4)$ and also too few ex-smokers currently using snuff $(n=10)$, these individuals were grouped as smokers and ex-smokers respectively during subsequent statistical analyses. Sensitivity analysis showed that exclusion of these categories of snuff users did not change the parameter estimates obtained in this study. Statistical significance was set at $p<0.05$.

\section{Results}

Of the study sample, $16.1 \%(n=719)$ reported current snuff use and $3.2 \%(n=142)$ reported CB. Subjects who met the questionnaire diagnostic criteria for CB had significantly lower mean PEFR values than those who did not (237L/min vs. 292L/min; $\mathrm{p}<0.01)$. The mean difference was $55 \mathrm{~L} / \mathrm{min}(95 \% \mathrm{CI} 38,71)$. The prevalence of both snuff use and of $C B$ were lowest among the most educated respondents and those in the highest socioeconomic class, and the incidence of $\mathrm{CB}$ was highest among those who reported a past history of TB (Table 7). Compared to those without a history of TB, respondents with a history of TB were also more likely to be current snuff users, $(23.3 \%$ vs. $15.9 \% ; p=0.06)$.

Current snuff users and current smokers were more likely to report CB than non-users of tobacco. Compared to those not currently using snuff, current snuff users were also more likely to present with a lower PEFR (275L/min vs. $293 \mathrm{~L} / \mathrm{min} ; \mathrm{p}<0.01)$. A history of domestic and/or occupational exposure to secondhand smoke was not significantly 
associated with CB (age-adjusted odds ratio [OR] 1.01, 95\%CI 0.67, 1.54), but occupational exposure to dust/fumes/strong smells and domestic exposure to smoky cooking fuels were strongly associated with both $\mathrm{CB}$ and snuff use in both the bivariate and multivariate analyses. Even after controlling for these potential confounders in a multivariate analysis, although the effect of snuff use was found to be grossly attenuated, a dose-response relationship remained between snuff use and CB (Table 8). Snuff use of $>8$ times per day remained significantly associated with $\mathrm{CB}$ (fully adjusted $\mathrm{OR}=2.86$, $95 \%$ CI 1.17, 7.02) and so was current smoking (fully adjusted OR 2.84, 1.60, 5.04), irrespective of the intensity of smoking. However, a non-linear dose-response was observed between the risk of $\mathrm{CB}$ and the reported number of cigarettes smoked per day (CPD) (Table 8). The median CPD was four. Compared to never smokers, those who reported smoking 1-4 CPD had a higher risk of presenting with CB than those who reported smoking $>4$ CPD. 
Table 7: Prevalence of snuff use and chronic bronchitis relative to socio-demographic and exposure characteristics

\begin{tabular}{|c|c|c|}
\hline Characteristics & Snuff use $(\%)^{\dagger}$ & Chronic bronchitis (\%) ${ }^{\dagger}$ \\
\hline Prevalence $(95 \% \mathrm{CI})$ & $16.1(14.6,17.6)$ & $3.2(2.6,3.8)$ \\
\hline \multicolumn{3}{|l|}{ Asset index (tertiles) $(n=4447)$} \\
\hline Poorest & 18.5 & 5.6 \\
\hline Middle & 16.6 & 2.4 \\
\hline \multirow[t]{2}{*}{ Richest } & 10.6 & 1.3 \\
\hline & $p<0.001$ & $\mathrm{p}<0.001$ \\
\hline \multicolumn{3}{|l|}{ Education level $(n=4449)$} \\
\hline None & 24.5 & 5.6 \\
\hline 1-7 years schooling & 16.6 & 3.3 \\
\hline $8-12$ years schooling & 11.5 & 1.8 \\
\hline \multirow[t]{2}{*}{$>12$ years schooling } & 2.5 & - \\
\hline & $\mathrm{p}<0.001$ & $p<0.001$ \\
\hline \multicolumn{3}{|l|}{ Residence $(n=4464)$} \\
\hline Urban & 15.3 & 2.2 \\
\hline Rural & 16.9 & 4.1 \\
\hline & $p=0.30$ & $p<0.01$ \\
\hline \multicolumn{3}{|l|}{ History of TB* $(n=4451)$} \\
\hline Never & 15.9 & 2.8 \\
\hline Ever & 23.3 & 21.1 \\
\hline & $p=0.06$ & $p<0.001$ \\
\hline \multicolumn{3}{|l|}{ Cooking fuel used $(n=4455)$} \\
\hline Gas/electricity/paraffin & 15.2 & 2.3 \\
\hline Wood/coal/dung (smoky) & 19.1 & 6.2 \\
\hline & $p=0.02$ & $p<0.001$ \\
\hline \multicolumn{3}{|l|}{ Occupational exposure $(n=4455)$} \\
\hline Never & 15.8 & 2.8 \\
\hline Ever & 21.7 & 5.8 \\
\hline & $\mathrm{p}<0.01$ & $p<0.001$ \\
\hline \multicolumn{3}{|l|}{ Smoking status $(n=4464)$} \\
\hline Never smoked & 17.1 & 2.9 \\
\hline Ex-smoker & 14.9 & 1.5 \\
\hline Current smoker & 1.3 & 7.3 \\
\hline & $p<0.001$ & $p<0.001$ \\
\hline \multicolumn{3}{|l|}{ Snuff use status $(n=4464)$} \\
\hline Non-user & & 2.8 \\
\hline Uses 1-8times/day & & 4.3 \\
\hline Uses $>8$ times/day & & 11.7 \\
\hline & & $\mathrm{p}<0.01$ \\
\hline
\end{tabular}

$*$ TB $=$ Tuberculosis.

tWeighted prevalence estimates.

Note: Sample sizes for some variables do not sum to the total $(4,464)$ due to missing data. 
Table 8: Multiple logistic regression model for chronic bronchitis $(\mathbf{N}=\mathbf{4 , 4 2 5})$

\begin{tabular}{|c|c|c|c|}
\hline & & $\begin{array}{c}\text { Crude } \\
\text { OR }\end{array}$ & $\begin{array}{c}\text { Fully adjusted* } \\
\text { OR }\end{array}$ \\
\hline \multirow[t]{3}{*}{ Snuff use } & Never/none-current & 1 & 1 \\
\hline & 1-8 times/day & $1.56(0.96,2.55)$ & $1.18(0.69,2.03)$ \\
\hline & $>8$ times/day & $4.63(2.09,10.22)$ & $2.86(1.17,7.02)$ \\
\hline \multirow[t]{4}{*}{ Smoking status } & Never smoked & 1 & 1 \\
\hline & Ex-smoker & $0.48(0.12,1.99)$ & $0.35(0.09,1.46)$ \\
\hline & $1-4$ CPD & $2.96(1.43,6.11)$ & $3.15(1.44,6.89)$ \\
\hline & $>4 \mathrm{CPD}$ & $2.31(1.16,4.59)$ & $2.54(1.26,5.14)$ \\
\hline \multirow[t]{3}{*}{ Asset (tertile) index } & Lowest rank (poorest) & 1 & 1 \\
\hline & Middle & $0.44(0.30,0.66)$ & $0.69(0.45,1.04)$ \\
\hline & Highest rank & $0.24(0.10,0.63)$ & $0.45(0.17,1.15)$ \\
\hline \multirow[t]{2}{*}{ Tuberculosis } & Never & 1 & 1 \\
\hline & Ever & $9.41(5.41,16.38)$ & $7.23(4.02,13.03)$ \\
\hline \multirow[t]{2}{*}{ Cooking fuel } & Gas/Electricity/Paraffin & 1 & 1 \\
\hline & Smoky fuels & $2.82(1.92,4.14)$ & $1.98(1.32,2.96)$ \\
\hline \multirow{2}{*}{$\begin{array}{l}\text { Occupational exposure } \\
\text { to irritants }\end{array}$} & Never & 1 & 1 \\
\hline & Ever & $2.12(1.31,3.43)$ & $1.95(1.20,3.17)$ \\
\hline
\end{tabular}

*In addition to these covariates, the model also controlled for age.

$\mathrm{CPD}=$ Cigarettes per day

\section{Discussion}

This study demonstrates the first findings of a significant association between snuff or SLT use and $\mathrm{CB}$. These findings also demonstrate common risk factors for snuff use and a diagnosis of $C B$, suggesting that snuff users in South Africa could be at a cumulative disadvantage for developing chronic airway diseases. Also significant is this study's support of a previous report, ${ }^{24}$ which suggested that a history of TB infection was strongly associated with CB. In addition, our study suggests that snuff users are more likely to present with a history of TB. This observation calls for further investigation of the potential risk of snuff users' spreading TB or being at high risk to contract TB, especially in countries like South Africa which have a relatively high prevalence of TB. Snuff users and those suffering from CB are also more likely to be poor, uneducated women, who are more likely to cook with smoky fuels and work in conditions where they are exposed to dust, fumes and/or strong smells. Significantly, however, even after controlling for these potential confounders, this study shows that current daily heavy ( $>8$ times/day) snuff users, but 
not less frequent users, had almost three times greater odds of developing CB when compared to non-users of snuff. In contrast, albeit consistent with the literature, ${ }^{28}$ those smoking even at low rates of 1-4 CPD as compared to never smokers were significantly more likely to present with a history of $\mathrm{CB}$.

Although somewhat consistent with the findings of a similar study that reported the correlates of occurrence of CB among the general population of South African women, ${ }^{24}$ the unexpected finding that black women that reported smoking 1-4 CPD had higher odds of developing $\mathrm{CB}$ than those smoking $>4 \mathrm{CPD}$ may be related to compensatory changes in smoking behaviour. This view is supported by findings of a recent study that showed similar unexpected non-linear relationship between changes in lung function and reduced smoking rates among smokers with early chronic obstructive pulmonary disease (COPD). ${ }^{29}$ It is indeed possible that heavy smokers that may have experienced early symptoms of COPD, may have opted to reduce their smoking rates, but because of compensatory smoking (e.g. deeper and more frequent puffs), would effectively still be exposed to similar or even greater levels of cigarette toxins as before the reduction. Nonetheless, the unexpected observation of larger impact of lower smoking rate on lung health in the current study may also be related to reporting bias. In a society where smoking by black women in particular is traditionally viewed as socially unacceptable, it is conceivable that heavier smokers may find it more socially desirable to report lower smoking rates.

Although it is still a possibility that uncontrolled residual confounders may explain the observed association of snuff use with $\mathrm{CB}$, it is biologically plausible that nasal use of snuff could lead to CB. A previous report notes nasal symptoms associated with nasal mucosal changes in snuff users ${ }^{30}$ and these nasal symptoms in turn have been associated with increased occurrence of $\mathrm{CB} .{ }^{31}$ Furthermore, this study's finding would be consistent with that of a previous case study of $C B$, which suggests that nasal use of snuff could have been the source of the bacteria in $\mathrm{CB} .^{21}$

Contrary to a recent suggestion that smoke constituents other than nicotine may be responsible for increased pulmonary airway resistance, ${ }^{32}$ this study's findings, supported by results from other studies, ${ }^{23,33-34}$ suggest that the nicotine in snuff could be associated with hyper-secretion of local bronchial glands and could therefore contribute to $C B$, especially in the presence of bacterial infection. Nicotine has also been shown to prolong the survival of neutrophils, ${ }^{35}$ the accumulation of which in the lungs has been implicated in the pathogenesis of $\mathrm{CB}^{36}$ The current study's findings may differ from those of other studies because the snuff products used in South Africa have a relatively high $\mathrm{pH}$ and thus a higher nicotine-delivery capability than the SLT products commercially available elsewhere. ${ }^{3}$ It is however, pertinent to note that Bolinder et al. ${ }^{37}$ also previously reported a significantly increased risk for reporting symptoms of COPD in a Swedish cohort of oral SLT users, as compared to non-users. Considering that similar respiratory problems have been noted among tobacco factory workers, ${ }^{38-39}$ although to a lesser degree, it is also possible that respirable snuff dust particles may inadvertently be inhaled during handling of loose snuff for oral application. This may over time invoke inflammatory responses in the airway similar to that associated with CB. Conceivably, dust inhalation would be less of a possibility if the snuff powder were enclosed, as is the case with the modern oral SLT 
products that are portion-packed in tea bag-like pouches. This view is further supported by a recent analysis of spit tobacco associated mortality, which demonstrated a significant association with increased risk for mortality from COPD among users in a 1959 - 1972 US cohort, but failed to detect significant mortality risk from COPD among those in the 1982 2000 cohort. $^{16}$ The later cohort presumably included those using newer SLT products as it coincides with the period when SLT had been introduced in pouches. Therefore, the findings of our study may not be generalisable to the use of other SLT products or other forms of nicotine-delivery vehicles such as nasal spray, which may also have different nicotine pharmocodynamics.

It has been suggested that different SLT products pose disease risks of different severity. ${ }^{40}$ The modern low-nitrosamine oral moist SLTs, some of which have recently been introduced onto the South African market, have been reported to pose considerably lower health risks compared to smoking. ${ }^{6}$ However, with the strong tradition of nasal use of snuff in South Africa, and the continued sale of snuff for nasal delivery by the same manufacturers of these modern oral SLT products, it remains to be seen if current marketing of the new oral SLTs will encourage South African smokers to switch to these oral SLT products or even to using the much cheaper traditional SLT products for nasal application. A major manufacturer of snuff in South Africa is also currently advocating that smokers switch to nasal SLT products in New Zealand. However, limited information is available on the health risks of nasal use of snuff, so most of the arguments made for switching to nasal snuff to reduce health risks are based on studies on oral moist snuff, ${ }^{8}$ which may be distinctly different SLT product.

This study's finding that a current frequent snuff user's risk of developing CB is the same as that of a current smoker weakens arguments that nasal snuff use may be sufficiently less harmful than smoking to be worth promoting as an alternative. Taking into account the risk-use equilibrium, ${ }^{41}$ promoting such a strategy in the studied population could be a potentially risky population experiment, given that the current number of black African women snuff users is already almost three times higher than the number of smokers. Furthermore, given that any suggestion of the relative safety of any snuff product in a fairly uneducated population could inadvertently encourage continued or increased snuff use, such a harm-reduction strategy could potentially increase total tobacco-related disease in the studied population, especially since a significant decline in smoking rates has already been observed in this population due to current governmental policy. ${ }^{1,42}$ Such a strategy would also be problematic in parts of Africa and India where the nasal use of snuff is still relatively common and the relatively high cost of modern oral SLT products may be prohibitive. Considering that these third-world populations of snuff users may be larger in number than those of current SLT users in developed countries, the findings of this study suggest that future policy debates on SLT as a harm-reduction strategy need to be broadened to include the implications of such a strategy for populations outside developed countries. 


\section{Study limitations}

Our study findings are subject to some limitations. Firstly, as mentioned above, the findings may not be generalisable to other SLT products. Secondly, the study relies on self-reporting of tobacco use and CB. The participants' responses are therefore potentially subject to reporting bias, especially in respect of smoking, which is generally regarded as a social taboo among black women. It is therefore possible that such reporting bias may have weakened the association reported between smoking and CB. Furthermore, the responses to questions used for $\mathrm{CB}$ diagnosis may be subject to recall bias. Nevertheless, the criteria used for $\mathrm{CB}$ diagnosis are similar to those used in many other national surveys, with which our results are thus comparable. Moreover, in our study, CB diagnosis was cross-validated with PEFR measurements. Thirdly, because this was a cross-sectional study, reverse causality is possible, although not likely. Accordingly, any inference about causality based on the current study should be made with caution. Snuff use must be confirmed as a true risk factor in longitudinal studies that take into account the temporal order of events. Fourthly, the SADHS did not include relevant information such as the exact form of SLT use, past history of use and the lifetime duration of use. Therefore, age (which is expected to correlate with years of use) was used as a covariate in all the analyses, irrespective of the level of statistical significance detected. Conceivably, if some of the study participants were in fact snuff-dippers or if a significant proportion of noncurrent users of snuff were ex-users of snuff, these may have attenuated rather than inflated the strength of the association reported for current snuff use in this study. Lastly, the data that were used are somewhat dated. However, considering that the biological relationship hypothesised between snuff and bronchitis is not time-dependent, this is not likely to influence the study findings significantly, except if the snuff products used before 1998 differed from those currently in use. However, the reported $\mathrm{pH}$ of a commonly used traditional snuff mixture ${ }^{43}$ and that of the most popular industrialised brand tested in the past [Ayo-Yusuf, unpublished data] are similar to the $\mathrm{pH}$ of similar products tested more recently. ${ }^{3}$ This implies that the nicotine-delivery capability of these products are also similar. Thus the nicotine-delivery potential of snuff products currently in use is not likely to be considerably lower than those used prior to 1998.

Despite these limitations, this study provides useful information about the risk of SLT products used by populations outside Europe.

\section{Conclusions}

Although further investigation is needed on the exact biological mechanisms, this study demonstrates for the first time that snuff use, in the form predominantly used in South Africa, increases the risk for CB. This challenges the idea that snuff may be a much less harmful alternative to smoking in South Africa and in particular, among black African women. The study findings also highlight the need for public health interventions that discourage the adoption of any form of tobacco use and promote tobacco use cessation, particularly among South African adolescents. 


\section{What this paper adds}

Only limited information is available about health risks associated with the use of smokeless tobacco (SLT) products other than those currently available in Europe and North America. However, the harm-reduction debate extends to populations as far removed from such markets as South Africa and New Zealand, where nasal use of snuff is either currently the predominant form of SLT use or the form currently being advocated. This study provides useful information needed to improve the current basis for risk assessment of SLT use in populations outside of Europe.

This study's findings, which suggest that heavy snuff use is equally as likely as smoking to be associated with chronic bronchitis in the studied South African population, challenge any public health strategy that may want to promote a switch to SLT use as a public policy response for the reduction of tobacco-related diseases in South Africa.

\section{Acknowledgements}

The 1998 SADHS survey was funded by the South African National Department of Health under the co-ordination of the Medical Research Council of South Africa. Data for this study were obtained with permission from the National Department of Health through the South African Data Archives (SADA) hosted at the South African National Research Foundation (NRF). The preparation of this manuscript was supported by grant received from the Cancer Association of South Africa (CANSA). 


\section{References}

1. Steyn K, Bradshaw D, Norman R et al. Tobacco use in South Africans during 1998: the first demographic and health survey. J Cardiovasc Risk 2002; 9:161-70.

2. Swart D, Reddy P, Panday S et al. The 2002 Global Youth Tobacco Survey (GYTS): the $2^{\text {nd }}$ GYTS in South Africa - a comparison between GYTS (SA) 1999 and GYTS (SA) 2002. Cape Town: South African Medical Research Council, 2004.

3. Ayo-Yusuf OA, Swart TJP, Pickworth WB. Nicotine delivery capabilities of smokeless tobacco products and implications for control of tobacco dependence in South Africa. Tob Control 2004; 13:186-9.

4. Ayo-Yusuf OA, Peltzer K, Mufamadi J. Traditional healers' perception of smokeless tobacco use and health in the Limpopo Province of South Africa. Subst Use Misuse 2006; 41: 211-222.

5. Stratton K, Shetty P, Wallace R. et al. Clearing the smoke: assessing the science base for tobacco harm reduction. Washington DC: National Academy of Sciences, National Academy Press 2001.

6. Critchley JA, Unal B. Health effects associated with smokeless tobacco: a systematic review. Thorax 2003; 58: 435-43.

7. Peltzer K. Smokeless tobacco and cigarette use among black secondary school students in South Africa. Subst Use Misuse 2003; 38: 1003-16.

8. Smokeless New Zealand. Nasal snuff - a traditional, less harmful way to use tobacco. URL: www.smokeless.org.nz/nasalsnuffMay06.pdf. (accessed 5 Jun 2007).

9. BBC News Magazine. Sniffing out the smoking ban. URL: http://news.bbc.co.uk/1/hi/magazine/4942446.stm. (accessed 5 Jun 2007)

10. England $\mathrm{U}$, Levin RJ, Mills JL et al. Adverse pregnancy outcomes in snuff users. Am J Obstet Gynecol 2003; 189: 939-43.

11. Winn DM, Blot WJ, Shy C et al. Snuff dipping and oral cancer among women in the southern United States. N Engl J Med 1981; 304: 745-9.

12. Idris AM, Ahmed HM, Malik, MOA. Toombak dipping and cancer of the oral cavity in the Sudan: a case-control study. Int J Cancer 1995; 63: 477-80.

13. Rodu B, Cole P. Smokeless tobacco use and cancer of the upper respiratory tract. Oral Surg Oral Med Oral Pathol Oral Radiol Endod 2002; 93: 511-5.

14. Alguacil J, Silverman DT. Smokeless and other non-cigarette tobacco use and pancreatic cancer: a case control study based on direct interviews. Cancer Epidemiol Biomarkers Prev 2004; 13: 55-8. 
15. Gupta PC, Mehta HC. Cohort study of all-cause mortality among tobacco users in Mumbai, India. Bull World Health Organ 2000; 78: 877-83.

16. Henley SJ, Thun MJ, Connell $\mathrm{C}$ et al. Two large prospective studies of mortality among men who use snuff or chewing tobacco (United States). Cancer Causes Contro/ 2005; 16: 347-58.

17. Accortt NA, Waterbor JW, Beall C et al. Chronic disease mortality in a cohort of smokeless tobacco users. Am J Epidemio/ 2002; 156: 730-7.

18. Accortt NA, Waterbor JW, Beall C et al. Cancer incidence among a cohort of smokeless tobacco users (United States). Cancer Causes Control 2005; 16:1107-15.

19. Sasco AJ, Merill RM, Dari I et al. A case-control study of lung cancer in Casablanca, Morocco. Cancer Causes Control 2002; 13: 609-16.

20. Sapundzhiev N, Werner JA. Nasal snuff: historical review and health related aspects. J Laryngol Otol 2003; 117: 686-91.

21. Dygert HP. Snuff: a source of pathogenic bacteria in chronic bronchitis. N Eng J Med 1957; 257: 311-13.

22. Ayo-Yusuf OA, Van Wyk C, Van Wyk CW et al. Smokeless tobacco products on the South African market do not inhibit oral bacterial flora: a pilot study. Southern African Journal of Epidemiology and Infection 2005; 20: 136-9.

23. Hummer B, Purnama I, Hahn HL. Stimulation of submucosal glands by nicotine applied locally to the airway mucosa. Klin Wochenschr 1988; 66: 161-69.

24. Ehrlich RI, White $\mathrm{N}$, Norman $\mathrm{R}$ et al. Predictors of chronic bronchitis in South Africa. Int $\mathrm{J}$ Tuberc Lung Dis 2004; 8: 369-76.

25. Medical Research Council. Respiratory symptoms questionnaire. London, The Council, 1976.

26. Cerviri I, Accordini S, Verlato $\mathrm{G}$ et al. Variations in the prevalence across countries of chronic bronchitis and smoking habits in young adults. Eur Respir J 2001; 18: 85-92.

27. Ayo-Yusuf OA, Swart TJP, Ayo-Yusuf IJ. Prevalence and pattern of snuff dipping in a rural South African population. SADJ 2000; 55: 610-4.

28. Bjartveit K, Tverdal A. Health consequences of smoking 1-4 cigarettes per day. Tob Control 2005; 14: 315-20.

29. Simmons MS, Connett JE, Nides MA et al. Smoking reduction and the rate of decline in FEV1: results from the Lung Health Study. Eur Respir J 2005; 25: 1011-17.

30. Sreedharan S, Kamath MP, Khadilkar U et al. Effect of snuff on nasal mucosa. Am J Otolaryngol 2005; 26: 151-6. 
31. Montnémery $\mathrm{P}$, Svensson $\mathrm{C}$, Ädelroth $\mathrm{E}$ et al. Prevalence of nasal symptoms and their relation to self-reported asthma and chronic bronchitis/emphysema. Eur Respir J 2001; 17:596-603.

32. Randhawa K, Mendes E, Wanner A. Acute effect of cigarette smoke and nicotine on airway blood flow and airflow in healthy smokers. Lung 2006; 184: 363-8.

33. Hansson L, Choudry NB, Karlsson JA et al. Inhaled nicotine in humans: effect on the respiratory and cardiovascular systems. J Appl Physiol 1994; 76: 2420-27.

34. Lee LY, Burki NK, Gerhardstein DC et al. Airway irritation and cough evoked by inhaled cigarette smoke: role of neuronal nicotinic acetylcholine receptors. Pulm Pharmacol Ther 2007; 20: 355-64.

35. Aoshiba K, Nagai A, Yasui $\mathrm{S}$ et al. Nicotine prolongs neutrophil survival by suppressing apoptosis. J Lab Clin Med 1996; 127: 186-94.

36. Hoidal JR. Pathogenesis of chronic bronchitis. Semin Respir Infect 1994;9: 8-12.

37. Bolinder GM, Ahlborg $\mathrm{BO}$, Lindell $\mathrm{JH}$. Use of smokeless tobacco: blood pressure elevation and other health hazards found in a large-scale population survey. J. Int Med 1992; 232: 327-34.

38. Lander F, Gravesen S. Respiratory disorders among tobacco workers. Br J Ind Med 1988; 45: 500-2.

39. Mustajbegovic J, Zuskin E, Schachter EN et al. Occupational and environmental lung disease. Respiratory findings in tobacco workers. Chest 2003; 123: 1740-8.

40. Rodu B, Godshall WT. Tobacco harm reduction: an alternative cessation strategy for inveterate smokers. Harm Reduct J 2006; 3: 37.

41. Kozlowski LT, Strasser AA, Giovino GA et al. Applying the risk/use equilibrium: use medical nicotine now for harm reduction. Tob Contro/ 2001; 10: 201-3.

42. Ayo-Yusuf OA. Re-emergence of traditional tobacco products' usage in South Africa: an unintended consequence of existing tobacco control policy. African Journal of Drug and Alcohol Studies 2005; 4: 32-43.

43. Van Wyk CW. The oral lesion caused by snuff: a clinico-pathological study. Medical Proc 1965; 11: $531-7$. 
Part 2:

Determinants of Oral Health-Related Risk Behaviours: Poor Oral Hygiene Care and Smoking 


\section{Chapter 4:}

\section{Adolescents' Sense of Coherence and Smoking Predicts Tooth Brushing Behaviour}

Accepted for publication as: OA Ayo-Yusuf, PS Reddy, BW van den Borne. Longitudinal association of adolescents' sense of coherence with tooth brushing using an integrated behaviour change model. Community Dentistry \& Oral Epidemiology. 


\section{Abstract}

Objective: To determine the association between adolescents' sense of coherence (SOC) and their tooth brushing behaviour.

Method: This 18 -month longitudinal study involved a representative sample of $8^{\text {th }}$-graders $(n=1,025)$ from 11 randomly selected public high schools in the Limpopo Province, South Africa. Data collected by means of a self-administered questionnaire included respondents' socio-demographic profiles, vulnerability to depression, smoking status, dental treatment attendance pattern, frequency of and motivation for tooth brushing. Based on the responses to the question on readiness to change brushing behaviour and in line with integrated change model, respondents were also categorised as being in the precontemplation, contemplation or preparation/action stages. Respondents' SOC was measured using a six-item adapted Antonovsky SOC scale. Data analysis included chi square analysis, t-tests and step-wise multiple logistic regression.

Results: At baseline, $72.6 \%(n=744)$ of the respondents reported not consistently brushing twice daily. Of those who did not brush twice daily and were followed up on $(n=578)$, those living with their mother at baseline not only presented with a greater increase in their SOC over time (follow-up minus baseline), but they were also more likely to be brushing twice daily at the time of the follow-up (15.4\%vs. $10.6 \% ; p=0.04)$. Adding baseline intention state to a multivariate model attenuated the influence of baseline SOC to a statistically insignificant level. However, increasing within-subject SOC changes $(\beta=$ $0.16 ; p<0.01)$, living with the mother $(\beta=0.11 ; p<0.05)$, smoking $(\beta=-0.14 ; p<0.05)$, being depression vulnerable $(\beta=-0.23 ; p<0.01)$ and in the preparation/action stage $(\beta=$ $0.13 ; p<0.05)$ remained associated with the transition to twice-daily tooth brushing.

Conclusions: In planning oral health promotion interventions, it should be considered that children's psychological predisposition and family environment might significantly influence their tooth brushing behaviour. 


\section{Introduction}

Brushing twice daily with fluoridated toothpaste is a universally recommended self-care practice to promote oral health. It remains the most effective practice for the prevention of periodontal disease (1) and dental caries (2). Considering the growing evidence of the association between poor oral health and systemic health (3), an understanding of the determinants of regular tooth brushing behaviour is important to general public health.

School-based brushing programmes and dental education programmes have not so far been found to be effective in promoting oral health in the long-term (4-5). It has been argued that one of the main reasons for the ineffectiveness of many oral health promotion or education interventions is that most of these interventions have not been based on any theoretical framework and have therefore not been systematically developed to ensure efficient implementation and quality evaluation (4-6). Moreover, in recognition of the growing evidence of the social determinants of oral health $(5,7)$, it has recently been suggested that many of the existing psychological theories that focus mainly on the individual have limitations in contemporary oral health promotion practices (5). So, for instance, it has been suggested that affective states such as stress or fatigue tend to deter self-efficacy (8). Conversely, there is also a growing interest in the role of stress and coping as a determinant of oral health (9-11).

One of the theoretical models that has been suggested and that holds some promise in oral health promotion is the salutogenic theory (5). According to this theory, stressors are intrinsic to the human condition, but people have internal and external resources they can use in the face of stressful situations, and thus to maintain health. According to Antonovsky (12), a person's sense of coherence (SOC) is a global orientation that expresses the extent to which the person has a pervasive, enduring but dynamic feeling of confidence enabling the person to apply general resistance resources (GRR). These GRRs can be found in both the immediate and the distant environment of every person. It may include coping strategies, social support, religion, cultural identity, preventive health orientation and even money (13). A person's SOC consists of three dimensions, namely comprehensibility (cognitive), manageability (behavioural) and meaningfulness (motivational). The stronger an individual's SOC, the more adequately he or she will cope with stressors and maintain his or her health.

The SOC has recently received significant empirical research support as a determinant of oral health behaviour in adults (14-15). However, so far, there have been only two published studies on adolescents' SOC in relation to oral health. One showed that adolescents' SOC was associated with children's dental attendance pattern (16); and the other demonstrated that mothers' SOC was associated with their children's oral health and dental attendance pattern (17). The latter study's findings suggest that the SOC construct may also provide insights into life-course influences on oral health (18).

Considering that every psychological theory or model is limited in its approach, one possibility for improvement is to develop multidimensional models (19), as exemplified by the integrated model of change (the I-Change Model) (20). This integrated model incorporates insights from the theory of planned behaviour (TPB) (21), social cognitive 
theory (8) and the trans-theoretical model (22). The I-Change model, like the TPB, assumes that the most important determinant of behaviour is behavioural intention, which is in turn influenced by three proximal factors, namely a person's overall evaluation of a behaviour (attitude), the behaviour of significant others (social influence, for example, that of the mother) and the control people perceive themselves to have over that behaviour (self-efficacy). However, differentiating the I-Change model from its constituent models or theories, distal factors such as socio-demographic factors (for example, age, gender, social environment) and psychological or other behavioural factors (for example, depression, and smoking) are assumed to influence behaviour via the proximal factors. Another difference between the I-Change model and its constituent models or theories is that the I-Change model explicitly identifies the role of awareness factors (20).

Figure 3: Conceptual framework: An adapted integrated behaviour change model (Adapted from De Vries et al., 2003)

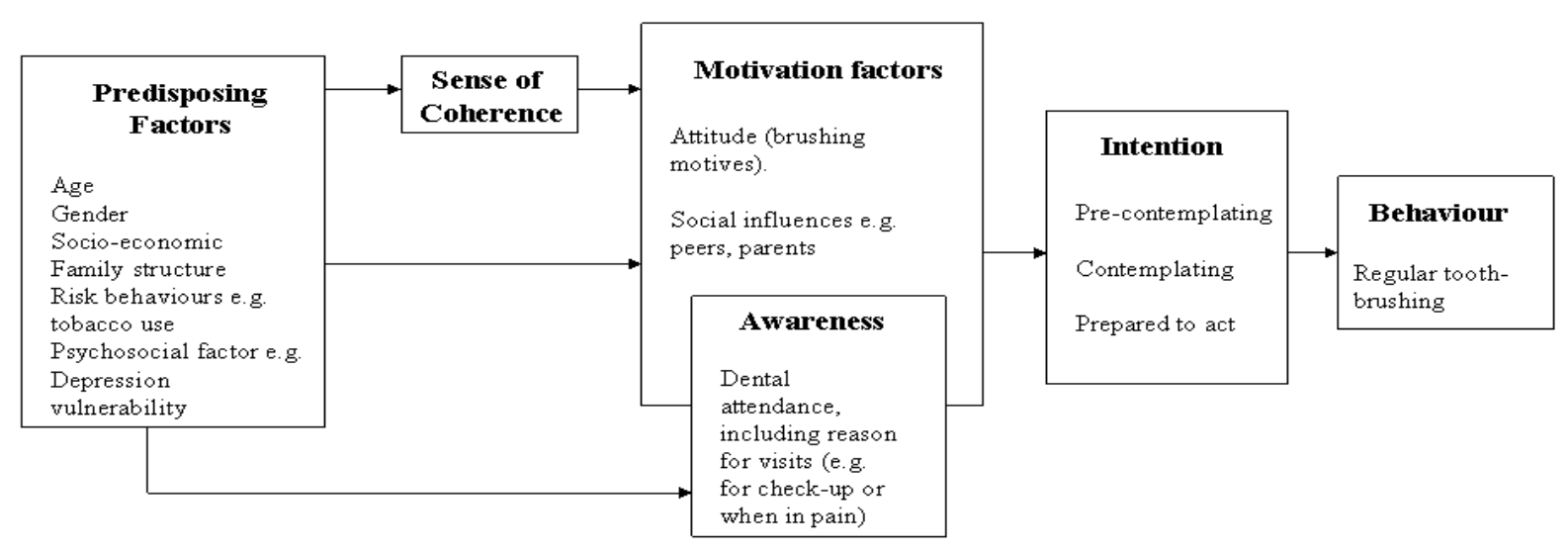

Although the different theoretical components of the I-Change model have previously been successfully used in predicting oral self-care $(17,23-25)$, but most of the studies have been cross-sectional or involved only a small sample of adults with short clinical follow-up periods. To date, no longitudinal study has examined the applicability of any of these models, either separately or in combination, in predicting tooth brushing behaviour among adolescents, particularly in low-resource settings. Hence, using an adapted IChange model as a conceptual model (Figure 3), this study sought to examine the determinants of a transition to regular tooth brushing among a population of South African adolescents. In addition, because several studies have suggested that mothers have a significant impact on their children's oral health $(17,26)$, and considering that people's SOC has been related to perceived social support (27-28), it was a secondary aim of this study to explore the role of adolescents' SOC as a mediator of the mother's influence on adolescents' tooth brushing behaviour. 


\section{Methods}

\section{Study population and sample design}

The participants in this study were $8^{\text {th }}$-graders from 11 randomly selected public high schools in the Limpopo Province in South Africa. A two-stage sampling technique was used to produce a provincially representative sample of $8^{\text {th }}$-graders $(n=1,025)$. The first stage of the sampling consisted of a random selection of 11 of the 31 school districts in the Limpopo Province. School districts were selected with a probability proportional to the number of schools in the district. The second stage consisted of a random selection of one school from the cluster of high schools in each selected school district. All the $8^{\text {th }}$-graders in the selected schools were eligible to participate in the study. Participation in the study required the informed consent of the participants, as well as that of their parents.

\section{Procedures}

After providing informed consent, the participants completed a pre-tested self-administered questionnaire during class time at baseline (T1), at 12 months (T2) and 18 months (T3). The original English questionnaires were translated into two local languages, namely Afrikaans and Sepedi for use with a few learners who were not proficient in English; otherwise the surveys were conducted in English. The validity of the translation was tested by means of back translation. The study protocol received approval from the University of Pretoria's Ethics Committee (22/2005).

\section{Measures and definitions}

\section{Socio-demographic features}

The study participants provided information about their age, gender, ethnicity (black African and others) and the type of dwelling they lived in (formal housing - a brick house/flat; or informal housing - huts/tents or a non-brick house). The type of dwelling indicated served as a proxy measure for the socio-economic status of the participating adolescents.

Information was also collected on the living arrangements of the study participants. About half of the children in the Limpopo province who are 15 years and younger live with only their mother; and another half live either with both parents (22\%) or with neither of their parents (29\%) (29). The data on the living arrangements of the study participants were therefore divided according to whether or not they lived with their mother. We also took into account the fact that previous studies have suggested that, irrespective of the level of resources available, children in South African households with mothers or headed by women, and children of household heads, as opposed to grandchildren or other children, have greater food security (30-31). Hence, we reasoned that the children living with their mothers may be those in environments with better application of GRR, which may in turn affect their SOC levels. 


\section{Tobacco use status}

Using items previously used in national and international youth tobacco surveys (32), the respondents themselves were categorised as current daily smokers if they indicated that they had smoked a cigarette within the 24 hours preceding the survey and had responded in the affirmative to a similar question on smoking in the last week and in the last 30 days preceding the date of the survey. A similar approach was used to define daily oral smokeless tobacco users.

\section{Depression vulnerability}

Because the concept of SOC is closely linked to mental health (13), and because depression has been linked to poor oral health (33), in this study vulnerability to depression in the recent past among the study participants was also measured. The depression screening item used was similar to one recently demonstrated to be a valid proxy measure of vulnerability to depression (34). Briefly, participants were asked the following: 'During the past 12 months, did you ever feel so sad or hopeless almost every day for two weeks or more in a row that you stopped doing some usual activities?' Those who answered in the affirmative were classified as being vulnerable to depression.

\section{Sense of Coherence (SOC)}

In line with a study by Fiore et al. (16), the 13-item short version of Antonovsky's 7-point Likert-type SOC scale was used in this study. The questions were included in the survey instrument. However, because the SOC scale has been less frequently used among adolescents, and in particular it has not been previously validated among South African adolescents, the instrument also had to be validated.

\section{Tooth brushing frequency}

To measure brushing frequency, respondents were asked the following question: 'In the past month (30-days), how often have you been brushing/cleaning your teeth?' Guided by the findings from the pilot test, the response options provided were: (1) 'I did not always clean daily'; (2) 'Always once daily'; (3) 'Most days once, but some days twice daily'; (4) 'Most days twice, but sometimes once'; and (5) 'Always at least twice daily'. Respondents who indicated always brushing at least twice were classified as having 'twice-a-day' or regular brushing behaviour.

\section{Self-reported gum bleeding}

Respondents were asked how frequently they had experienced bleeding gums while brushing in the last three months. Those who indicated that their gums bled frequently or often were categorised as having bleeding gums and those who reported that their gums never bled or seldom bled were categorised as not having bleeding gums.

\section{Recent dental attendance (awareness factor)}

Because it is usually recommended that people visit their dentist every six months, we controlled for dental attendance status six months before the last follow-up survey. Based on the responses to the survey question at T2 (six months before T3) on what the main 
reason was for past dental visits, if at all they had visited a dental clinic within the last 12 months, the respondents were categorised as either having never paid a visit to a dentist, or having had a recent pain visit or having had a recent check-up visit.

\section{Motivation for brushing teeth}

In line with the approach used in a study by Macgregor et al. (35), at baseline, the respondents were asked to report their main reason for brushing or cleaning their teeth. Response options were: 'Because I like fresh breath', 'Makes my mouth feel clean', 'So that my teeth will look nice', 'So as to avoid toothache' and 'So as to avoid false teeth'. Respondents who brush in order to avoid toothache or false teeth were classified as being motivated to brush more by preventive dental health or cognitive reasons, while the others were classified as being motivated by social or affective reasons.

\section{Readiness to change brushing behaviour (stage of change)}

To assess intention state, the respondents were asked the following: 'At any time during the next 6 months, do you think you will always be brushing twice every day?' Response options were: 'Definitely not', 'Probably not', 'Probably would', 'Definitely would', and 'I already brush twice sometimes'. Respondents who indicated at baseline that they would definitely or probably not be brushing twice were classified as being in the precontemplation stage; those who stated that they probably would or definitely would were classified as being in the contemplation state; and those who already sometimes brush twice were classified as being in the preparation/action stage of change.

\section{Data analysis}

Only those who reported not consistently brushing at least twice a day at baseline were the focus of analysis. Descriptive and multivariate analyses were conducted to assess the rates and correlates of tooth brushing at the follow-up. The chi square test and t-tests were used in order to test for group differences among categorical variables and continuous variables respectively.

In order to assess the structure of the SOC-13 scale, principal component analyses with oblique rotation were implemented with the $13 \mathrm{SOC}$ items. Because the usual factor retention criterion of an eigenvalue $>1$ sometimes produces too many factors (36), we also applied the criteria of interpretability and content validity (36). The internal consistency of the scale was measured using Cronbach's alpha coefficient. To assess content validity, we compared the components of the items loaded with those of the standard 13-item scale and its components. In order to assess construct validity, using the cross-sectional sample of the baseline study participants, the association between their SOC score and established correlates, such as vulnerability to depression (37) and socioeconomic status (38) was assessed. We also compared the SOC scores of the two ethnic groupings (Black Africans vs. non-blacks) and gender, as it was anticipated that they would not differ (12). SOC was analysed as a continuous variable because the analysis on whether to transform the summed scores showed a normal distribution. Given that the SOC may not be fully stable in adolescence (37), we computed a variable (which we called SOC development) by subtracting baseline SOC scores from the last follow-up SOC score. 
This variable was used in the multivariate analysis, while controlling for baseline SOC. Adjustment for the baseline level of SOC was necessary to control the floor effect constraining score declines on groups at the bottom, and ceiling effects constraining score increases on groups at the top. It was also done to control for the decreased likelihood that adolescents with higher levels of SOC would report changes in SOC, as they tend to buffer life stress more effectively, and generally experience less instability than individuals with a low SOC (38).

To test the difference between the direct effects of the potential explanatory variables on the transition to consistently brushing twice daily, a sequential multiple logistic regression analysis was carried out, using a stepwise approach, with age as a covariate, irrespective of the level of significance. To test for any possible mediating effects of SOC, we applied the approach suggested by Baron and Kenny (39). According to Baron and Kenny (39), perfect mediation holds when the independent variable has no effect on the dependent variable (brushing twice daily) when the mediator (SOC) is controlled, and the independent variable and the mediator are correlated. Similar to the approach described by De Vries et al. (20) and guided by our conceptual framework, logistic regression analysis was done, entering the variables in four blocks: (1) socio-demographic variables, including risk behaviours; (2) baseline SOC and the extent of SOC development; (3) motivation for brushing and awareness factor (main reason for recent dental visit); (4) intention to start always brushing twice daily. Those respondents who reported not brushing consistently twice daily at the follow-up stage was used as the reference category.

For the modelling, only subjects for whom complete data were available for the models were included in the analysis. All statistical analyses were done using the STATA Release 8 package (Stata Corporation, College Station, Texas, USA). The option 'robust cluster' for the procedure 'logit' in Stata was used to take into account the complex sample design used in this study, particularly the fact that participants were nested in schools, which were the ultimate sampling units. Differences are significant when $p<0.05$.

\section{Results}

\section{Psychometric evaluation of the SOC-13 and validity test}

Although all the items of the SOC-13 loaded on three factors, the original three-factor structure of the SOC-13 could not be replicated in this adolescent population. Only one meaningful or interpretable factor with six items emerged from this scale (Table 9). These six items contained at least one item from each of the three domains of the original SOC13 and accounted for $35 \%$ of the total variance of the scale. The internal consistency coefficient was similar to that of the SOC-13 when both were compared as a unidimensional scale (Cronbach $a=0.63$ ). The summed SOC-6 scores for those respondents positive on depression screening and those respondents living in informal housing were significantly lower than the scores of the respondents who were negative on depression screening ( 25.06 vs. $26.42 ; p=0.02$ ) and those who lived in formal housing structures ( 23.70 vs. $26.51 ; p<0.001)$ respectively. However, the SOC scores among those who identified themselves as black Africans and boys were not significantly different from 
those of non-black Africans ( 26.22 vs. $25.63 ; p=0.59)$ and girls ( 26.02 vs. $26.28 ; p=0.58)$ respectively.

Table 9: Six-item Sense of coherence (SOC) questionnaire used

\begin{tabular}{ccccccccc}
\hline Question item & $\begin{array}{c}\text { Very } \\
\text { often } \\
1\end{array}$ & 2 & 3 & 4 & 5 & 6 & 7 \\
\hline
\end{tabular}

1. How often do you have the feeling that you are in an unfamiliar situation and don't know what to do?

2. How often do you have very mixed-up feelings and ideas?

3. How often does it happen that you have feelings inside you that you would rather not feel?

4. In general, how often do you have the feeling that you're being treated unfairly?

5. How often do you have the feelings that you're not sure you can keep under control?

6. How often do you have feelings that there's little meaning in the things you do in your daily life?

\section{Baseline characteristics of the study population and attrition analysis}

The study participants were between 12 and 19 years old, with a mean (SD) age of 14.4 (SD 1.5) years. Of those who were not brushing twice daily at baseline $(n=744)$, a total of $77.7 \%(n=578)$ provided data at follow-up. An analysis of those lost to follow-up showed that they were more likely to have been those living in informal housing structures $(18.6 \%$ vs. $11.7 \% ; p=0.02$ ) and tended to be slightly older (14.7yrs vs. $14.4 y r s ; p=0.06)$. No other significant differences were noted between the baseline social or behavioural characteristics of the current study participants and those lost to follow-up (see Table 10). 
Table 10: Baseline characteristics of study participants compared to that of drop-outs who were not regularly brushing their teeth at least twice daily

\begin{tabular}{lccc}
\hline Baseline characteristics & $\begin{array}{c}\text { Study participants } \\
\text { \% }(\mathbf{N}=\mathbf{5 7 8})\end{array}$ & $\begin{array}{c}\text { Drop-outs } \\
\mathbf{\%}(\mathbf{N}=\mathbf{1 6 5})\end{array}$ & p-value \\
\hline Black Africans & $96.1 \%(n=547)$ & $92.6 \%(n=151)$ & 0.17 \\
Lives in informal housing structure & $11.7 \%(n=67)$ & $18.6 \%(n=30)$ & 0.02 \\
Lives without the mother & $25.2 \%(n=145)$ & $31.5 \%(n=52)$ & 0.11 \\
Daily smoker & $7.3 \%(n=42)$ & $4.3 \%(n=7)$ & 0.20 \\
Female & $52.8 \%(n=304)$ & $48.5 \%(n=80)$ & 0.36 \\
Owns a toothbrush & $99.1 \%(n=567)$ & $99.4 \%(n=164)$ & 0.78 \\
Does not always brush daily & $23.7 \%(n=136)$ & $26.8 \%(n=44)$ & 0.44 \\
Brush motive - affective/social & $83.5 \%(n=476)$ & $80.6 \%(n=133)$ & 0.43 \\
In the Preparation/action stage & $22.4 \%(n=127)$ & $18.9 \%(n=31)$ & 0.51 \\
& & & \\
\hline Mean SOC-6 score & $26.3(S D 7.2)$ & $25.7(S D 7.2)$ & 0.35 \\
Mean age & $14.4(S D 1.5)$ & $14.7(S D 1.8)$ & 0.06 \\
\hline Note: Totals ( $n)$ may be lower than expected because of missing data. & & \\
\hline
\end{tabular}

About one in four adolescents participating in the study did not live with the mother. Compared to the participants living with their mothers, those who did not live with their mothers also tended to live in informal housing structures ( $31.3 \%$ vs. $24.5 \% ; p=0.11)$. Table 2 also illustrates that almost all the study participants owned a toothbrush, but $23.7 \%(n=136)$ did not always brush daily. Most of the adolescents $(45.3 \%)$ were in precontemplation, and only $22.4 \% \quad(n=127)$ could be classified as being in the preparation/action stage of transition to consistently brushing twice daily. The majority of the adolescents are motivated by social or affective reasons.

\section{Prospective analysis}

By the last follow-up (T3), only $14.4 \%(n=81)$ had started brushing consistently twice or more daily, while $30.1 \%(n=166)$ did not always brush daily. None of those who identified themselves as non-black Africans $(n=22)$ or used oral snuff at baseline $(n=8)$ had made the transition to consistently brushing twice daily. Oral snuff users were significantly more likely not to be brushing daily ( $62.5 \%$ vs. $29.6 \%$; $p=0.03)$. The proportion of those in late adolescence (15-19 years) did not differ significantly from the proportion of those in early adolescence (12 - 14 years) who started brushing consistently twice daily ( $16.3 \%$ vs. $12.9 \% ; p=0.33)$.

Of those who provided follow-up data on the most recent dental visit $(n=550)$, only $19.4 \%(n=110)$ had made a dental visit. Of these, $63.6 \%(n=70)$ had visited the dentist 
because of pain. Only $16.6 \%(n=94)$ of the respondents who reported frequent bleeding gums at baseline did not report frequent bleeding gums at follow-up. Those who had started brushing regularly twice were significantly more likely to have experienced a reduction in frequently bleeding gums compared to those who were still not regularly brushing at least twice daily ( $22.2 \%$ vs. $15.6 \% ; p=0.04)$.

The mean (SD) total SOC score of the adolescents at baseline was 26.3 (SD 7.4) and this increased to an average of 27.2 (SD 8.6) by the follow-up (T3) 18 months later (pairwise t-test; $p=0.06)$. Compared to the respondents who were not living with their mother, those living with their mother at baseline not only tended to have experienced an increase in SOC ( -0.36 vs. $+1.36 ; p=0.11)$, but were also significantly more likely to be brushing twice daily at the follow-up stage $(10.6 \%$ vs. $15.4 \% ; p=0.04)$. Conversely, although they were not different in the SOC level at baseline, when compared to those who did not make the transition to consistently brushing twice daily (26.4 vs. 26.2; $\mathrm{p}=0.89$ ), those who made the transition to consistently brushing twice daily had attained a significantly higher SOC level by T2 (28.9 vs. $26.6 ; \mathrm{p}=0.02)$ and T3 (29.3 vs. 26.9; $\mathrm{p}=0.02$ ).

Frequent brushing was also significantly lower among those positive on depression screening at the follow-up stage (Step 1; Table 11). Adding within-subject SOC changes to the model did not change the significant influence of living with the mother (Step 2). With the addition of the motivational variables, daily smoking and baseline SOC became significant predictors, and having had a recent dental check-up visit and, reporting preventive dental health as the motive for brushing were also significantly associated with making the transition to regularly brushing twice daily (Step 3). Being in the preparation/action stage of change at the baseline was also a significant predictor of the transition to consistently brushing twice daily (Step 4; Table 11). Furthermore, the addition of the intention state attenuated the influence of baseline SOC to a statistically insignificant level. Being vulnerable to depression had the strongest, but negative influence on adolescents' transition to consistently brushing twice daily $(\beta=-0.23$; $\mathrm{p}<0.01$ ). The area under the ROC curve for the final model was 0.70 . 
Table 11: Sequential logistic regression analysis predicting consistent twice-a-day brushing

\begin{tabular}{|c|c|c|c|c|c|}
\hline $\begin{array}{l}\text { Explanatory } \\
\text { variables }\end{array}$ & $\begin{array}{c}\text { Model } 1 \\
\text { OR }(95 \% \mathrm{CI})\end{array}$ & $\begin{array}{c}\text { Model } 2 \\
\text { OR }(95 \% \mathrm{CI})\end{array}$ & $\begin{array}{c}\text { Model } 3 \\
\text { OR }(95 \% \mathrm{CI})\end{array}$ & $\begin{array}{c}\text { Model } 4 \\
\text { OR }(95 \% \text { CI })\end{array}$ & $\begin{array}{c}\text { Standardized } \\
\text { regression } \\
(\boldsymbol{\beta}) \\
\text { coefficient }\end{array}$ \\
\hline \multicolumn{6}{|l|}{$\begin{array}{l}\text { Step } 1 \\
\text { (predisposing/ } \\
\text { distal factors) }\end{array}$} \\
\hline No mother & 1 & 1 & 1 & 1 & \\
\hline Lives with mother & $1.43(1.04-1.97)$ & $1.41(1.04-1.92)$ & $1.50(1.06-2.13)$ & $1.58(1.14-2.18)$ & 0.11 \\
\hline $\begin{array}{l}\text { Not depression- } \\
\text { vulnerable }\end{array}$ & 1 & 1 & 1 & 1 & \\
\hline $\begin{array}{l}\text { Depression- } \\
\text { vulnerable }\end{array}$ & $0.37(0.19-0.75)$ & $0.40(0.20-0.80)$ & $0.38(0.19-0.75)$ & $0.39(0.20-0.78)$ & -0.23 \\
\hline $\begin{array}{l}\text { Never smokes/ } \\
\text { non-regular smoker }\end{array}$ & 1 & 1 & 1 & 1 & \\
\hline Daily smoker & $0.43(0.18-1.05)^{\mathrm{N}}$ & $0.44(0.18-1.07)^{\mathrm{N}}$ & $0.39(0.17-0.90)$ & $0.37(0.16-0.82)$ & -0.14 \\
\hline Step 2 & & & & & \\
\hline $\begin{array}{l}\text { SOC } \\
\text { development } \\
\text { (continuous) }\end{array}$ & & $1.02(1.01-1.04)$ & $1.03(1.01-1.05)$ & $1.03(1.01-1.05)$ & 0.16 \\
\hline SOC at baseline & & $1.03(0.99-1.06)^{\mathrm{N}}$ & $1.03(1.00-1.06)$ & $1.02(0.99-1.06)^{\mathrm{N}}$ & 0.09 \\
\hline $\begin{array}{l}\text { Step } 3 \\
\text { (motivational/ } \\
\text { proximal) }\end{array}$ & & & & & \\
\hline $\begin{array}{l}\text { No recent dental } \\
\text { visit }\end{array}$ & & & 1 & 1 & \\
\hline Recent pain visit & & & $0.87(0.38-1.98)$ & $0.79(0.34-1.85)$ & -0.04 \\
\hline $\begin{array}{l}\text { Recent check-up } \\
\text { visit }\end{array}$ & & & $2.51(1.72-3.67)$ & $2.46(1.70-3.57)$ & 0.12 \\
\hline $\begin{array}{l}\text { Brushing for } \\
\text { affective reasons }\end{array}$ & & & 1 & 1 & \\
\hline $\begin{array}{l}\text { Brushing for } \\
\text { cognitive reasons }\end{array}$ & & & $1.62(1.05-2.52)$ & $1.70(1.11-2.63)$ & 0.11 \\
\hline $\begin{array}{l}\text { Step } 4 \\
\text { (Intention state) }\end{array}$ & & & & & \\
\hline Pre-contemplation & & & & 1 & \\
\hline Contemplation & & & & $1.49(0.90-2.46)$ & 0.10 \\
\hline Preparation/action & & & & $1.74(1.04-2.94)$ & 0.13 \\
\hline
\end{tabular}

Note: All models controlled for age and included only black Africans and those with complete data $(n=526)$.

$\mathrm{N}=$ Not statistically significant, but had $\mathrm{p}<0.25$ (a priori cut-off criteria), so was retained in the subsequent models. 


\section{Discussion}

This study's findings supported the applicability of the SOC construct in a South African adolescent population and demonstrated that the most significant determinants of transition to consistently brushing twice daily are related to the psychological predisposition of the individual concerned, namely the person's SOC levels and vulnerability to depression. This corroborates findings from previous studies on the influence of psychological mood $(11,33)$ and self-concept (35) on oral health behaviours. No evidence was found to support the hypothesis of SOC as a mediator of mothers' influence on children's oral health behaviour, but, in line with the I-Change model assumptions and consistent with the salutogenic theory, there was evidence to suggest that the influence of SOC on adolescent tooth brushing may be partly mediated through the adolescents' intention state.

Considering that the change in SOC among adolescents who were living with their mothers compared to adolescents who were not living with their mothers was more positive (albeit statistically insignificantly) and the fact that those living with their mothers also tended to live in formal housing structures, which in turn was associated with significantly higher SOC, it may be reasonable to suggest that a family environment with a mother may be an important salutogenic factor. Such a family environment could indeed support further development of children's SOC by making available the GRR that would promote healthy behaviours. Nevertheless, the fact that living with the mother also had a direct influence on brushing behaviour is also suggestive of a more proximal social influence. This is consistent with the suggestion that parents, particularly mothers, may be important role models for the oral health behaviour of their children well into their adolescence (40).

Furthermore, the fact that baseline SOC levels became significant only while controlling for motivational variables, including dental attendance patterns, suggests that these motivational factors provided the context for the relevance of a SOC. This finding is consistent with the central construct of salutogenesis and corroborates findings from previous studies that demonstrated that people with a higher SOC are more likely to make regular dental visits (14) and that, when they do so, they do so mainly for check-ups (16). Considering that SOC has also been connected with attitudes and behaviours (13), it is conceivable that adolescents with a higher SOC might have been able to comprehend the benefit of regular brushing better and perceive there to be greater value or worth in pursuing good oral health, as this also relates to social relations (in other words, a higher positive outcome expectancy) (41). It was also noteworthy that the inclusion of these motivational variables also significantly increased the influence of not being a regular smoker on the adoption of regular tooth brushing habits. Although dental service utilization in this study was much lower than in Scotland (40), this finding is nevertheless consistent with previous observations of an association between smoking and dental visit patterns in a Scottish adolescent population of similar age (40). Considering that a high SOC has been associated with a lower risk for adolescent smoking (42), taken together, our study findings suggest that a high SOC, and by implication a greater ability to cope with stress and perhaps a better attitude to oral health, may be a common salutogenic factor promoting smoking abstinence and regular tooth brushing. 
The fact that the influence of SOC is mediated through the intention state further supports a salutogenic interpretation for the I-Change model. It is indeed conceivable that those with a high SOC would be more optimistic, perceive themselves to have more control or be more confident in their ability to attain the goal of brushing consistently twice daily. This view is supported by a previous report that suggests that there is a pathway that connects SOC with the concept of self-efficacy (27). However, unlike self-efficacy measures, which are of necessity tailored to specific domains of functioning and possibly to specific population characteristics (43), SOC is a general construct with cross-cultural applications (12). With the additional benefit of having to administer fewer questions, this study's findings suggest that it may be useful to investigate the inclusion of the SOC- 6 scale in the I-Change model further by examining the determinants of other health behaviours, instead of function-specific self-efficacy measures that require several items for measurement (20).

The findings of this study should be considered in relation to its methodological strengths and limitations. A major limitation of this study is the reliance on self-reported tooth brushing behaviour, creating potential reporting bias. However, to limit the possibility of socially desirable responses, the most conservative definition for brushing twice daily was used in this study. Moreover, the fact that those who reported a transition to more regular brushing experienced a $40 \%$ greater reduction in bleeding gums provides some support for the validity of the measure used. It is possible that respondents could also have been misclassified in terms of their stage of change, but, given that the distribution of the study population in the different stages closely matched that reported as a rule of thumb for atrisk populations (22), we are fairly confident that our stage classification is fairly reflective of the true stage. Lastly, the internal consistency of the SOC-6 $(a=0.63)$ was lower than the benchmark of 0.70 (13). However, considering that only six items were used and this questionnaire performed better than the 0.42 obtained using the SOC- 13 scale in a recent study among a South African adult population (28), the SOC- 6 scale could be considered fairly reliable for the studied population. Nevertheless, we acknowledge that the scale and the model performance could still be significantly improved.

Despite these limitations, this study, the first to examine the longitudinal relationship between SOC and oral health behaviour among adolescents, provides useful information. It has several implications for oral health promotion practice and public policy.

The study findings provide support for the integration of the salutogenic construct with the I-Change model as this is instructive with regard to planning and evaluating oral health promotion interventions. For instance, it highlights the need to tailor oral health counselling to the stage of change of an individual (44). Furthermore, given that smoking was found to be a significant modifiable risk factor for irregular brushing, this model provides the theoretical basis for the integration of oral health promotion with smoking prevention programmes that could target improvements in the attitude to oral health and could also provide life-skills training such as coping skills. The influence of the family environment should also not be underestimated. With an increasing proportion of South African households with at least one maternal orphan (45), the implication for the promotion of adolescents' oral and general health becomes apparent from such an integrated salutogenic behaviour change model. 
In conclusion, when planning oral health promotion interventions, due consideration should be given to the fact that children's psychological predispositions and family environment might significantly influence their tooth brushing behaviour, and subsequently their oral health.

\section{Acknowledgements}

The study was supported by grants received from the Medical Research Council, South Africa, and the Cancer Association of South Africa. The authors are also grateful to Colgate and GlaxoSmithKline for donating toothbrushes and toothpaste given to all study participants. 


\section{References}

1. Lang WP, Ronis DL, Farghaly MM. Preventive behaviours as correlates of periodontal health status. J Public Health Dent 1995; 55: 10-7.

2. Nguyen L, Hakkinen U, Knuuttila M, Järvelin M. Should we brush twice a day? Determinants of dental health among young adults in Finland. Health Econ. 2008; 17: 267-86.

3. Joshipura K, Ritchie C, Douglass C. Strength of evidence linking oral conditions and systemic disease. Compend Contin Educ Dent 2000; 30 (Suppl):12-23.

4. Kay L, Locker D. Is dental health education effective? A systematic review of current evidence. Community Dent Oral Epidemiol 1996; 24: 231-5.

5. Watt RG. Emerging theories into the social determinants of health: implications for oral health promotion. Community Dent Oral Epidemiol 2002; 30: 241-7.

6. Brown LF. Research in dental health education and health promotion: a review of the literature. Health Educ Q 1994; 21: 83-102.

7. Petersen PE. The world oral health report 2003: continuous improvement of oral health in the $21^{\text {st }}$ century - the approach of the WHO global oral health programme. Community Dent Oral Epidemiol 2003; 31 (Suppl.1):3-24.

8. Bandura A. Social foundations of thoughts and action. Englewood Cliffs, NJ: Prentice Hall 1986.

9. Grossi, S. Smoking and stress: common denominator for periodontal disease, heart disease and diabetes mellitus. Compend Contin Edu Dent 2000; 30: 31-9.

10. Merchant AT, Pitiphat W, Ahmed B, Kawachi I, Joshipura K. A prospective study of social support, anger expression and risk of periodontitis in men. J Am Dent Assoc 2003; 134: 1591-6.

11. Deinzer R. Granrath N, Spahl M, Linz S, Waschul B, Herforth A. Stress, oral health behaviour and clinical outcome. Br J Health Psychol 2005; 10: 269-83.

12. Antonovsky A. The structure and properties of the sense of coherence scale. Soc Sci Med 1993; 36: 725-33.

13. Eriksson M, Lindström B. Antonovsky's sense of coherence scale and the relation with health: a systematic review. J Epidemiol Community Health 2006; 60: 376-81.

14. Savolainen J, Knuuttila M, Suominen-Taipale L, Martelin T, Nordlad A, Niskanen M, Uutela A. A strong sense of coherence promotes regular dental attendance in adults. Community Dent Health 2004; 21: 271-6. 
15. Savolainen JJ, Suominen-Taipale AL, Uutela AK, Martelin TP, Niskanen MC, Knuuttila ML. Sense of coherence as a determinant of tooth brushing frequency and level of oral hygiene. J Periodontol 2005; 76: 1006-12.

16. Freire MCM, Sheiham A, Hardy R. Adolescents' sense of coherence, oral health status, and oral health-related behaviours. Community Dent Oral Epidemiol 2001; 29: 204-12.

17. Freire MCM, Hardy R, Sheiham A. Mothers' sense of coherence and their adolescent children's oral health status and behaviours. Community Dent Health 2002; 19: 24-31.

18. Nicolau B, Marcenes W, Hardy R, Sheiham A. A life-course approach to assess the relationship between social and psychological circumstances and gingival status in adolescents. J Clin Periodontol 2003; 30: 1038-45.

19. Hollister MC, Anema MG. Health behaviour models and oral health: a review. J Dent Hyg 2004; 78: $1-8$.

20. De Vries H, Mudde A, Leijs I, Charlton A, Vartiainen E, Buijs G, et al. The European Smoking Prevention Framework Approach (EFSA): an example of integral prevention. Health Educ Res 2003; 18: 611-26.

21. Ajzen I. The Theory of Planned Behaviour. Organisational Behaviour and Human Decision Processes 1991; 50: 179-211.

22. Prochaska JO, Velicer WF. The trans-theoretical model of health behaviour change. Am J Health Promot 1997; 12: 38-48.

23. McCaul KD, Glasgow RE, Gustafson C. Predicting levels of preventive dental behaviours. JADA 1985; 111: 601-5.

24. Tedesco LA, Keffer MA, Fleck-Kandath C. Self-efficacy, reasoned action, and oral health behaviour reports: a social cognitive approach to compliance. J Behav Med 1991; 14: 34154 .

25. Tillis TSI, Stach DJ, Cross-Poline GN, Annan SD, Astroth DB, Wolfe P. The trans-theoretical model applied to an oral self-care behavioural change: development and testing of instruments for stages of change and decisional balance. J Dent Hyg 2003; 77: 16-25.

26. Reisine S, Litt M. Social and psychological theories and their use for dental practice. Int Dent J 1993; 43: 279-87.

27. McSherry WC, Holm JE. Sense of coherence: its effects on psychological and physiological processes prior to, during, and after a stressful situation. J Clin Psychol 1994; 50: 476-87.

28. Corless IB, Nicholas PK, Wantland D, McInerney P, Ncama B, Bhengu B, et al. The impact of meaning in life and life goals on adherence to a tuberculosis medication regimen in South Africa. Int J Tuberc Lung Dis 2006; 10: 1159-65. 
29. Lemke S, Vorster HH, Jansen van Rensburg NS, Ziche J. Empowered women, social networks and the contribution of qualitative research: broadening our understanding of underlying causes of food and nutrition insecurity. Public Health Nutr 2003; 6: 759-64.

30. Bomela N. Child nutritional status and household patterns in South Africa. AJFAND Online 2007; 7: 1-18. URL: http://www.ajfand.net/Issue16/PDFs/Bomela 2140.pdf. Date accessed: $18 / 03 / 2008$.

31. South African Demographic and Health Survey 2003. Preliminary report. Department of Health Pretoria, South Africa. 2004. URL: http://www.healthe.org.za/resources/SA\%20Demo\&Health2003pt1.pdf. Date accessed: 18/03/2008.

32. Swart D, Reddy P, Panday S, Phillip JL, Naidoo N, Ngobeni N. The 2002 Global Youth Tobacco Survey (GYTS): The $2^{\text {nd }}$ GYTS in South Africa - A comparison between GYTS (SA) 1999 and GYTS (SA) 2002. Cape Town: South African Medical Research Council, 2004.

33. Kurer JR, Watts TL, Weinman J, Gower DB. (1995) Psychological mood of regular dental attenders in relation to oral hygiene behaviour and gingival health. J Clin Periodontol 1995; 22: $52-5$.

34. McChargue DE, Cook JW. Depression vulnerability within smoking research: how accurate are one-item screening items? Addict Behav 2007; 32: 404-9.

35. Macgregor IDM, Regis D, Balding JW. Self-concept and dental health behaviours in adolescents. J Clin Periodontol 1997; 24: 335-9.

36. Velicer WF. Determining the number of components from the matrix correlations. Psychometrika 1976; 41: 321-37.

37. Geyser S. Some conceptual considerations on the sense of coherence. Soc Sci Med 1997; 44: 1771-9.

38. Smith PM, Breslin FC, Beaton D. Questioning the stability of sense of coherence. The impact of socio-economic status and working conditions in the Canadian population. Soc Psychiatr Epidemiol 2003; 38: 475-84.

39. Baron RM, Kenny DA. The moderator-mediator variable distinction in social psychological research: Conceptual, strategic, and statistical considerations. J. Pers Soc Psychol 1986; 51: 1173-82.

40. Attwood D, West P, Blinkhorn AS. Factors associated with the dental visiting habits of adolescents in the west of Scotland. Community Dent Health 1993; 10: 365-73.

41. Ajzen I. Nature and Operation of Attitudes. Annu Rev Psychol 2001; 52: 27-58.

42. Glanz K, Maskarinec G, Carlin L. Ethnicity, sense of coherence, and tobacco use among adolescents. Ann Behav Med 2005; 29: 192-9. 
43. Maibach E, Murphy DA. Self-efficacy in health promotion research and practice: conceptualization and measurement. Health Edu Res 1995; 10: 37-50.

44. Kasila K, Poskiparta M, Kettunen T, Pietilä I. Oral health counselling in changing schoolchildren's oral hygiene habits: a qualitative study. Community Dent Oral Epidemiol 2006: 34; 419-28.

45. Madhavan S, Schatz EJ. Coping with change: household structure and composition in rural South Africa, 1992-2003. Scand J Public Health Suppl. 2007; 69: 85-93. 


\section{Chapter 5:}

\section{Association of Smoking-Related Oral Health Attitude with Adolescents' Smoking Onset}

Accepted for publication as: Ayo-Yusuf OA, van den Borne BW, Reddy PS, van Wyk PJ, Severson $\mathrm{HH}$. Longitudinal association of smoking-related attitude to oral health with Adolescents' smoking onset. Journal of Public Health Dentistry. 


\section{Abstract}

Objective: The negative oral health effects of smoking, such as stained teeth, gum infection and bad breath may be more salient to adolescents and therefore more important expectancies for adolescent smokers and non-smokers alike. Informed by the social cognitive theory, this prospective study sought to determine the role of smokingrelated attitude to oral health on smoking onset among adolescents over a 12-month interval.

Method: This prospective study involved a community sample of 422 non-smoking $8^{\text {th }}-$ graders selected from three public schools in the capital city of South Africa. Data were collected through a questionnaire, which included a 5-point likert-scale type question on dental disease belief related to smoking (smoking causes plaque and bad breath) and an affective evaluation of this effect (bad breath causes peer rejection). The product of these two later variables was used to compute an attitude score. Higher scores represent a more favorable oral health attitude. Health-risk behaviours recorded included past-month smoking and alcohol use.

Results: The mean age of the participants was $13.9 \mathrm{yrs}$ at baseline. At one-year follow-up, $11.4 \%(n=48)$ of non-smokers at baseline had initiated smoking. Compared to nonsmokers, current smokers were more likely to report frequent bleeding gums $(51.2 \%$ vs. $33.1 \% ; p=0.02$ ), but there was no significant difference in proportions brushing twice daily (64.4\% vs. $56.5 \% ; \mathrm{p}=0.30)$. In addition to the independent influence of peers' smoking and own binge-drinking, smoking-related attitude towards oral health significantly influenced smoking onset.

Conclusion: The study findings support the development of smoking prevention programmes that include restructuring of cognitions about the oral health outcomes of smoking. 


\section{Introduction}

Smoking, in addition to being associated with premature deaths, increases the risk for the development of cancer, cardiovascular diseases, chronic obstructive airway diseases, adverse reproductive outcomes, periodontitis and other oral conditions in adulthood. Adolescence is however, the period during which the vast majority of adult smokers begin to smoke. Smoking prevalence of $18.5 \%$ among South African adolescents remains unacceptably high (1). Furthermore, given the fact that there are no organized adolescent tobacco prevention programmes currently in South Africa, there is growing impetus to understand why South African adolescents become smokers so as to be able to develop effective preventive programmes. Most of the studies on determinants of adolescent smoking have been carried out in developed countries, and the few conducted in South Africa have been cross-sectional studies $(2,3)$, which precludes statements about causality.

Nevertheless, in support of Bandura'a social cognitive theory of health behaviour (4), the most consistently demonstrated psychosocial factors related to adolescent tobacco use include attitude, social influence (influence of peers or significant-others) and self-efficacy to refuse an offer to smoke (5). An important construct of current social learning accounts of drug use is outcome expectancy $(6,7)$. Outcome expectancies refer to an individual's ability to utilize information stored in memory to guide and organize future behaviour (8). In order words, expectancies are beliefs about the probable consequences of engaging in a specific behaviour (9). It has however also been recognized that an individual's expectation of a particular outcome of performing a behaviour is influenced by the evaluation of the impact it might have $(10,11)$. This impact has been conceptualized as expectancy salience or value (11). According to Ajzen (10), attitude can be operationalised as the multiplicative function of outcome expectancy belief and value.

It has been noted that expectancies do not have to be accurate in order for them to motivate behaviour (7). It is however of necessity that such expectancies represent relevant or accessible beliefs that can be easily activated from memory to influence behaviour (10). Smoking consequences questionnaires have typically been used to measure expectancies among adult smokers, and the adolescent version recently used (12) had excluded items on health risks based on the belief that such expectancies are not accessible, that is, it cannot be acquired by adolescent non-smokers (13). However, a more recent study suggests that even non-smokers conceive health-risk expectancies from smoking and recommended investigations of non-smoker adolescents' health-risk smoking expectancies (13). Recognizing that long-term health outcomes may not be a major deterrent among adolescents, tobacco prevention programs have emphasized short-term negative consequences of smoking that may be more salient to adolescents (14). The oral health effects of smoking, such as stained teeth, gum infection and bad breath may indeed be more salient to adolescents and therefore more accessible beliefs for smokers and non-smokers alike. However, a recent study failed to demonstrate significant association between negative expectations of oral health consequences of smoking and smoking susceptibility among an adolescent population in the United States (15). This 
study was however also cross-sectional and did not examine the role of the subjective evaluation of the expected negative oral health consequences of smoking.

This study therefore sought to determine the role of smoking-related oral health attitude on smoking onset among adolescents in a longitudinal study over a 12-month period.

\section{Method}

\section{Study population and design}

This study included a sample of eighth-graders from three public schools in the TshwaneNorth School district in the capital city Pretoria, South Africa. The three schools were randomly selected from a list of six schools in the North of Pretoria, participating in the then University of Pretoria's Telematic community-outreach education project. Data were collected as part of an effort to provide an informed curriculum-design for life-skills for the secondary schools participating in the project. Two schools from a historically socioeconomically disadvantaged area or 'township' and, the only one participating public school located in a more affluent 'suburb' in the North of Pretoria were selected. Of the 586 learners who provided consent in addition to a written parental informed consent of their participation at baseline (T1), only 489 (83.5\% follow-up rate) could be traced after two visits to the school 12-months later (T2) to conduct a second survey using the same questionnaire. The learners completed each survey in the classroom in the absence of the classroom teachers, but under the supervision of trained research assistants. The study protocol was approved by the University of Pretoria's school of dentistry research committee.

\section{Measures}

Data were collected both at T1 (May 2004) and T2 (May 2005) using a pre-tested selfadministered questionnaire, which was used to obtain information on the socio-demographic characteristics of respondents, including ethnicity (black/Africa or non-black), past-month alcohol use, smoking, snuff use and oral health-related outcome expectancy of smoking. Those who reported having taken five glasses or bottles of alcoholic drink in a row, at least on one occasion in the month preceding the survey date, were classified as binge-drinkers.

\section{Smoking status}

Current smokers were those who indicated smoking (even a puff) at least once in the 30 days preceeding the day of the survey. Participants were also asked to indicate how many of their closest friends smoke. Response options ranged from 'none of them' to 'all of them'. For their measure of peer influence, participants' responses were collapsed into dichotomous variables - those having most or all of their close friends smoking and those having few or none of their close friends smoking. One item - 'If you were offered a cigarette by your best friend, would you smoke it?' was used to assess self-efficacy to refuse an offer to smoke. Response options ranged from 'definitely would' (1) to 'definitely would not' (4). The participants also indicated if any member of their household smokes cigarettes. 


\section{Oral hygiene status}

Following questionnaire administration, all the eligible surveyed study participants were also invited for oral examination at baseline and at follow-up. Using mobile chairs and dental lamps, two trained and calibrated examiners conducted the oral examinations in a dedicated room on the school premises. The patient hygiene performance (PHP) was used to assess oral cleanliness (16). Respondents were subsequently categorized as having a poor/fair oral hygiene or having a good to excellent oral hygiene. Other oral-health related variables recorded included daily tooth brushing frequency and self-reported past-month frequency of bleeding gums while brushing.

\section{Oral health-related outcome expectancy belief and value (attitude)}

$\mathrm{OH}-\mathrm{R}$ smoking outcome expectancy belief and value was assessed using two items adapted from previous similar studies $(15,17)$ and pre-tested among adolescents locally for local relevance. The negative outcome expectancy or disease belief measured was 'smoking would cause me to have plaque and bad breath'. The expectancy value or social belief was 'bad breath would make me unacceptable among my friends'. The study participants were asked to indicate whether they agreed or disagreed with each of the two statements by using a five-point likert response scale, with responses ranging from 'strongly disagree'(1) to 'strongly agree'(5). A smoking-related attitude to oral health score was then computed as the product of outcome expectancy and expectancy value (10).

\section{Data analysis}

The socio-demographic characteristics of the cohort at follow-up were compared to the cohort at baseline to determine differences in study participants' characteristics attributable to differential attrition rates. In bivariate analyses, the association between the outcome variable (past-month smoking at follow-up) and potential explanatory variables were tested using chi-square statistics and t-tests. Variables found to be significant were then included in a stepwise multiple logistic regression analysis using a hierarchical approach. The probability for stepwise use was a priori set at 0.10 to remove a variable from the equation or the final predictive model. This was done to control for confounding variables by testing for their independent influence on past-month smoking at T2 among those who had not indicated past-month smoking at baseline $(n=422)$. The influence of oral health attitude was analyzed using an adapted analytic procedure previously described (11). Briefly, the attitude score was added in a separate block to the first predictive model that had fitted other potential explanatory variables. Likelihood ratio tests were then performed to compare models obtained. For all analyses, a p-value of less than 0.05 was considered significant.

\section{Results}

\section{Analysis of study drop-outs}

Of the 586 study participants at baseline, $53.9 \%$ were females, and $85 \%$ self-identified as black Africans, the rest being whites or coloureds (mixed ancestry). The Mean age ( $\pm S D$ ) of the participants at baseline was 13.9 yrs $( \pm 1.0)$, but those lost to follow-up were 
significantly older (14.4yrs) at baseline, more likely to be males ( $57 \%$ vs. $44.2 \% ; p=0.03$ ), smokers ( $25.6 \%$ vs. $12.7 \% ; p<0.01)$ and binge-drinkers ( $21.2 \%$ vs. $12.8 \% ; p=0.04)$. No other comparisons were statistically significant.

\section{Cross-sectional analyses of smoking onset and oral health at follow-up}

Of the non-smokers followed-up $(n=422), 11.4 \%(n=48)$ had initiated smoking. The study participants that reported brushing twice daily were less likely to report frequent bleeding gums $(29.6 \%$ vs. $42.2 \% ; p=0.01)$. Compared to those who refrained from smoking, those who had initiated smoking were more likely to report frequent bleeding gums $(51.2 \%$ vs.33.1\%; $p=0.02)$ at follow-up, but no statistically significant differences were noted in the proportion that reported brushing twice daily $(64.4 \%$ vs. $56.5 \%$; $p=0.30)$ or that presented with poor oral hygiene $(12.7 \%$ vs. $9.1 \% ; p=0.49)$.

\section{Prospective analyses predicting smoking onset}

In a bivariate analysis, smoking onset was not significantly associated with ethnicity or age. Although a higher proportion of those who had initiated smoking were more likely to have experimented with snuff at baseline, this association did not reach statistical significance (Table 12). However, compared to those who remained non-smokers after 12months, adolescents who initiated regular smoking were not only more likely to have reported binge-drinking, but were also more likely to have reported having most or all of their friends smoking at baseline. Cigarette-offer refusal self-efficacy, although higher among those who refrained, was not significantly associated with smoking onset (Table 12). Males were more likely than females to have initiated regular smoking at follow-up $(15.3 \%$ vs. $8.9 \% ; p=0.04)$. However, this gender influence did not reach statistical significance after controlling for potential confounding effects of peer influence and bingedrinking in subsequent multivariate analysis. 
Table 12: Characteristics of non-smokers at baseline by smoking status after 12 months

\begin{tabular}{lccc}
\hline Baseline characteristics & $\begin{array}{c}\text { Among continued } \\
\text { non- smokers at } \\
\text { T2 }(\mathbf{n}=\mathbf{3 7 4})\end{array}$ & $\begin{array}{c}\text { Among those } \\
\text { who initiated } \\
\text { smoking at T2 (n } \\
\mathbf{= 4 8 )}\end{array}$ & p-value \\
\hline Binge-drinking $(\mathrm{n}=421)$ & $(\%)$ & $(\%)$ & \\
Experimented with snuff $(\mathrm{n}=409)$ & 7.5 & 18.8 & 0.01 \\
All/most peers smoke $(\mathrm{n}=421)$ & 11.9 & 19.1 & 0.16 \\
Smoker in the household $(\mathrm{n}=411)$ & 28.2 & 47.9 & 0.01 \\
Attends 'suburb school' $(\mathrm{n}=422)$ & 48.5 & 52.1 & 0.64 \\
Black/African ( $\mathrm{n}=422)$ & 12.8 & 14.6 & 0.74 \\
& 86.9 & 85.4 & 0.78 \\
Age & $13.8(1.21)$ & $14.2(1.11)$ & 0.06 \\
Oral health attitude & $15.10(6.76)$ & $12.08(6.70)$ & 0.01 \\
Refusal Self-efficacy & $3.90(0.34)$ & $3.85(0.40)$ & 0.16 \\
\hline
\end{tabular}

NB: Total did not always add up to 422 because of some incomplete data.

Table 13: Predictive models assessing the influence of oral health attitude on smoking initiation

\begin{tabular}{lccc}
\hline & $\begin{array}{c}\text { Model 1 } \\
\left(\chi^{2}=11.14 ; \mathrm{R}^{2}=0.05\right)\end{array}$ & $\begin{array}{c}\text { Model 2 } \\
\left(\chi^{2}=18.87 ; \mathrm{R}^{2}=0.09\right)\end{array}$ & \\
\hline Explanatory variables & $\mathbf{9 5 \%}$ Confidence interval & $\begin{array}{c}\text { Standardized } \\
\text { regression } \\
\text { coefficient }\end{array}$ \\
\hline Peer smoking & $2.19(1.18-4.03)$ & $2.08(1.10-3.94)$ & 0.18 \\
Binge-drinking & $2.65(1.14-6.15)$ & $2.41(1.02-5.68)$ & 0.16 \\
Oral health attitude ${ }^{\dagger}$ & - & $0.94(0.90-0.98)$ & -0.23 \\
\hline
\end{tabular}

$\chi^{2}=$ Goodness of fit, represented as the improvement on the null model.

$\mathrm{R}^{2}=$ Percentage of outcome 'variance' explained.

${ }^{\dagger}$ Ordinal variable ranging in value from 0 to 25 .

Compared to those who initiated smoking, those who refrained from smoking had a significantly more favourable smoking-related attitude to oral health (Table 12). Table 13, illustrates that when the attitude to oral health was added to the first predictive model (Model 1), the improvement in fit of this model on the previous model was significant, and smoking-related attitude to oral health was significantly associated (OR $=0.94 ; 0.90-$ 0.98) with smoking onset (Model 2). In other words, smoking onset was least likely when 
youth strongly believe that smoking causes bad breath and that bad breath has negative social consequences.

\section{Discussion}

This prospective study demonstrated that adolescents' smoking-related attitude to oral health is a significant predictor of smoking onset. Indeed, beliefs that smoking is associated with negative social consequences, such as peer rejection, have been associated with less susceptibility to smoking $(18,19)$. Also consistent with the literature, this study illustrated the significant role peer influence plays in smoking uptake among South African adolescents (3). It is pertinent to note that existing risk behaviour, namely binge-drinking was although also significantly associated with smoking onset, but its influence was attenuated when attitude to oral health was included in the model. It is conceivable that those who value fresh breath would also not likely engage in alcohol binge drinking. Our study finding is therefore consistent with the construct of the integrated model of change (I-Change model) that suggests that existing risk behaviours and mere risk perceptions are distal or predisposing factors that influence behaviour via proximal factors such as attitude (20). This construct of the I-change model may therefore explain the difference in findings obtained from this study and a previous study that merely examined the relationship between beliefs regarding the expected negative oral health consequences of smoking and smoking susceptibility (15).

Contrary to findings from a previous study in South Africa (3) and elsewhere (20), this study failed to demonstrate a significant association between refusal self-efficacy and smoking onset. This may be related to differences in measures of self-efficacy and/or the fact that unlike the other South African study that involved mostly adolescent smokers of mixed ancestry, this study involved mostly black African children. Panday et al. (3) indeed reported that the strength of association between self-efficacy and smoking was lowest among the black African respondents in their multiethnic cross-sectional study. Given that smoking in black South African communities is relatively less common than among other ethnic groups (1), it is conceivable that the issue of refusing an offer of a cigarette may be less relevant among this population group. Nevertheless, our study findings are consistent with the view that outcome expectancy or attitude may be more important than selfefficacy in preventive health risk behaviour (smoking uptake) and self-efficacy may be more important than attitude when the behaviour in question is difficult to change, e.g. an established addictive behaviour such as smoking (21).

At present, few, if any, tobacco use prevention studies with adolescents have explicitly attempted to alter smoking-related oral health attitude or to establish a link between oral health attitude change and smoking behaviour change. Our results suggest that it may be useful to do so. Such efforts to change the cognition about the impact of the negative oral health consequences of smoking on social interaction should not only be age and culturally responsive with regards message content and emotional tone (22), but should also be designed in a manner that it may not be construed as a scare tactics, as this may interfere with precautionary motivation (23). 
A major limitation of this study is its reliance on adolescents' self-report of tobacco use. An objective measure of tobacco use status was not done due to logistical and financial constraints. However, as this was part of a study measuring oral health status, participants were told that subsequent oral examinations carried out would be able to confirm smoking status. This thus served as a 'bogus' pipeline procedure, which has been shown to improve reliability of self-reports of substance use among adolescents (24). Furthermore, several studies have suggested that adolescent self-report of tobacco use is generally reliable and valid (25). Another important limitation of the current study is that due to a relatively small sample size (relatively low smoking rates), only a limited set of variables have been assessed that focused on smoking consequences. Nevertheless, other variables of established theoretical relevance to the onset of smoking were included in the current analysis. It is however pertinent to note that some concerns related to the conceptual interpretation of the multiplicative composite of belief*value had been expressed in the literature (11). For example, a highly likely but little valued outcomes $(5 \times 1=5)$ would be represented as equivalent to highly unlikely but highly valued ones $(1 \times 5=5)$ and, it can be argued that this need not necessarily be a valid equivalence in the real world. Considering that this problem of interpretation would be most apparent at the extreme ends of the scales, and given that our analysis showed that $<20 \%$ of our study respondents (data not displayed) were anchored at these extreme ends of the scale, we do not think this would have any significant influence on the interpretation of the results obtained in the current study. Lastly, because the study sample was primarily a nonrandom sample of school-going black African adolescents and, because some significant behavioural differences between those followed-up and those lost to follow-up were found, the results obtained may not be generalisable to all other adolescent populations.

Despite these limitations, this study represents the first attempt to provide information on the longitudinal association of adolescents' attitude to oral health and smoking onset. Although, further studies are indicated, this study's findings have the potential to inform the development of more effective smoking prevention programmes. In particular, the findings support the integration of oral health promotion initiatives with adolescent tobacco use prevention programmes.

\section{Conclusions}

The study findings suggest that teaching adolescents about the negative oral health consequences of smoking alone may not be enough to prevent them from smoking. Preventive efforts, in addition to enhancing skills to resist peer influence, should also create opportunities to positively change adolescents' cognitions about the impact of the negative oral health consequences of smoking on social interaction.

\section{Acknowledgements}

This study was funded from a grant received from the University of Pretoria's Research Development Programme (RDP). The authors also acknowledge statistical support received from the University of Pretoria's statistics department. 


\section{References}

1. Swart D, Reddy P, Panday S, Philip J, Naidoo N, Ngobeni N. The 2002 Global Youth Tobacco Survey (GYTS): The $2^{\text {nd }}$ GYTS in South Africa - A comparison between GYTS (SA) 1999 and GYTS (SA) 2002. Cape Town: South African Medical Research Council, 2004.

2. Brook JS, Morojele NK, Brook DW, Zhang C, Whiteman M. Personal, interpersonal, and cultural predictors of stages of cigarette smoking among adolescents in Johannesburg, South Africa. Tob control 2006; 15: 48-53.

3. Panday S, Reddy PS, Ruiter RAC, Bergström E, De Vries H. Determinants of smoking among adolescents in the Southern Cape-Karoo region, South Africa. Health Promot Int 2007; 22: 207-17.

4. Bandura A. Self-efficacy: Towards a unifying theory of behavioural change. Psychol Rev 1977; 84: 191-215.

5. Tyas SL, Pederson LL. Psychological factors related to adolescent smoking: A critical review of the literature. Tob Control 1998; 7: 409-20.

6. Bandura A. Social foundations of thoughts and action. Englewood Cliffs, NJ: Prentice Hall 1986.

7. Brandon $\mathrm{TH}$, Herzog TA, Irvin JE, Gwaltney CJ. Cognitive and social learning models of drug dependence: Implications for the assessment of tobacco dependence in adolescents. Addiction 2004; 99: 51-77.

8. Tolman EC. Purposive behaviour in animals and men. Oxford England: Appleton-Century 1932.

9. Goldman MS. Expectancy and risk for alcoholism: The unfortunate exploitation of a fundamental characteristic of neuro-behavioural adaptation. Alcohol Clin Exp Res 2002; 26: 737-746.

10. Ajzen I. Nature and Operation of Attitudes. Annu Rev Psychol 2001; 52: 27-58.

11. Jones BT, McMahon J. A comparison of positive and negative alcohol expectancy and value and their multiplicative composite as predictors of post-treatment abstinence survivorship. Addiction 1996; 91: 89-99.

12. Lewis-Esquerre J, Rodrigue JR, Kahler CW. Development and validation of an adolescent smoking consequences questionnaire. Nicotine Tob Res 2005: 7: 81-90.

13. Reig-Ferrer A, Cepeda-Benito A. Smoking expectancies in smokers and never smokers: an examination of smoking consequences questionnaire - Spanish. Addict Behav 2007; 32: 1405-15.

14. Glynn T. Essential elements of school-based smoking prevention programs. J Sch Health 1989; 59: $181-87$.

15. Dalton MA, Sargent JD, Beach ML, Bernhardt AM, Stevens M. Positive and negative outcome expectations of smoking: Implications for prevention. Prev Med 1999; 29: 460-65. 
16. Podshadley AG, Haley J. A method for evaluating oral hygiene performance. Pub Health Rep 1968; 83: 259.

17. Stewart JE, Strack S, Graves P. Development of oral hygiene self-efficacy and outcome expectancy questionnaires. Community Dent Oral Epidemiol 1997; 25: 337-42.

18. Chassin L, Presson CC, Sherman SJ, Edwards DA. Four pathways to young-adult smoking status: Adolescent social-psychological antecedents in a Midwestern community sample. Health Psychol 1991; 10: 409-18.

19. Unger JB, Rohrbach LA, Howard-Pitney B, Ritt-Olson A, Mouttapa M. Peer influence and susceptibility to smoking among Californian adolescents. Subst Use Misuse 2001; 36: 551-71.

20. De Vries H, Mudde A, Leijs I, Charlton A, Vartiainen E, Buijs G, et al. The European Smoking Prevention Framework Approach (EFSA): an example of integral prevention. Health Educ Res 2003; 18: 611-26.

21. Stretcher VJ, Mc Evoy B, Becker MH, Rosenstock IM. The role of self-efficacy in achieving health behaviour change. Health Educ Q 1986; 13: 73-91.

22. Biener $L, J i M$, Gilpin $E A$, Albers $A B$. The impact of emotional tone, message, and broadcast parameters in youth anti-smoking advertisements. J Health Commun 2004; 9: 259-74.

23. Ruiter RAC, Abraham C, Kok G. Scary warnings and rational precautions: a review of the psychology of fear appeals. Psychol Health 2001; 16: 613-30.

24. Murray DM, Perry CL. The measurement of substance use among adolescents: when is the 'bogus pipeline' method needed? Addict Behav 1987; 12: 225-33.

25. Dolcini MM, Adler NE, Lee P, Bauman KE. An assessment of the validity of adolescent selfreported smoking using three biological indicators. Nicotine Tob Res 2003; 5: 478-83. 
Part 3:

Evaluating an Integrated Social SkillsBased Educational Intervention 


\section{Chapter 6:}

\section{Oral Health Promotion Integrated with Smoking Prevention: Outcomes from a Randomized Controlled Trial}

Submitted as: Ayo-Yusuf OA, Reddy PS, van den Borne BW. Life skills training for adolescents' oral health promotion and smoking prevention: a cluster-randomized controlled trial. Journal of Adolescent Health. 


\section{Abstract}

Objective: Only limited information is available on the effectiveness of general health promotion strategies that incorporates oral health education. This randomised-controlled trial sought to evaluate the impact of a life skills training (LST) for smoking prevention on adolescents' oral health.

Methods: This study was conducted among 21 schools in rural Limpopo province, South Africa (age 12-19 years; $n=2,119$ ). The 10 intervention schools received an adapted South African version of the US LST curriculum beginning in Grade 8 and continuing through Grade 9 (booster dose), while the 11 control schools received the standard curriculum. The intervention focused on building general and tobacco-use specific life skills including, decision-making, stress management, and resisting peer pressure to smoke. The programme in particular made prominent the effect of bad breath on social interaction, especially as it relates to adolescents' romantic aspirations. To evaluate programme's effect, a self-administered questionnaire was used to assess oral health and tobacco use outcome measures at baseline (T1), 12-month (T2) and 18-month (T3). The programme's effects were analysed using multilevel random coefficients models.

Results: Compared to control schools, the intervention schools demonstrated a $14 \%$ relative reduction in smoking prevalence over time, but the impact of the programme on smoking reduction was not statistically significant $(O R=0.88 ; p=0.26)$. However, compared to control schools, the adolescents in the intervention schools were significantly more likely to report daily brushing $(O R=1.64 ; p<0.001)$ and experienced less frequent gum bleeding $(\mathrm{OR}=0.84 ; \mathrm{p}=0.01)$. Furthermore, the adolescents in the intervention schools demonstrated a significantly more favourable oral health attitude and cigarette-offer refusal self-efficacy at T3.

Conclusions: LST did not have a statistically significant effect on preventing smoking among adolescents, but it was significantly very effective in promoting their oral health. 


\section{Introduction}

Oral health contributes to overall quality of life, self-esteem and confidence in social interaction. The growing evidence of the association between poor oral health and systemic health (Joshipura, Ritchie \& Douglas, 2000; Ayo-Yusuf \& Ayo-Yusuf, 2008), has provided additional impetus for developing effective oral health promotion programmes. The determinants of oral diseases are known - they are the risk factors common to a number of chronic diseases, namely poor diet and inadequate hygiene, smoking, alcohol, and stress (Sheiham \& Watt, 2000). Smoking, in addition to its long-term adverse effects on the respiratory and cardiovascular system, also affects the mouth in many ways; most typically through discoloration of the teeth and gums, bad breath and oral cancer. Informed by the evidence of common risk factors, and the reality of limited resources available for oral disease-focused prevention programmes, there are growing calls especially in resource-poor countries to integrate oral disease prevention programmes into strategies for promoting general health (Watt 2002; Sheiham \& Watt, 2000). Although the World Health Organisation (WHO) and national governments endorse this integrated strategy (Petersen, 2003), only limited evidence is available on the effectiveness of such strategies at a programmatic level.

In general, the limited contribution of oral health promotion intervention research to the development of oral health policy at a programmatic level has been related to the limited use of theoretical frameworks for the design and evaluation of these interventions (Brown, 1994; Kay \& Locker, 1996). Recent studies suggest that an integration of oral health promotion intervention with adolescent smoking prevention programmes holds promise (Kentala et al., 1999; Ayo-Yusuf et al., in press a; Ayo-Yusuf, Reddy \& van den Borne, in press $b$ ). Adolescent smoking behaviour has been related to adolescent selfconcept, in particular, physical self-concept (Thornton, Douglas \& Houghton, 1999). A significant association between smoking-related attitude to oral health and smoking onset among South African adolescents has also been recently demonstrated (Ayo-Yusuf et al., in press a). Adolescents who strongly believed that smoking negatively impacts on oral health (gum disease and bad breath) and highly rated the value of fresh breath for social interaction were less likely to take up smoking (Ayo-Yusuf et al., in press a). Similarly, adolescents who smoke have also been shown to be less likely to brush regularly (AyoYusuf et al., in press $b$ ). Given that the process leading to smoking begins with the formation of positive attitudes towards smoking, it seems reasonable, therefore, to assume that efforts directed at reinforcing adolescents' value for fresh breath may not only promote adolescents' oral self-care but may also prevent smoking onset.

Furthermore, considering that sense of coherence (SOC) - a measure of stress-coping ability - has been related to both smoking behaviour (Glanz, Maskarinec \& Carlin, 2005) and tooth brushing behaviour (Ayo-Yusuf et al., in press $b$ ), programmes that provide opportunities to develop social skills such as how to cope with stress may not only promote smoking abstinence, but may have additional influence on promoting regular tooth brushing and oral health. One such programme widely adopted in the US and found to be effective even after long-term follow-up periods, is the life skills training (LST) for 
substance use prevention (Botvin, Eng \& Williams, 1980; Botvin et al., 1990; Botvin et al., 1995). This programme grounded in the social learning theory (Bandura, 1986), in addition to teaching peer resistance skills, focuses mainly on short-term health consequences of smoking (stained teeth and bad breath) and includes additional components to enhance decision-making skills and, provides training in stress and anxiety management. This study therefore sought to evaluate the effect of a locally adapted LST curriculum for adolescents' tobacco use prevention and oral health promotion.

\section{Methods}

\section{The Intervention - An adapted Life Skills Training curriculum}

The LST curriculum being evaluated in this study was the US LST adapted for South African learners and the South African educational system by the South African Medical Research Council (MRC, 2007). Details of this adaptation have been previous described (Resnicow et al. in press). Briefly, prior to designing the LST curriculum lessons, a series of focus groups were conducted with learners ( $n=9$ groups) and teachers ( $n=7$ groups) from South African public schools, local curriculum writers familiar with school health education and the state requirements for health-related learner outcomes were employed to develop the final curriculum. A graphic artist was employed to design the curriculum and generate required photographic and line-drawn images. In addition, the original developers of the US LST served as consultants and co-writers to maximize conceptual integrity of the adapted LST intervention. However, the LST curriculum used in the current study was slightly modified further to make more prominent, issues regarding oral health promotion and to accommodate the fact that smokeless tobacco use is also particularly common in the Limpopo province (Swart et al., 2004).

The LST curriculum was designed to be taught by Life Orientation (LO) teachers. LO is a separate mandatory topic in South African schools similar to health education in the US that includes learner outcomes for health behaviors and social skills development. The LST curriculum comprised 8 units for each of grades 8 (12 lessons) and 9 ( 9 booster lessons). Most units contained more than one activity and therefore may have required more than one classroom session to complete. In both years learners were provided with individual workbooks and teachers were provided with an educator's manual. Content focused on building general and substance-use specific life skills including decision-making, stress management, affect management, assertive communication, and resisting peer pressure (Table 14). 


\section{Table 14: The structure of the LST intervention by grade level}

\begin{tabular}{lcc}
\hline LST Units & Number of lessons per grade level \\
\hline & $8^{\text {th }}$ grade & $9^{\text {th }}$ grade \\
Goal-setting/improving self-image & 2 & 1 \\
Decision-making & 2 & 1 \\
$\begin{array}{l}\text { Information on substance/tobacco ust } \\
\text { (including oral health effects) }\end{array}$ & 1 & 1 \\
Coping with stress & 1 & 1 \\
Preventing stress & 1 & 1 \\
Communicating and socialising & 2 & 1 \\
Assertiveness/conflict resolution & 1 & 2 \\
Resisting peer pressure to smoke & 2 & 1 \\
\hline
\end{tabular}

Where the information about consequences of smoking was included, short-term health and social consequences of tobacco use was the focus. Modification of the LST for the purpose of the current study included making more prominent the information on shortterm consequences and subsequent influence on social interaction, especially as it relates to the adolescents' romantic aspirations. In particular, we provided participants with worksheets in grade 8, to identify individually and then consider in a group discussion why oral hygiene care is an important part of socializing (part of the lesson unit Communicating and socializing skills). In grade 9, apart from a worksheet activity on setting a goal to improve their oral health (goal setting and decision-making skills), we further provided participants with a photographic illustration of a boy rejected by a girl because of his bad breath, subsequent to smoking to overcome shyness to talk to the same girl (Communicating and socializing). A section (bold text) then followed this on what one can do to avoid bad breath, namely avoid using tobacco and excessive drinking, brushing twice daily, eating lots of fruits and little sugary food and, visiting a dental clinic twice a year for check-up.

Although the primary language used was English, each lesson included optional adaptations for Sepedi-speaking youth, the main cultural groups of black African South Africans in the Limpopo province. Prior to implementing the curriculum, teachers participated in a three-day in-service training during which they learned about the theoretical underpinnings of the LST curriculum, practiced sample lessons, and planned their implementation schedule for the upcoming year.

\section{Curriculum implementation}

To maximize curriculum implementation each teacher was visited at least 3 times over the 2-year period. During these visits the teachers' implementation of the lesson was observed on several aspects namely explanation of the lessons, management of the lesson plan, management of the learners during the lesson, response by the learners to questions, and 
encouragement of discussion by the teacher amongst others. Teachers were given feedback about their classroom lesson and offered technical assistance where indicated.

\section{Study population and sampling}

\section{Study setting and sampling framework}

This school-based cluster-randomised controlled trial was conducted in the Limpopo province of South Africa between April 2005 and October 2006. Of the nine provinces in South Africa, the Limpopo province ( $90 \%$ rural) has the lowest human development index and has the highest proportion of black Africans (people of African descent) (Statistics South Africa, 2001). The Limpopo province with its population of 5.3 million is located along the northern border of South Africa. The province borders on three other African countries namely Mozambique, Botswana and Zimbabwe.

The sampling frame included all public high schools on an existing database provided to us by the provincial education department. Based on considerations of tobacco use prevalence of $15 \%$ and the expected intra-class cluster correlation of 0.01 at school level (Murray \& Short, 1997), it was determined that, 10 schools per condition were needed to detect an intervention effect of 5\%. However, 22 schools were approached for participation. The eligible schools were clustered at the level of school districts (geographically distant units) in an effort to reduce the probability of treatment contamination that might result from close proximity between the control and the intervention schools. A two-stage sampling design was thus used to produce a provincially representative sample of $8^{\text {th }}$-graders. The first stage of sampling consisted of a random selection of 22 of the 31 school districts to participate (Figure 4). The school districts were selected with a probability proportional to the number of schools in the district. The second stage involved a random selection of one school from the cluster of high schools within each selected school district. The 22 public schools were then randomly assigned to one of two groups. Group 1 (control) schools $(n=11)$ received usual tobacco and substance use education, which involves little specific smoking prevention or oral health promotion programming. Group 2 (intervention) schools $(n=11)$ received the adapted South African version of the "Life Skills Training" curriculum beginning in Grade 8 and continuing through Grade 9 (booster dose). However, one school that was assigned to the intervention harm opted out of the study before the programme started, as the school did not have a life orientation teacher available to attend training or run the programme.

All the $8^{\text {th }}$-graders in the selected schools were eligible to participate in the study. Participation in the study required the participants' assent as well as written informed consent from the parents of the participants. The study received approval from the University of Pretoria's Ethics Committee.

\section{Outcome evaluation}

The principal outcomes for the current study were past-month smoking and tooth brushing frequency. These, as well as secondary outcome measures of cigarette-offer refusal self-efficacy, oral health attitude and gingival health were assessed with a self- 
report questionnaire adapted from prior studies conducted in South Africa (Ayo-Yusuf et al., in press $b \& c$ ). The oral health attitude was measured using a four item Likert-type scale $(a=0.55)$, with response options scored from -2 to +2 and total score ranging from -8 (most negative attitude) to +8 (most positive attitude) (Table 15). We used the cigarette-offer refusal self-efficacy measure as a proxy for smoking susceptibility. This was measured using one-item question that have been used in past national tobacco survey in South Africa (Swart et al, 2004). The respondents were asked the questions: "If one of your best friends were to offer you a cigarette, would you smoke it?" Response options included 'definitely will' (coded 1), 'probably will' (coded 2), 'probably will not' (coded 3), and 'definitely will not' (coded 4). However, because the frequency distribution of the scores obtained was highly skewed, we dichotomized this variable. Adolescents were considered to have a weak refusal self-efficacy and thus susceptible to smoking if they answered anything except "definitely will not".

The secondary outcome of the current study also included an objective measure of improved plaque control using the patient hygiene performance index as previously described (Maraj \& Kroon, 2004), with higher plaque score representing poorer oral hygiene (see Chapter 1 ).

Table 15: Four-item oral health attitude scale

\section{Scale Items}

Scored from -2 to +2 (strongly disagree to strongly agree)

1. Bad breath could make me socially unacceptable among my friends

\section{Oral Health Attitude}

$(a=0.55)$
2. I keep my teeth and mouth as clean and healthy as they can be

3. Brushing my teeth twice daily removes plaque and prevents gum bleeding

4. Smoking can cause plaque on my teeth and the mouth to smell bad even if I brush daily

For all the three waves of survey, the questionnaires were administered in the classroom by trained research assistants. Teachers were asked to vacate the room during the questionnaire administration. All participating learners were also invited for oral examination using protocols previously described (Ayo-Yusuf, Reddy \& Van den Borne, in press $c$ ). All six trained examiners who conducted the oral screening between one and six weeks after questionnaire surveys were completed, were blinded to the completed questionnaires and the participants' group assignment. The inter-examiner agreement on plaque scoring during training and calibration was consider good with the Kappa coefficient ranging between 072 and 0.88 . No repeat examinations were conducted during fieldwork to determine intra-examiner variability, as this was not feasible considering that plaque deposit is likely to be altered with repeated tooth staining with the disclosing agents. Each participant was provided with a toothbrush and toothpaste after his/her oral 
examination. Each learner was assigned a confidential identifying number that was prewritten on their questionnaire.

\section{Programme exposure}

To assess teacher implementation of the LST classroom curriculum, 10 randomly selected learner workbooks from each school were examined. The worksheets in the workbooks were audited for completion rates over the intervention period. To assess exposure to teachings on tobacco and oral health, all learners including those in the control group were asked at baseline and post-intervention the question: "During this school year were you taught in any of your classes that smoking makes your teeth yellow, causes skin to wrinkle or makes you smell bad?" Those who responded in affirmative were categorized as having been exposed to this key component of the programme.

\section{Analytic Model}

\section{Assessment schedule}

Learners completed questionnaires on three occasions: 1) Baseline in beginning of $8^{\text {th }}$ grade, 2) Posttest 1 at the beginning of $9^{\text {th }}$ grade, and, 3) Posttest 2 at the end of $9^{\text {th }}$ grade. For the two post-test assessments only individuals who were in the school at the beginning of grade 8 and who completed the baseline evaluation were assessed.

The primary statistical approach to examine intervention effects, accounting for the design effect of randomizing schools rather than individuals to treatments, was the random coefficient model. This included fitting generalized estimating equation (GEE) models according to the 'xtgee' procedure in Stata version 8.2 (Stata Corporation, College Station, Texas, USA) for the outcome variables with logit link function for binary data and identity link function for the continuous variables, and an 'unstructured' within-cluster correlation structure was specified (as the assessment intervals were not equal). 


\section{Figure 4: Flow diagram of recruitment of study participants (consort figure)}

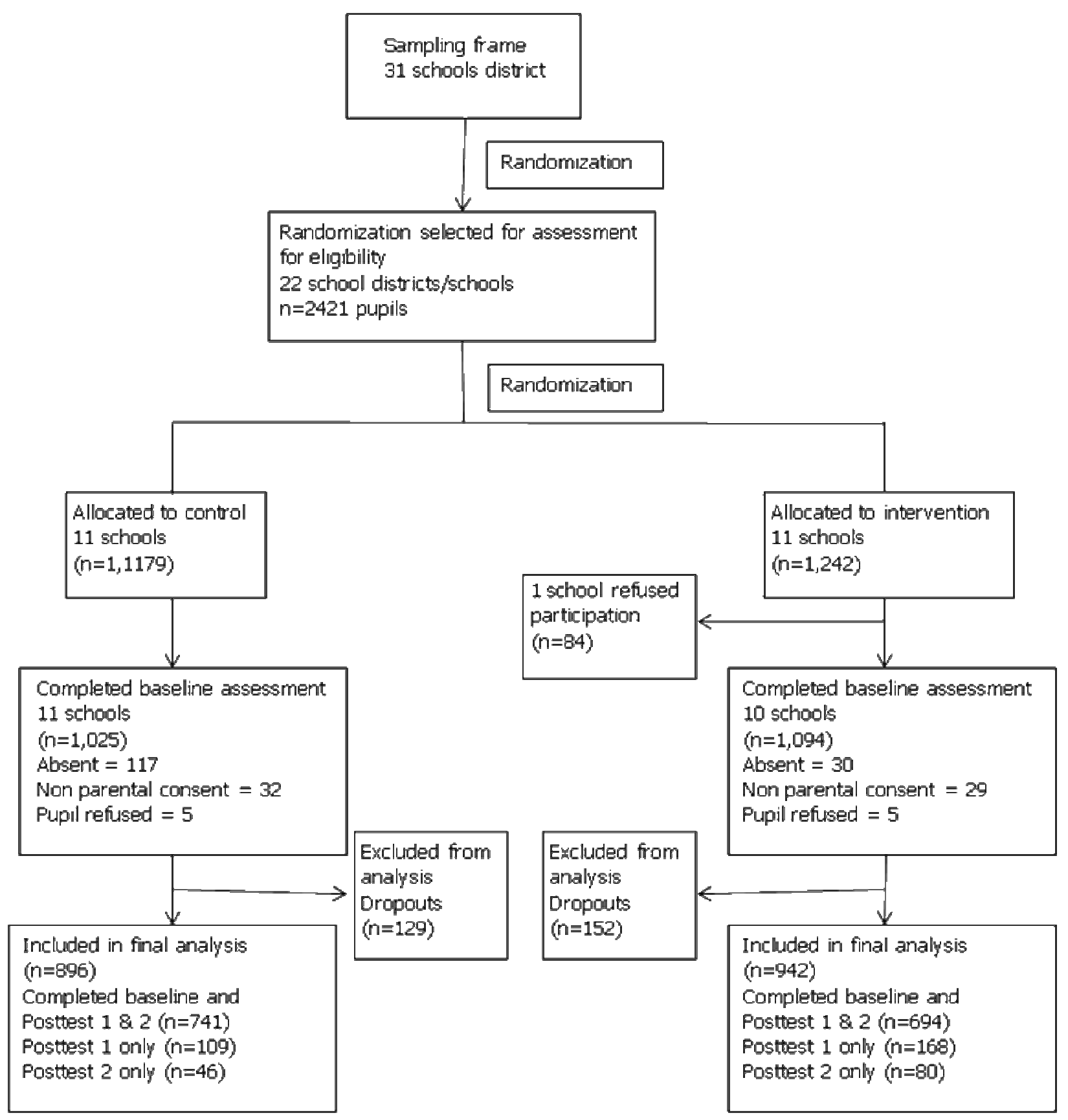

The model nested learners within schools within treatment condition. The model included values at three time points; baseline, post-test 1 , and post-test 2 .

All available data at all time points were used in the analyses. However, the analysis of the clinical outcome was confined to only children who consented to oral examination at baseline $(n=1932)$ and were also available for oral examination at final follow-up $(n=1117)$. Due to unforeseen logistical constraints there was no oral examination conducted at the second wave of the questionnaire survey. All outcome analyses, a priori examined potential moderating effects of gender. In addition, because smoking is also 
particularly common among snuff users (Haukkala et al., 2006), we also explored moderating effects of past month snuff use at baseline on smoking outcome.

\section{Results}

\section{Sample description}

A total of 2,119 learners completed the baseline survey. Based on the school rosters provided there were 2,337 eligible learners, which equates to a response rate of $91 \%$. Of these, $1,838(87 \%)$ completed at least one of the two post-test assessments. Drop-outs, defined as learners with baseline data but no data at either follow-up, were not significantly different from cohort members (baseline and at least one follow-up), for any of the outcome variables (Table 16). Except that drop outs were significantly more likely to have been those 15 years and older at baseline, there was no evidence of differential attrition. However, although at baseline the control group and experimental group did not differ on primary outcomes on smoking and brushing, the intervention group had a better oral health attitude, had less black African learners, had more smoking susceptible students and were slightly older as compared to the control group. All analysis thus took account of these baseline group differences.

Intra-class correlation (ICC) in the study ranged from 0.02 (twice daily brushing) to 0.18 (oral health attitude). The actual ICC for past-month smoking (0.04) was higher than anticipated (0.01). All analyses were however adjusted for these cluster effects.

Table 16: Sample Description: Cohort and drop-outs by group assignment

\begin{tabular}{ccccccc}
\hline & \multicolumn{3}{c}{ Cohort } & \multicolumn{3}{c}{ ^Drop out } \\
\hline & Control & LST & Total & Control & LST & Total \\
& $(\mathrm{n}=896)$ & $(\mathrm{n}=942)$ & $(\mathrm{n}=1,838)$ & $(\mathrm{n}=129)$ & $(\mathrm{n}=152)$ & $(\mathrm{n}=281)$ \\
Gender (\%male) & 47.8 & 51.9 & 49.9 & 48.4 & 52.0 & 50.4 \\
Age mean ( $\pm \mathrm{sd}){ }^{\dagger}$ & 14.4 & $14.7(1.6)$ & $14.6(1.6)^{*}$ & $14.7(1.9)$ & $15.2(1.9)$ & $15.0(1.6)^{*}$ \\
& $(1.5)$ & & & & & \\
\% Black Africans & 94.8 & 85.0 & $89.8^{*}$ & 92.9 & 84.2 & $88.2^{*}$ \\
30-day smoking & 13.7 & 14.4 & 14.1 & 12.2 & 15.2 & 13.9 \\
30-day snuff use & 12.5 & 10.1 & 11.3 & 9.8 & 15.3 & 12.8 \\
Daily brushing & 81.5 & 82.5 & 82.0 & 88.2 & 81.9 & 84.2 \\
Brushing twice/day & 27.6 & 29.5 & 28.3 & 29.1 & 31.6 & 30.5 \\
Refusal self-efficacy & 93.5 & 88.9 & $91.2 *$ & 91.7 & 90.6 & 91.1 \\
Bleeding gums & 36.9 & 32.2 & 34.5 & 34.6 & 35.8 & 35.3 \\
OH attitude mean & 2.73 & 3.07 & $2.89 *$ & 2.86 & 3.05 & 2.96 \\
(range -8 to +8) & $( \pm 3.17)$ & $( \pm 2.91)$ & $( \pm 3.05)$ & $( \pm 3.48)$ & $( \pm 2.87)$ & $( \pm 3.16)$ \\
Mean plaque score & 2.83 & 2.72 & $2.77^{*}$ & 2.81 & 2.72 & 2.77 \\
(range 0 to 5) & $( \pm 0.70)$ & $( \pm 0.95)$ & $( \pm 0.87)$ & $( \pm 0.70)$ & $( \pm 0.90)$ & $( \pm 0.80)$ \\
\hline
\end{tabular}

*Differences exist between assigned groups at $p<0.05$.

${ }^{\dagger}$ Differences exist between cohort total and dropout total at $p<0.05$.

^Dropouts defined as having baseline but neither post-test 1 nor post-test 2

${ }^{9}$ Cigarette-refusal self-efficacy among baseline cohort non-smokers $(n=1,565)$. 


\section{0-day smoking}

Considering the entire sample, 30-day cigarette use in the control group at baseline, 12month follow-up and 18-month follow-ups was $13.7 \%, 11.2 \%$, and $12.2 \%$, respectively. The corresponding rates in the LST group were $14.4 \%, 11.3 \%$, and $11.2 \%$ (Table 17). The net percentage change from baseline to 18-month follow-up in the control group was $-1.5 \%$ compared to $-3.2 \%$ in the LST schools. This represents a $13.9 \%$ relative reduction in smoking prevalence in intervention schools compared to control schools $(3.2 \%-1.5 \%$ / $12.2 \%)$. The treatment $X$ time interaction however, was not statistically significant $(\mathrm{OR}=0.88 ; 0.72-1.09)$. Restricting the sample to baseline nonsmokers yielded a similar pattern of results.

Table 17: Primary outcomes at baseline and follow-up by assigned groups

\begin{tabular}{|c|c|c|c|c|c|c|}
\hline & \multicolumn{3}{|c|}{ Control } & \multicolumn{3}{|c|}{ Life skills intervention } \\
\hline & $\begin{array}{c}\text { Baseline } \\
\quad(n= \\
1025)\end{array}$ & $\begin{array}{l}\text { 12-months } \\
(n=850)\end{array}$ & $\begin{array}{c}\text { 18-months } \\
(n=787)\end{array}$ & $\begin{array}{c}\text { Baseline } \\
(\mathrm{n}=1094)\end{array}$ & $\begin{array}{l}\text { 12-months } \\
(n=862)\end{array}$ & $\begin{array}{l}\text { 18-months } \\
(n=774)\end{array}$ \\
\hline 30-day smoking ${ }^{\dagger \dagger}$ & & & & & \multicolumn{2}{|c|}{$\mathrm{OR}=0.88(0.72-1.09)$} \\
\hline Males & 18.5 & 15.0 & 17.3 & 17.4 & 13.5 & 12.8 \\
\hline Females & 9.3 & 8.0 & 7.5 & 11.1 & 9.1 & 9.3 \\
\hline Non-snuff users & 7.6 & 9.9 & 10.7 & 9.4 & 10.6 & 10.1 \\
\hline Snuff users & 55.8 & 21.5 & 22.9 & 55.3 & 20.0 & 21.1 \\
\hline Total $(p=0.26)$ & 13.7 & 11.2 & 12.2 & 14.4 & 11.3 & 11.2 \\
\hline Daily brushing $*^{\dagger}$ & & & & & \multicolumn{2}{|c|}{$\mathrm{OR}=1.64(1.38-1.95)$} \\
\hline Males & 82.8 & 72.7 & 67.5 & 81.1 & 74.3 & 83.5 \\
\hline Females & 81.9 & 80.4 & 71.8 & 83.6 & 85.1 & 88.7 \\
\hline Total $(p<0.001)$ & 82.3 & 76.7 & 69.8 & 82.3 & 79.6 & 86.0 \\
\hline $\begin{array}{c}\text { Brushing } \\
\text { twice/day* } *^{\dagger}\end{array}$ & & & & & \multicolumn{2}{|c|}{$\mathrm{OR}=1.24(1.06-1.45)$} \\
\hline Males & 27.0 & 19.7 & 15.2 & 27.5 & 23.9 & 24.3 \\
\hline Females & 28.0 & 23.2 & 18.8 & 31.9 & 24.9 & 28.9 \\
\hline Total $(p=0.01)$ & 27.6 & 21.6 & 17.0 & 29.5 & 24.5 & 26.1 \\
\hline
\end{tabular}

\section{Tooth brushing}

Past month daily tooth brushing decreased by $12.5 \%$ (net change) in control schools, compared to an increase of $3.7 \%$ in the LST schools. Even after controlling for group differences in ethnicity and age at baseline, the treatment $X$ time interaction, remained statistically significant $(p<0.001)$. Considering the entire sample, the absolute change in 
twice daily tooth brushing from baseline to 18-month follow-up in the control group was $10.6 \%$ (38.4\% reduction) compared to $-3.4 \%$ ( $11.5 \%$ reduction) in the LST schools, a $70 \%$ less reduction in twice daily brushing. Even after controlling for group differences in ethnicity and age at baseline, the treatment $X$ time interaction, remained statistically significant in favour of LST schools $(p=0.01)$.

\section{Treatment moderators}

The treatment $X$ time $X$ gender interaction was not significant for past-month smoking ( $p$ $=0.32$ ). Treatment $X$ time $X$ baseline snuff use interaction was significant for past-month smoking ( $O R=0.50 ; 0.37-0.69)$, but the treatment group differences within snuff user categories were, however, not statistically significant. The treatment $X$ time $X$ gender interaction was significant for daily tooth brushing $(p<0.01)$. As illustrated in Figure 5 , with regards daily tooth brushing outcome, over time, the LST intervention had a greater impact on female learners $(\mathrm{OR}=1.74 ; 1.34-2.26)$ than on male learners $(\mathrm{OR}=1.59 ; 1.25$ 2.03).

Figure 5: Daily brushing prevalence by treatment group and gender

\section{A. Male Participants}

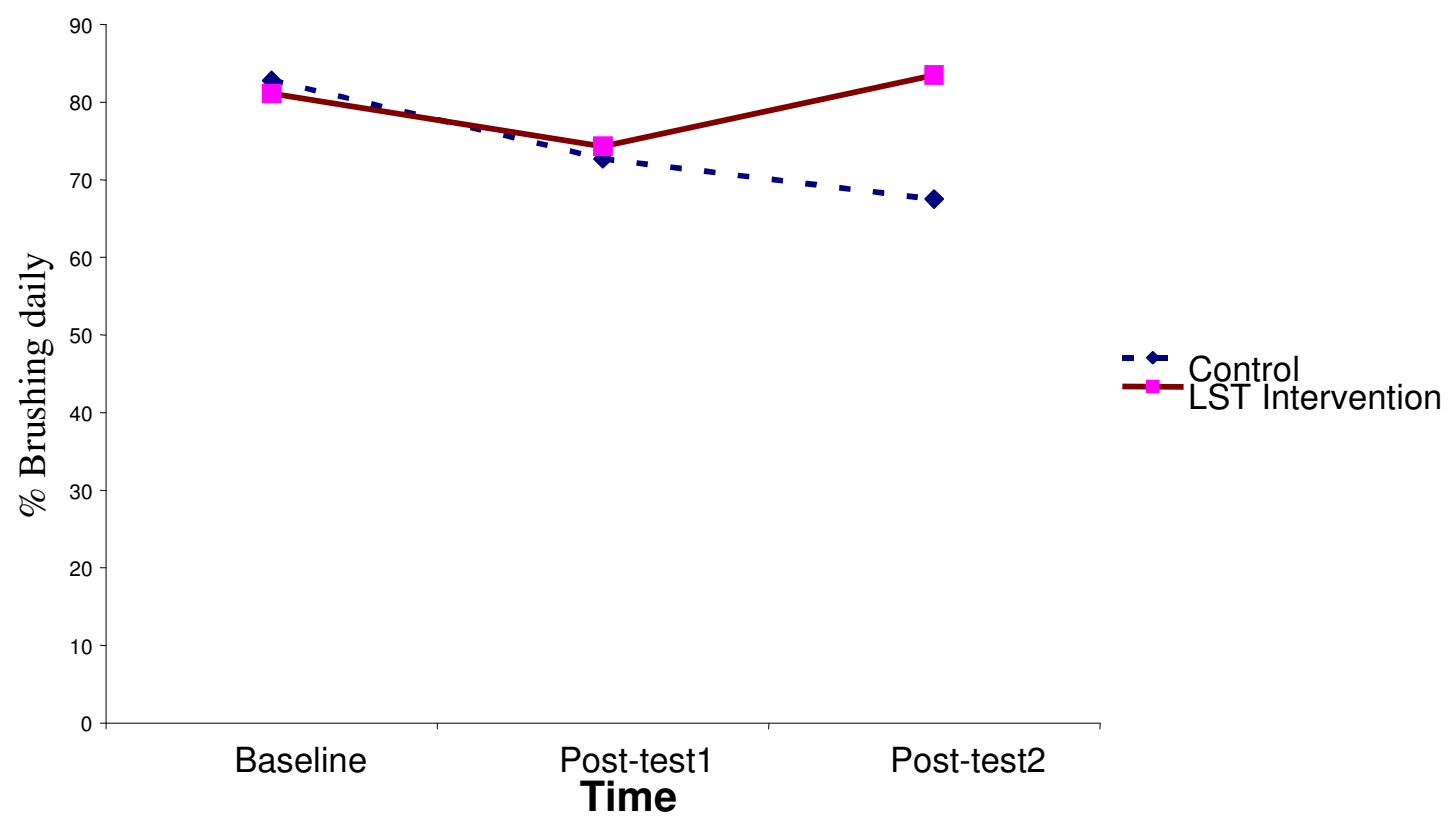




\section{B. Female participants}

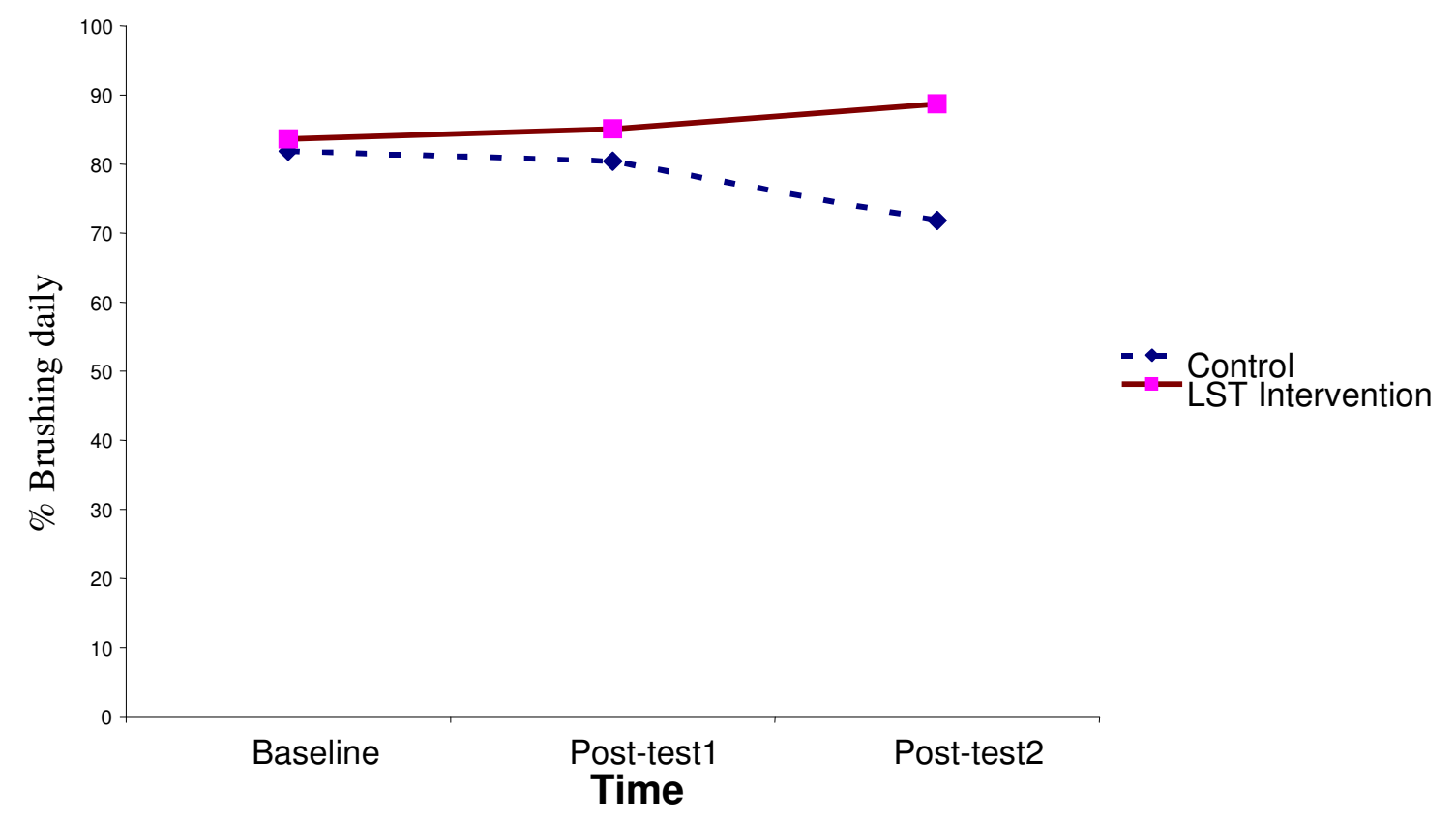

\section{Secondary outcomes}

As shown in Table 18, considering male and female nonsmokers at baseline together, refusal self-efficacy reduced $2.7 \%$ in the control condition compared to an increase of $1.7 \%$ in the LST group $(p<0.05)$. A similar pattern of results was observed when the sample was not restricted to only baseline nonsmokers. Sensitivity analysis also showed that similar results were observed when the self-efficacy measure was used as a continuous variable.

Frequent bleeding gums increased $8 \%$ in control schools compared to $0.1 \%$ in the LST schools. The schools that received the intervention significantly reported less frequent bleeding gums when compared to the control schools (Table 18). 
Table 18: Secondary outcomes at baseline and follow-up by assigned group and gender

\begin{tabular}{|c|c|c|c|c|c|c|}
\hline & \multicolumn{3}{|c|}{ Control } & \multicolumn{3}{|c|}{ Life skills intervention } \\
\hline & $\begin{array}{l}\text { Baseline } \\
(n=1025)\end{array}$ & $\begin{array}{l}\text { 12-months } \\
(n=850)\end{array}$ & $\begin{array}{l}\text { 18-months } \\
(n=787)\end{array}$ & $\begin{array}{l}\text { Baseline } \\
(n=1094)\end{array}$ & $\begin{array}{l}\text { 12-months } \\
(n=862)\end{array}$ & $\begin{array}{l}\text { 18-months } \\
(n=774)\end{array}$ \\
\hline $\begin{array}{l}\text { Refusal self- } \\
\text { efficacy }^{\uparrow} *\end{array}$ & & & & & \multicolumn{2}{|c|}{$\mathrm{OR}=1.34(1.04-1.72)$} \\
\hline Males & 93.0 & 89.4 & 89.3 & 90.8 & 89.6 & 91.3 \\
\hline Females & 94.2 & 93.6 & 92.2 & 86.9 & 92.6 & 89.6 \\
\hline Total $(p=0.02)$ & 93.5 & 91.8 & 90.8 & 88.9 & 91.1 & 90.6 \\
\hline Bleeding gums* & & & & & \multicolumn{2}{|c|}{$\mathrm{OR}=0.84(0.73-0.96)$} \\
\hline Males & 40.3 & 49.9 & 44.2 & 31.4 & 41.4 & 34.0 \\
\hline Females & 33.3 & 44.5 & 45.2 & 34.0 & 40.7 & 31.6 \\
\hline Total $(p=0.01)$ & 36.6 & 46.9 & 44.6 & 32.7 & 41.2 & 32.8 \\
\hline $\begin{array}{l}\text { Oral health } \\
\text { attitude }^{\dagger} *\end{array}$ & & & & & \multicolumn{2}{|c|}{$\mathrm{OR}=1.59(1.30-1.93)$} \\
\hline Males & 2.60 & 2.06 & 1.96 & 2.95 & 2.80 & 3.02 \\
\hline Females & 2.85 & 2.15 & 1.98 & 3.20 & 3.31 & 3.46 \\
\hline Total $(p<0.001)$ & $2.73( \pm 3.21)$ & $2.11( \pm 3.06)$ & $1.98( \pm 3.10)$ & $3.07( \pm 2.90)$ & $3.05( \pm 3.12)$ & $3.23( \pm 3.35)$ \\
\hline $\begin{array}{l}\text { Mean Plaque } \\
\text { score* }\end{array}$ & & & & & \multicolumn{2}{|c|}{$\mathrm{OR}=0.87(0.78-0.96)$} \\
\hline Males & 2.84 & - & 3.33 & 2.75 & - & 3.06 \\
\hline Females & 2.81 & - & 3.26 & 2.68 & - & 3.04 \\
\hline Total $(p=0.02)$ & $\begin{array}{c}2.83 \\
( \pm 0.70)\end{array}$ & & $\begin{array}{c}3.29 \\
( \pm 0.70)\end{array}$ & $\begin{array}{c}2.72 \\
( \pm 0.95)\end{array}$ & & $\begin{array}{c}3.05 \\
( \pm 0.71)\end{array}$ \\
\hline
\end{tabular}

*Time $\mathrm{X}$ treatment interaction was significant at $\mathrm{p}<0.05$.

${ }^{\dagger}$ Time $X$ treatment $X$ gender interaction was significant at $p<0.05$; in favour of females.

"Among baseline non-smokers.

Finally, both oral health attitude and plaque score were less favourable in control schools compared to the LST schools after 18-months, even after controlling for baseline differences in oral health attitude. All of these between-group differences were statistically significant at $p<0.05$ (Table 18). However, over time, plaque score increased in both the control $(+0.46)$ and intervention schools $(+0.33)$, but the intervention schools showed a $28 \%$ (or $0.13 / 0.46$ ) less increase when compared to the learners in the intervention schools.

We also explored gender interactions for the secondary outcomes. For all, but oral health attitude, gender was not a significant treatment moderator. For oral health attitude, 
subsequent stratified analysis demonstrated that the interaction effect was driven by a more positive change in oral health attitude among females in schools receiving the LST intervention as compared to the females in the control schools.

At baseline, there was no significant difference in the proportion of learners who reported to have had a lesson on the influence of tobacco use on oral health in the year passed when intervention schools were compared with controls ( $46.3 \%$ vs. $55 \%$; $p=0.43$ ). However, at post-test 2, those in the intervention were significantly more likely to report having been thought effects of tobacco use on oral health $(69.3 \%$ vs. $27.1 ; p<0.001)$, with no gender predilection. The audit of workbooks used in the intervention schools showed an average completion rate of $61 \%$. There was however no evidence of a doseeffect on the study outcomes.

\section{Discussion}

This study demonstrated that the smoking prevention programme that promoted the value of fresh breath on confidence in social interaction, while achieving a statistically significant effect on promoting adolescent oral health, also produced a reduction in smoking, albeit did not reach statistical significance. Furthermore, consistent with the literature on the potential for snuff use to serve as a gateway for future smoking (Severson, Forrester \& Biglan, 2007), the current study also suggested that the programme tended to be more effective in reducing smoking prevalence among schools whose learners had not initiated regular snuff use as at the start of the programme.

Considering the higher than expected ICC observed for smoking in this study, the lack of statistically valid significant reductions observed with smoking behaviour in this study may be due to the lower power to detect a difference at this level (Type II error). Nonetheless, the lack of significant impact on smoking may also be a reflection of the inherent challenge of multiple risk behaviour interventions, namely that individuals with multiple risk behaviours may be confused about the relative importance of each risk behaviour, or may feel overwhelmed by the sheer number of 'bad things' they need to improve (Strecher et al., 2002). The fact that the programme had a significant impact on oral health attitude and on smoking susceptibility, but not smoking behaviour may be attributable to lower self-efficacy observed among learners in the intervention schools as compared to those in control schools at baseline. It has been suggested that even when outcome expectations are strong, a person is unlikely to attempt to perform a behaviour when the self-efficacy for that behaviour is low (Bartholomew et al., 2006).

The lack of significant impact on smoking behaviour could also be attributable to a 'sleeper effect', such that change in oral health attitude may be the necessary step towards reducing smoking in future. It therefore remains to be determined if this would translate to tobacco use prevention in the longer-term. Notwithstanding the lack of statistical significance in smoking reduction observed, a 14\% relative reduction in smoking prevalence achieved by this multiple-risk behaviour intervention can be considered promising with regards public health significance, when taken together with a significant positive impact on the adolescents smoking susceptibility and oral health. This percentage reduction compares favourably with an average of $7 \%$ annual change in adolescent 
smoking prevalence reported in South Africa during the period 1999 - 2002 (Swart et al., 2004).

The greater impact of this programme on female tooth brushing may be related to the more prominence of physical self-concept in the current LST programme and, the higher correlation between self-concept and brushing previously reported for females when compared to males (Macgregor, Regis \& Balding, 1997). The gender differences in tooth brushing and oral health attitude change may be an expression of how boys and girls take advantage of learning situation in varying social context. Lastly, the gender differences observed could be related to observed gender differences in smoking susceptibility. Even though these differences were controlled for in our analysis, it is pertinent to note that the females in the intervention schools were more susceptible at baseline to smoking uptake than their male counterparts or the females in the control schools. This may have increased their level of attention to the various components of the programme, although not enough to produce a statistically significant impact on smoking reduction.

Considering that the study realized only a $61 \%$ implementation rate, it is considerable that this program produced a significant effect on reducing smoking susceptibility in intervention schools and on both self-reported and objective measures of all oral health outcomes investigated. It is was however striking that regular brushing declined considerably in control schools, but tended to remain flat in intervention schools. The general decline in regular daily brushing and related increase in plaque accumulation, may be related to the fact that as adolescents get older they begin to participate in more social activities that may be considered more important than regular brushing e.g. attending parties or movies till late, increased stress and anxiety in association with social relationships. It is pertinent to note that research has suggested that lifestyle factors such as watching television till late and getting up from sleep late negatively influenced adolescent brushing frequency (Macgregor, Balding \& Regis, 1996). It was therefore not surprising that the schools that received this programme, which taught social skills such as decision-making and stress management and, affirmed adolescents' negative outcome expectation of the impact of poor oral health on confidence in social interaction, did not experience a decrease in regular brushing and oral hygiene performance to the extent observed with those in control schools. This was especially relevant considering that the learners in control schools reported dramatic reduction in exposure to lessons related to smoking and oral health in the second year of school as compared with the first year of school.

The effectiveness of this classroom delivered LST curriculum on oral health may be attributed to the fact that it used three important elements of interventions that have been demonstrated to achieve at least short-term positive changes in plaque and bleeding scores (Brown, 1994). These elements include the use of an appropriate educational media, use of multiple sessions and requiring learners' participation/active involvement (role play and feedbacks). The significant positive impact of including booster lessons in educational interventions was evident in the current study, as most of the programme's impact on study outcomes was more evident in the second year of implementation. This study has also shown that objective measures of oral health and self-reported behaviour 
changes can be achieved even in the long term with programmes that feature these important design elements in addition to a social cognitive/social learning theoretical grounding. In particular, the difference in oral hygiene levels achieved in schools that received this programme compared to those in the control after 18-months is comparable, and in some instances better than the difference in plaque levels previously attributed to educational programmes with an average of 6-month follow-up (Brown, 1994; Watt \& Marinho, 2005). A similar social cognitive approach has also been previously successfully applied to promote oral health among a European adolescent population (Redmond et al., 1999).

A major limitation of this study is its reliance on adolescents' self-reports of tobacco use and tooth brushing behaviour. However, the observed changes in reported brushing behaviour were confirmed by an objective measure of oral hygiene performance and significant reduction in self-reported bleeding gums. Self-reported bleeding gum has indeed been shown to be valid in monitoring adolescent gingival health (Kallio \& Murtomaa, 1997; Taani \& Alhaija, 2003). Furthermore, as this was part of a study measuring oral health status, participants were told that subsequent oral examinations carried out could confirm tobacco use status. This thus served as a 'bogus' pipeline procedure, which has been shown to improve reliability of self-reports of substance use among adolescents (Murray \& Perry, 1987). This notwithstanding, adolescent self-report of tobacco use is considered to be generally reliable and valid (Dolcini et al., 2003). Finally, because those who dropped out of the study were more likely to be older adolescents the results may be subject to selection bias and by implication the study findings may not be generalised to all adolescents, especially those older and out of school. Despite these limitations, this study represents one of the very first attempts to systematically evaluate and provide empirical evidence of the effectiveness of integrating oral health promotion with other health promotion intervention at a programmatic level.

This study finding, consistent with the Ottawa charter on health promotion, suggest a significant improvement in adolescents' oral health can be achieved through enhancing life skills. Despite the lack of statistical significance, the magnitude of the effect observed with smoking suggests that it may be useful to further investigate how the LST curriculum could be made more effective. While further studies are needed, the current study's findings suggest smokeless tobacco use may compromise smoking prevention among adolescents. The study findings also suggest that more detailed process analysis may be needed to identify implementation challenges in order to support efforts to make the programme effective for smoking prevention. It may be particularly useful to identify opportunities to collaborate with the community at large, especially to involve parents and families.

\section{Acknowledgements}

This study was supported by research grants received from the Medical Research Council, South Africa and the Cancer Association of South Africa (CANSA). The authors thank the dentists and oral hygienists from the Limpopo province's Department of Health who participated in the oral examination. The authors are also grateful to Max Petzold of the 
Nordic School of Public Health, Sweden, who provided invaluable advice on the sampling procedure. The authors are also particularly grateful to Tracy Nicol of the University of North Carolina, USA, for her invaluable advice on the adaptation of the LST curriculum. 


\section{References}

Ayo-Yusuf, O.A. and Ayo-Yusuf, I.J (2008). Association of tooth loss with hypertension. South African Medical Journal, 98: 381-385.

Ayo-Yusuf, O.A., Van den Borne, B.H., Reddy, P.S., Van Wyk, P.J. and Severson, H.H. Longitudinal association of smoking-related oral health attitude with adolescents' smoking onset. Journal of Public Health Dentistry (in press a).

Ayo-Yusuf, O.A., Reddy, P.S. and Van den Borne, B.W. Longitudinal association of adolescents' sense of coherence with tooth brushing using an integrated-behaviour change model. Community Dentistry \& Oral Epidemiology (in press b).

Ayo-Yusuf, O.A., Reddy, P.S. and Van den Borne, BW. Adolescents' sense of coherence and smoking as longitudinal predictors of self-reported gingivitis. Journal of Clinical Periodontology (in press c).

Bandura, A. (1986). Social foundations of thoughts and action. Englewood Cliffs, NJ: Prentice Hall.

Bartholomew, L.K., Parcel, G.S., Kok, G. and Gottlieb, N.H. (2006). Planning health promotion programs: an intervention mapping approach. $2^{\text {nd }}$ Edition. New York: John Wiley \& Sons.

Botvin, G.J., Baker, E., Dusenbury, L., Botvin, E.M. and Diaz, T. (1995). Long-term follow-up results of a randomised drug abuse prevention trial in a white middle-class population. Journal of the American Medical Association, 273: 1106-1112.

Botvin, G.J., Baker, E., Filazzola, A.D. and Botvin, E.M. (1990). A cognitive-behaviour approach to substance abuse prevention: One-year follow-up. Addictive Behaviors, 15, 47-63.

Botvin, G.J., Eng, A. and Williams, C.L. (1980). Preventing the onset of cigarette smoking through life skills training. Preventive Medicine, 9: 135-143.

Brown, L.F. (1994). Research in dental health education and health promotion: a review of the literature. Health Education Quarterly, 21: 83-102.

Dolcini, M.M., Adler, N.E., Lee, P. and Bauman, K.E. (2003). An assessment of the validity of adolescent self-reported smoking using three biological indicators. Nicotine \& Tobacco Research, 5: 478-83.

Glanz, K., Maskarinec, G. and Carlin, L. (2005). Ethnicity, sense of coherence, and tobacco use among adolescents. Annals of Behavioural Medicine; 29: 192-9.

Haukkala, A., Vartianen, E. and De Vries, H. (2006). Progression of oral snuff use among Finnish 13-16 year old students and its relation to smoking behaviour. Addition, 101: 581-89.

Joshipura, K., Ritchie, C. and Douglass C. (2000). Strength of evidence linking oral conditions and systemic disease. Compend Contin Educ Dent, 30 (Suppl): 12-23. 
Kallio, P. and Murtomaa, H. (1997). Determinants of self-assessed gingival health among adolescents. Acta Odontologica Scandinavica, 55, 106-110.

Kay, L. and Locker, D. (1996). Is dental health education effective? A systematic review of current evidence. Community Dentistry \& Oral Epidemiology, 24: 231-235.

Kentala, J., Utriainen, P., Pahkala, K. and Mattila, K. (1999). Can brief intervention through community dental care have an effect on adolescent smoking? Preventive Medicine, 29: 107111.

Macgregor, I.D.M., Regis, D. and Balding, J.W. (1997). Self-concept and dental health behaviours in adolescents. Journal of Clinical Periodontology, 24: 335-339.

Macgregor, I.D., Balding, J. and Regis, D. (1996). Tooth brushing schedule, motivation and 'lifestyle' behaviours in 7,770 young adolescents. Community Dental Health, 13: 232-237.

Maraj, E. and Kroon, J. (2004). The impact of a school dental service on the periodontal health and hygiene status of 6-year-old Sowetan learners. South African Dental Journal, 59: 374-6, 378.

Medical Research Council of South Africa (MRC). South African tobacco and substance use prevention school based study - the effectiveness of 2 curricula. URL: http://www.mrc.ac.za/healthpromotion/tobaccostudy.pdf (Accessed 11/12/2007).

Murray, D.M. and Perry, C.L. (1987). The measurement of substance use among adolescents: when is the 'bogus pipeline' method needed? Addictive Behaviors, 12, 225-33.

Murray, D.M. and Short, B.J. (1997). Intra-class correlation among measures related to tobacco use by adolescents: estimates, correlates, and applications in intervention studies. Addictive Behaviors, 22: 1-12.

Petersen, P.E. (2003). The world oral health report 2003: continuous improvement of oral health in the $21^{\text {st }}$ century - the approach of the WHO global oral health programme. Community Dentistry \& Oral Epidemiology, 31 (Suppl.1), 3-24.

Redmond, C.A., Blinkhorn, F.A, Kay, E.J., Davies, R.M., Worthington, H.V. and Blinkhorn, A.S. (1999). A cluster randomized controlled trial testing the effectiveness of a school-based dental health education program for adolescents. Journal of Public Health Dentistry, 59: 1217.

Resnicow, K., Reddy, P.S., James, S., Omardie, R.G., Kambaran, N.S., Langner, H.G. et al. Comparison of two school-based smoking prevention programs among South African high school students: results from a randomized trial. Annals of Behavioral Medicine (in press).

Severson, H.H., Forrester, K.K., and Biglan A. (2007). Use of smokeless tobacco is a risk factor for cigarette smoking. Nicotine \& Tobacco Research, 9: 1331-1337.

Sheiham, A. and Watt, R.G. (2000). The common risk factor approach: a rational basis for promoting oral health. Community Dentistry \& Oral Epidemiology, 28: 399-406. 
Statistics South Africa (2001). Census in brief. RSA Government printers. Pretoria

Strecher, V., Wang, C., Derry, H., Wildenhaus, K. and Johnson, C. (2002). Tailored interventions for multiple risk behaviours. Health Education Research, 17: 619-626.

Swart, D., Reddy, P., Panday, S., Phillip, J.L., Naidoo N. and Ngobeni, N. (2004). The 2002 Global Youth Tobacco Survey (GYTS): The $2^{\text {nd }}$ GYTS in South Africa - A comparison between GYTS (SA) 1999 and GYTS (SA) 2002. Cape Town: South African Medical Research Council.

Taani, D.Q. and Alhaija, E.S. (2003). Self-assessed bleeding as an indicator of gingival health among 12-14-year-old children. Journal of Oral Rehabilitation, 30: 78-81.

Thornton, W., Douglas, G.A. and Houghton, S.J. (1999). Transition through stages of smoking: the effect of gender and self-concept on adolescent smoking behavior. Journal of Adolescent Health, 25: 284-289

Watt, R.G. (2002). Emerging theories into the social determinants of health: implications for oral health promotion. Community Dentistry \& Oral Epidemiology, 30: 241-247.

Watt, R.G. and Marinho, V.C. (2005). Does oral health promotion improve oral hygiene and gingival health? Periodontal 2000, 37: 35-47. 


\section{General Discussion and Conclusions}




\section{General discussion and conclusions}

This dissertation reports on an investigation of the proposition that the integration of oral health promotion with smoking prevention would be an effective intervention in terms of its wider public health impact - namely the concurrent prevention of oral and systemic health-related risk behaviours. This proposition was partly supported by the findings from the studies reported in this dissertation. Smoking was indeed identified as a modifiable common-risk factor for poor oral health (Chapter 1) and for poor systemic health (Chapters 3 and 4). On the one hand, smoking was also associated with irregular tooth brushing behaviour (Chapter 4), and, on the other hand, oral health-related outcome expectancy (or attitude) of smoking was associated with smoking onset (Chapter 5). A social skills-based smoking prevention programme that made prominent messages to change cognitions of the oral health-related outcomes of smoking and its potential influence on social interaction was implemented and evaluated (Chapter 6). While this programme significantly improved adolescents' oral health behaviour (regular tooth brushing) and their oral health (reduction of gingivitis), this programme did not significantly reduce smoking prevalence (Chapter 6).

The purpose of this final Chapter is to summarise and discuss the results of the studies presented in this dissertation, and to discuss their theoretical and practical implications, and their methodological limitations. It also makes suggestions for future research. The main results are described and discussed separately for the three parts of the dissertation.

\section{Part 1: Health problems: tobacco use as a common-risk behaviour for poor oral and systemic health in South Africa}

The first part of the dissertation report's findings examining the contribution of smoking and smokeless tobacco use to general and oral health in South Africa (Chapters 1 to 3). It also provides information on the association between the end-stage of poor oral health (namely tooth loss) and the major chronic disease burden in South Africa (hypertension). Chapter 1 examines the burden of periodontal disease and explores the role of sense of coherence (SOC) and smoking as predictors of self-reported gingivitis. Chapter 2 examines tooth loss as a correlate of hypertension in South Africa; and Chapter 3 examines the association of smokeless tobacco use and smoking with the prevalence of chronic bronchitis in South Africa.

The findings set out in Chapter 1 of this dissertation demonstrated that during an 18month follow-up period, three-quarters of the study participants in the Limpopo Province experienced gingivitis. This finding confirmed the high burden of periodontal disease among adolescents in this Province already noted by Van Wyk (2003). The study reported on in Chapter 1 was the first to examine the longitudinal course of self-reported gingival health among South African adolescents. The study demonstrated that adolescents with a higher SOC were less likely to have experienced gingivitis or frequent gum bleeding. This finding is consistent with the salutogenic theory (Antonovsky, 1993). A significant observation from this study was that SOC had a suppressor effect on the effect of plaque control on reporting bleeding gums (gingivitis). This finding corroborates the findings of other studies that have demonstrated that the effect of stress or inadequate coping may be partly related to the fact 
that people who are feeling stressed are less likely to brush regularly, and that when they do, they may not brush with sufficient quality to prevent periodontal disease.

Although poverty was demonstrated to be an independent predictor of poor oral health, this study's finding suggests that the influence of poverty on poor oral health was partly mediated by the adolescents' SOC level. Indeed, the results of the study reported in Chapter 4 of this dissertation demonstrated that children from households marked by material deprivation (households in informal housing) had a significantly lower SOC than their betteroff counterparts. It has been suggested that the more a person's life experiences are characterized by consistency, participation in shaping outcomes (that is, decision-making), and a balance between an under load and an overload of stimuli, the more one is likely to see the world as coherent and predictable (Antonovsky \& Sagy, 1986). Load balance describes the extent to which life demands match a person's resources and thus the ability to carry out expectations. It is conceivable that in the face of constant deprivation, adolescents are less likely to have at their disposal what Antonovosky (1993) describes as general resistance resources (GRRs) that allow people to effectively cope in the event of stress and thus stay healthy. Some of these GRRs may include coping strategies, social support, religion, cultural identity, preventive health orientation and even money. It is therefore reasonable to suggest that efforts to improve oral health in resource-poor settings like the Limpopo Province should consider not only poverty alleviation programmes, but also the teaching of coping skills (Pincus \& Friedman, 2004).

The modifiable behavioural risk factors that were found to be significantly associated with self-reported poor gingival health included inadequate plaque control and regular smoking. This finding corroborates the findings from other similar studies reported in the most extensive review of global risk factors to date (Albandar, 2002). Importantly, the study in Chapter 1 demonstrated that irrespective of the level of oral hygiene, social class or psychological disposition of the individual, regular smoking is a strong predictor of poor gingival health, which may lead to tooth loss in the future.

This dissertation demonstrated in Chapter 2 for the first time in the general population of a developing country that complete tooth loss might be a risk indicator for hypertension. This finding corroborates earlier findings in a population of women (Taguchi et al., 2004). The fact that the observed association between tooth loss and hypertension remained even after controlling for socioeconomic class differences is consistent with findings from a recent large-scale follow-up study (Cabrera et al., 2005). In the study reported in Chapter 2, traditional risk factors, such as increased salt intake, obesity, smoking and family history, were also confirmed to be associated with hypertension. The findings of the study reported in Chapter 2, also suggest that tooth loss is more common among smokers (Axelsson, Paulander \& Lindhe, 1998; Albandar et al., 2000) and among people who are overweight and/or obese than among non-smokers and people with a normal body mass index. The study findings also suggest that if tooth loss is confirmed as a true risk factor in future studies, one in ten South African hypertensive adults could be hypertension-free if complete tooth loss could be eliminated. This study therefore concluded that priority should be given to public health or 'common-risk factors' interventions to reduce tooth loss. 
Such a common-risk factor approach would theoretically include the integration of dietary control and smoking prevention with the promotion of oral health. An integrated approach that focuses on smoking prevention was considered particularly relevant in a setting such as the Limpopo Province, where periodontal disease has been identified as the main oral health problem among adolescents (Van Wyk, 2003). Furthermore, given that periodontal disease is not influenced by dietary control as much as dental caries is, it was considered potentially useful to prioritize the integration of smoking prevention with oral hygiene promotion through the use of tooth brushing. Regular use of tooth brushing with fluoridated toothpaste would not only mechanically remove the plaque that causes gingivitis, but would make fluoride in the toothpaste available to prevent tooth decay (caries). This study therefore suggested that it may be more efficient with regard to public health gains to integrate smoking prevention with oral hygiene care in the studied adolescent population as this may prevent the two major oral diseases that may lead to complete tooth loss in adulthood. Moreover, considering that smoking rates are still relatively low in the Limpopo Province and that the region may be targeted as a potential market for the tobacco industry there is a unique opportunity to prevent a future tobacco epidemic in this region.

The significant oral and general health burden associated with smoking as identified and discussed in Chapters 2 and 3 has prompted a discussion on harm reduction strategies involving the offering of supposedly much less harmful smokeless tobacco to those smokers who are unable or unwilling to quit smoking (Rodu \& Godshall, 2006). In addition to the known threats to oral health (Offenbacher \& Weathers, 1985; Ayo-Yusuf, Swart \& Ayo-Yusuf, 2000), findings from the study reported in Chapter 3 challenge the claim that snuff may be a much less harmful alternative to smoking in South Africa, at least with regard to chronic bronchitis. This finding provides a further impetus to understanding why South African adolescents become smokers with the aim of being able to develop more effective preventive programmes. Based on the first part of the present dissertation, it can be concluded that (1) a person's global orientation with regard to the response to stress as measured on the SOC scale may be a significant determinant of oral health (gingivitis) among South African adolescents (2) smoking is a significant risk factor for poor oral health (gingivitis) among South African adolescents; (3) the end-stage of poor oral health (that is, tooth loss) may be an important risk indicator for hypertension a significant health problem in South Africa; (4) tobacco smoking is a common-risk factor for poor oral and general health in South Africa; (5) the use of snuff may pose less risk for oral health than smoking, but snuff may not be a much safer alternative to smoking because it poses a significant risk with regard to other systemic conditions in adulthood and (6) interventions jointly directed at promoting regular tooth brushing and discouraging smoking would be an efficient 'common-risk' approach to promoting oral and general health.

Part 2: Determinants of oral health-related risk behaviours: poor oral self-care and smoking

The results from the studies reported on in Part 1 of this dissertation provided further motivation for understanding why South African adolescents smoke and why they develop poor oral self-care behaviour (irregular or less than twice-daily tooth brushing). Two 
longitudinal studies were conducted to identify relevant predictors of regular tooth brushing and smoking onset among adolescents (aged 12 to 19 years) in the Limpopo Province and in a similar setting in the Gauteng Province. Chapter 4 describes the psychosocial predictors of the transition to twice-daily tooth brushing among a representative sample of adolescents in the Limpopo Province who had not been regularly brushing at least twice daily. Chapter 5 describes the predictors of smoking onset among a non-random sample of non-smoking adolescents mostly from a socioeconomically less privileged region of the Gauteng Province.

Although almost all (99\%) study participants in the study presented in Chapter 4 claimed that they owned a toothbrush, only $76.3 \%$ indicated that always brushed at least once daily. This figure was lower than the figure of $88.9 \%$ obtained from adolescents of a similar aged range in the Limpopo Province during the 2002 South African National Youth Risk Behaviour survey (Reddy et al., 2003). Most of the adolescents (45.3\%) were in the pre-contemplation stage of transition to twice daily brushing and only $22.4 \%$ could be classified as being in the preparation/action stage of change as described by Prochaska and Velicer (1997). Most of those who did not brush daily were over-represented in the pre-contemplation stage. This indicates that most of the adolescents in the study reported on in Chapter 4 were not willing to brush twice daily. Indeed, in terms of their stage of change, the distribution of the participants in this study closely matched the distribution that has been reported as a rule of thumb for at-risk populations (Prochaska \& Velicer, 1997). The proportion of adolescents consistently brushing twice daily decreased considerably over the 18-month period of the study, but remained highest among those classified as being in the preparation/action stage of change at baseline. Adolescents who lived with their mother were also more likely to be brushing twice daily, suggesting a direct and proximal social influence on brushing behaviour. This is consistent with the view that parents, particularly mothers, may be important role models for the oral health behaviour of their children well into their adolescence (Attwood, West \& Blinkhorn, 1993).

It was interesting to note that the dental health life-plans of the majority of the adolescents in the study were dominated by aesthetic motives, as $84 \%$ of them indicated that they brushed their teeth for social reasons such as having fresh breath and white teeth; and only $15 \%$ indicated they brushed their teeth in order to prevent dental diseases such as tooth decay. This may be considered a reflection of social influence on tooth brushing. This finding of a dominant aesthetic motive for brushing among adolescents is consistent with findings from other studies among adolescents even in developed countries (Macgregor, Balding \& Regis, 1996; Källestål, Dahlgren \& Stenlund, 2000; Stokes, Ashcroft \& Platt, 2006). Consistent with the findings from a cross-sectional study by Macgregor et al. (1996), the study presented in Chapter 4 showed that adolescents who brush for aesthetic reasons are more likely to brush only once or less daily, compared to those who brush for preventive dental health reasons.

The differences observed in behaviour might be related to what has been reported as the differences in the norm distribution of these two groups of adolescents (Källestål et al, 2000). The group with a predominantly aesthetic dental life-plan may have been influenced more by the media, which present a discourse in which nice-looking teeth are 
held to be important to the image of young people and consequently for their self-esteem. The second group may have been influenced more by dental professionals who promote a discourse in which good dental health is prescribed on the basis of rational health benefits. It is therefore conceivable that the latter group of adolescents may consist of individuals who might have already have experienced the negative outcomes of not brushing regularly or may have received more cues to action because they have had more contacts with dental professionals than adolescents in the group focusing on aesthetic reasons for brushing their teeth.

Consistent with this hypothesis of increased awareness driving positive behavioural change, the study reported in Chapter 4 confirmed that adolescents who visited a dental office for preventive care were more likely to make the transition to brushing twice daily. It is possible that a visit to a dental professional may be an important first step in getting a person to consider a change in tooth brushing behaviour (that is, such a visit is "a cue to action"). It is pertinent to note that dental attendance patterns remained independently related to behavioural change, irrespective of how they may have influenced the adolescents' motives for brushing their teeth (that is, they remained a proximal determinant). It is also important that while recent dental attendance was a significant predictor of change in tooth brushing behaviour, it was not a significant predictor of actual disease state, as was observed in the study presented in Chapter 1 of this dissertation. Indeed, if dental attendance does not actually lead to behavioural change in both quantity (to twice or more frequent brushing) and quality (to the level of cleanliness or plaque removal that is achieved by brushing), then dental attendance by itself will not produce an improvement in the actual disease state. As was observed in the study reported on in Chapter 1 , it is the actual level of plaque control that is achieved by brushing (that is, related to the quality of brushing), and not merely frequent brushing that determines the level of a person's gingival health.

This study presented in Chapter 4 also demonstrated the applicability of the sense of coherence (SOC) construct in explaining brushing behaviour among South African adolescents and it showed that the most significant determinants of a transition to consistently brushing twice daily are related to the psychological predisposition of the individual concerned, namely the person's SOC level and vulnerability to depression. This finding is consistent with findings reported in Chapter 1 that suggest that a person's SOC is a significant predictor of gingival health. The findings in Chapter 4 further suggest that a high SOC can be associated with greater willingness or confidence in the ability to make the transition to regular brushing. This study finding corroborates findings from previous studies on the influence of psychological mood (Kurer et al., 1995; Deinzer et al., 2005) and self-concept (Macgregor, Regis \& Balding, 1997) on oral health behaviours. This study's findings also support the view that good oral health behaviour is a part of a broader pattern of coping ability (Källestål et al., 2000).

Importantly, regular tobacco use was found to be a significant modifiable risk factor for irregular brushing (Chapter 4). Given that smoking was also established as a significant determinant of poor gingival health and two important systemic diseases in South Africa, 
this finding provided further support for the integration of tobacco smoking prevention with oral health promotion.

The final explanatory model obtained in the study reported on in Chapter 4, builds on the salutogenic theory (Antonovsky, 1993) and the integrated change model (De Vries et al., 2003). This model provides a theoretical basis for the integration of oral health promotion with smoking prevention programmes that could target a risk factor, such as a person's ability to cope with stress, common to both irregular tooth brushing (Ayo-Yusuf, Reddy \& Van den Borne, in press) and smoking behaviour (Glanz, Maskarinec \& Carlin, 2005) among adolescents.

In another longitudinal study reported in Chapter 5 of this dissertation, smoking onset was found to be strongly associated with adolescents' smoking-related attitude towards oral health. In particular, after one year, smoking onset was least likely when youths strongly believed that smoking causes bad breath and that bad breath has negative social consequences. This finding is consistent with that of previous research which has demonstrated that a belief that smoking is associated with negative social consequences, such as peer rejection, is associated with a reduced susceptibility to smoking (Chassin et al, 1991; Unger et al., 2001). Alcohol binge drinking and adolescents' having most or all their peers smoking were also significant predictors of smoking uptake.

The study findings suggest that teaching adolescents about the negative oral health consequences of smoking alone may not be enough to prevent them from smoking. In addition to enhancing skills to resist peer influence, preventive efforts should also create opportunities to positively change adolescents' cognitions about the impact of the negative oral health consequences of smoking on their social interaction. In further support of the salience of this affective negative outcome expectancy with regards adolescents, it is pertinent to note that a study among South African adolescents by Panday (2005) has also illustrated that an item related to oral health (that is, "it improves the smell of my breath") loaded highest among a list of items on the pros of non-smoking that formed part of the attitude scale measured using a principal component factor analysis procedure. Furthermore, a recent study showed that the exposure of adolescent smokers to a lossframe version of a graphic cigarette health warning label featuring decaying teeth resulted in a significantly lower intention to smoke in the future as compared to their exposure to other health-related graphic labels and/or with a gain-framing message (Goodall \& Appiah, 2008).

Based on the determinant studies and findings from Chapters 4 and 5 of this dissertation it can be concluded (1) that in planning oral health promotion interventions, it should be considered that children's psychological predisposition in responding to stresses and their family environment might significantly influence their tooth brushing behaviour (2) that South African adolescents' social environment (such as their family living arrangement and household poverty) may have a significant influence on the development of a favourable SOC, and (3) that it may be effective and economical to integrate smoking prevention with oral health promotion interventions programmes for adolescents. In particular, in addition to teaching stress-coping and peer pressure resistance skills, such a programme may develop strategies to address changing cognitions on the oral-health 
related negative outcomes of smoking and the relevance of ensuing poor oral health (such as bad breath) by focusing on the negative impact of poor oral health on their social interaction (that is, an affective loss-framed message).

\section{Part 3: Implementing and evaluating an integrated educational intervention}

The results from the determinant studies reported in Part 2 of this dissertation also supports the decision to implement an intervention integrating oral health education with a smoking prevention programme. The intervention schools received the adapted South African version of the US LifeSkills Training (LST) curriculum beginning in Grade 8 and continuing in Grade 9 (a booster dose). In both years, learners were provided with individual workbooks and teachers were provided with an educator's manual after a threeday training workshop. The modification made to the South African version of the LST for the purpose of the current study included making more prominent the information on the short-term consequences of smoking (such as bad breath and stained teeth) and their subsequent influence on social interaction, especially as it relates to the adolescents' romantic aspirations. In particular, we provided participants with additional worksheets in Grade 8, to identify individually and then consider in a group discussion, why oral hygiene care is an important part of socializing (this as part of the lesson unit 'Communicating and socializing skills'). In Grade 9, apart from a worksheet activity on setting a goal to improve their oral health ('Goal setting and decision-making skills'), we also provided participants with a photographic illustration of a boy rejected by a girl because of his bad breath, subsequent to smoking to overcome shyness to talk to the same girl ('Communicating and socializing'). A section (bold text) then followed this worksheet. It commented on what one can do to avoid bad breath, namely avoid using tobacco and avoid excessive drinking, brushing twice daily, eat lots of fruits and little sugary food and visit a dental clinic twice a year for check-ups.

The content of the intervention programme generally focused on building general and substance-use specific life skills including decision-making, stress management, affect management, assertive communication, and resisting peer pressure. Where information about the consequences of smoking was included, the focus was on short-term health and the social consequences of tobacco use.

Chapter 6 reports on the results of the evaluation of the effect of this integrated intervention. The impact was assessed of the education programme on (1) brushing daily and twice daily; (2) past-month smoking; (3) self-efficacy in resisting a cigarette offered by friends; (4) oral health attitude (5) bleeding gum frequency (a symptom of gingivitis); and (6) plaque level (a reflection of the quality of the level of oral hygiene performance).

Adolescents exposed to the programme were significantly more likely to brush more frequently, had a more positive oral health-related attitude, a better oral hygiene (lower plaque levels) and reported fewer frequent bleeding gums. The fact that the intervention did not have a significant impact on smoking prevention, but had a significant positive impact on adolescents' cigarette refusal self-efficacy could be seen as a strong, but a limited result of the intervention. The result was strong in the sense that in addition to improving adolescents' attitude to oral health, it was demonstrated that this education intervention provided the participating adolescents with skills they needed to resist peer 
pressure to smoke (in order words, it reduced their susceptibility to smoking). However, the outcome of the intervention was limited because this skill did not translate to a statistically significant reduction in smoking prevalence.

The $14 \%$ relative reduction in smoking prevalence obtained in this study in the intervention schools as compared to the reduction in the control schools, although lower than the $30-60 \%$ reduction reported for the original US LST (Botvin et al., 1995), is consistent with the findings of the impact of a similar LST intervention tested in a different region of South Africa (Resnicow et al., in press). Consistent with our findings, the study by Resnicow et al. (in press) also demonstrated a lack of statistical significance, despite the magnitude of the observed effect. This suggests that the inclusion of the oral health educational component neither improved nor reduced the impact of this social skills-based intervention on smoking prevention. However, it demonstrates that if it is designed with strategies to positively change oral health-related social cognitions, this programme can have a significant impact on promoting oral health among adolescents. A similar social cognitive approach has also been previously successfully applied to promote oral health among a European adolescent population (Redmond et al., 1999).

As far as we could ascertain, this education intervention is the first aimed both at promoting oral health and at preventing smoking among adolescents; hence, the results can only be partly compared with those of other studies. The results obtained in the current study may be a reflection of the inherent challenge of multiple risk behaviour interventions; individuals with multiple risk behaviours may be confused about the relative importance of each risk behaviour, or may feel overwhelmed by the sheer number of 'bad things' they need to improve (Strecher et al., 2002). It may be noted that the intervention tended to have a greater positive impact on smoking reduction among adolescents who were not snuff users at baseline, but this impact was not statistically significant.

Notwithstanding the lack of a statistically significant effect on smoking reduction, the more favourable oral hygiene levels achieved in the schools that were exposed to this programme, as opposed to the levels achieved in the control schools after 18 months, is comparable, and in some instances better than, the reduction in plaque levels previously attributed to educational programmes with an average of only a 6-month follow-up (Brown, 1994; Watt \& Marinho, 2005).

Based on the results from this part of the dissertation, it can be concluded that the LST curriculum as applied in this study is very effective in promoting adolescents' oral health. However, the non-significant effect of this programme on smoking behaviour needs further investigation.

\section{School-based education programmes and their effectiveness}

Schools provide fairly stable access to a large proportion of children and youth and have a professional workforce of teachers who are educating children and youth at a critical stage of their development. We therefore decided to implement a school-based oral health education programme integrated with smoking prevention for adolescents aged 12 to 19 years. Successful school-based education interventions appear to involve similar elements (Flay, 1985). 
First, educational interventions are more likely to be effective in changing behaviour when they focus on the specific behaviours and on the determinants of these behaviours, and when they focus on behavioural skills instead of being knowledge-based. Accordingly, this school-based integrated oral health education intervention focused on encouraging frequent daily tooth brushing in particular, as well as on corresponding determinants and behavioural skills (for example, by including a smoking resistance skill sessions and the enhancement of generic social skills).

Another characteristic of an effective intervention is the application of an appropriate theoretical framework. In our intervention, we mostly applied Bandura's social cognitive theory (SCT) and supplemented this with other social psychological theories such as the salutogenic theory and the integrated behaviour-change model.

Lastly, school-based interventions are more likely to be effective if they include relevant environmental components, particularly family involvement. The present integrated oral health educational intervention was not supplemented with an intervention that involved the parents. Although the study presented in Chapter 5 failed to show a significant influence of parental smoking on smoking onset, it is conceivable that adolescents from homes where smoking regularly takes place will experience this programme as incongruent with their life experiences. Such inconsistencies have indeed been shown to influence the development of adolescents' SOC, and by implication the ability to successfully cope with stresses of life (Antonovsky \& Sagy, 1986). Since the existing literature suggests that parents exert an important influence on adolescents' decision-making to smoke and to implement regular oral self-care practices, future research might include active family involvement of some sort.

This dissertation also supports the inclusion of three other important elements of interventions that have been demonstrated to achieve at least short-term positive changes in plaque and bleeding scores (Brown, 1994). These elements are the use of appropriate educational media (such as the use of graphic illustrations in this intervention), the use of multiple sessions, and learners' active involvement. The significant positive impact of including booster lessons in educational interventions was evident in the current study, as most of the programme's impact on study outcomes was more evident in the second year of implementation. In general, research on health education interventions shows that interventions with a longer duration or contact hours are more effective in achieving behavioural change than shorter interventions (Brown, 1994).

Considering that providing information that motivates individuals to change is the first step in realizing behavioural change by means of health education, the choice of educational media should be such that it ensures a persuasive impact. In line with the persuasion-communication matrix adapted to health education (Bartholomew et al., 2006), the choice of educational media used in the tested intervention aimed to optimize the adolescents' attention and comprehension of the message focused on changing their attitudes, and recruited social support for the positive behaviour(s) being recommended. The educational message in this programme was made relevant by focusing on the shortterm effects and consequences of smoking, such as its effect on oral health. The message was made functional and convincing by matching the likely outcomes with the way 
adolescents at this stage look at their world, in other words, linking it to their romantic aspirations. These are indeed pre-requisites for successful communication in health education (Bartholomew et al., 2006).

\section{Theoretical reflection}

In addition to earlier discussions of the relevant Chapters, this section discusses several other theoretical issues related to this study and the findings presented in this dissertation. It briefly explains the rationale behind selecting Bandura's SCT as the theoretical framework for this dissertation and discusses some of the limitations of this framework, namely the discrepancy between positive attitudes and subsequent behaviour, and the discrepancy between positive intentions and subsequent behaviour. This section then ends with the implications for the future use of the identified theories or constructs in explaining smoking behaviour.

\section{Cognition-behavioural models and their limitations}

The integrated behaviour change model and one of its constituent theories - the social cognitive theory (SCT) - was mainly used to examine possible determinants of smoking behaviour. In combination with the salutogenic theory, it was used to examine the determinants of frequent tooth brushing. The SCT is the cognition-behavioural model most frequently used in research on adolescents (Parcel, Kelder \& Basen-Engquist, 2000); and it was relevant to our studies for several reasons. First, SCT integrates cognitive, emotional and behaviouristic understandings of behavioural change. These understanding may be very helpful in explaining behaviours such as frequent tooth brushing and smoking. Second, it allowed us to address in concert the psychological correlates (for example, outcome expectation) associated with both irregular tooth brushing and smoking. Thirdly, because SCT allows aspects of other disciplines to be incorporated (Parcel et al., 2000), we were able to benefit from additional insights provided by other theories, for example, the construct of SOC. Fourthly, because a key concept of SCT is that of reciprocal determinism (that is the notion that behaviour, personal factors and environmental events operate as interacting determinants of each other) we were able to examine family structure as a social determinant of brushing behaviour. Lastly, the adapted LifeSkills Training (LST) employed as an intervention used behavioural change methods within the framework of SCT (Botvin et al., 1995) namely, active learning, reinforcement, modelling and guided practice, and persuasion.

Considering that every psychological theory or model is limited in its approach, one suggested possibility for improvement is to develop multidimensional models (Hollister \& Anema, 2004), as exemplified by the integrated model of change (the I-Change Model) (De Vries et al., 2003). This integrated model incorporates insights from the theory of planned behaviour (Ajzen, 1991); social cognitive theory (Bandura, 1986) and the transtheoretical model (Prochaska \& Velicer, 1997). The I-Change model, like other cognitionbehavioural models, assumes that the most important determinant of behaviour is behavioural intention, which is in turn influenced by three proximal factors, namely a person's overall evaluation of a behaviour (attitude), the behaviour of significant others 
(social influence, for example, that of the mother) and the control that people perceive themselves to have over that behaviour (self-efficacy) (Bandura, 1997).

However, differentiating the I-Change model from its constituent models or theories, distal factors such as socio-demographic factors (for example, age, gender, social environment) and psychological or other behavioural factors (for example, depression, and smoking) are assumed to influence behaviour via the proximal factors. Another difference between the I-Change model and its constituent models or theories is that the I-Change model explicitly identifies the role of awareness factors (De Vries et al., 2003), such as those relevant to oral health education.

Notwithstanding the usefulness of these cognition-behavioural models, two issues are particularly relevant in understanding their limitations in explaining smoking and tooth brushing behaviour, namely the attitude-behaviour discrepancy and the intentionbehaviour discrepancy.

\section{Attitude-behaviour discrepancy}

Understanding the consistency (or lack of it) between attitude and behaviour is clearly evident with regard to the issue of smoking and poor oral health. According to Ajzen (2001), attitude can be operationalised as the multiplicative function of outcome expectation and the value that an individual attaches to the expected outcome. It has been noted that outcome expectations do not have to be accurate in order for them to motivate behaviour (Brandon et al., 2004). It is, however, necessary that such outcome expectations represent relevant or accessible beliefs that can be easily activated from memory to influence behaviour (Ajzen, 2001). Fazio and Zanna (1981) have also noted that greater attitude accessibility might be an important mediator of attitude-behaviour consistency.

Most adolescents are not likely to be confronted by the long-term health consequences of smoking. Recognizing that long-term health outcomes may not be a major deterrent among adolescents, tobacco prevention programmes have instead tended to emphasize the short-term negative consequences of smoking that may be more salient to adolescents (Glynn, 1989). The oral health effects of smoking, such as stained teeth, gum infections (gum bleeding) and bad breath may indeed be more salient to adolescents and are therefore more accessible beliefs for smokers and non-smokers alike.

The fact that irregular tooth brushing has been demonstrably linked to bad breath may have brought about greater attitude-behaviour consistency as observed with the measured oral health outcomes of the intervention. However, cognitions or attitudes are derived from social interaction and communication processes. It is possible that many adolescents may not yet have been confronted with rejection by members of the opposite sex as a result of bad breath related to smoking. The lessons on the negative impact of smoking on socialization, particularly relating to bad breath may well have been their first encounter with this possibility. This may have brought about the attitude-behaviour inconsistency observed with regard to the smoking outcome. The observed inconsistency may also be related to the fact that self-efficacy was lower in the intervention schools than in the controls schools; and it has been suggested that, even when outcome expectations (and 
by implication attitude) are strong, a person is unlikely to attempt to perform a behaviour when the person's self-efficacy for that behaviour is low (Bartholomew et al., 2006).

\section{Intention-behaviour discrepancy}

In SCT and other cognition-behavioural models, intention is presumed to be the most immediate and important predictor of behaviour (Ajzen, 1991; Bandura 1986). Metaanalytic reviews have suggested that intention accounts for $20 \%$ to $30 \%$ of the variance in behaviour (Godin \& Kok, 1996; Sheeran, 2002). The implication of this finding is that intention does not always result in performance of the intended behaviour. The gap between intention and actual behaviour may also be apparent with regard to twice-daily brushing. The actual proportion of adolescents who made the transition to consistently brushing twice-daily in our study (Chapter 4) was considerably lower than the rate reportedly contemplating or preparing to change (14\% vs. $55 \%)$.

It has previously been noted that behavioural performance can also influence intentional state (Fishbein et al., 2001). Individuals may form a positive intention to brush twice daily, and may in fact brush twice daily, at least in part because they believe that this will lead to a positive outcome (for example, it will preventive tooth decay). However, this outcome may not occur when some individuals perform this behaviour. Conceivably, this information will influence the person's behavioural beliefs (or outcome expectations), which may in turn influence intentions and future behavioural performances. Nonetheless, the trans-theoretical model (Prochaska, Redding \& Evers, 2002) suggests that cognitive and affective methods raise awareness of negative outcomes - the first step in the change process. Therefore, it was not surprising that the programme implemented, which used these methods, succeeded in moving some people from pre-contemplation to action, with regards regular brushing.

Gollwitzer's concept of implementation intentions (Gollwitzer, 1993; Gollwitzer \& Brandstatter, 1997) may also explain the intention-behaviour inconsistency. Implementation intentions are plans that commit a person to a time and place to perform the intended behaviour. Studies of several behaviours have provided evidence to suggest that people who possess goal intentions (for example, 'I will always brush my teeth twice daily') supplemented by an implementation intention (for example, 'I will brush my teeth after my breakfast in the morning and again in the evening after I finish watching the TV') are more likely to successfully perform the intended behaviour (namely consistently brushing twice daily) successfully than people who do not have implementation intentions (Gollwitzer \& Brandstätter, 1997; Sheeran \& Orbell, 1999; Sheeran \& Silverman, 2003). Implementation intentions are said to be effective because they create memory traces that may influence attentional and memorial processes relevant to a successful enactment of one's intentions. It may therefore be useful to measure implementation intentions in future studies of determinants of tooth brushing behaviour change.

\section{Other theoretical models with implications for oral health promotion}

One of the theoretical models that has been suggested and that holds some promise in oral health promotion is the salutogenic theory (Watt, 2002). According to this theory, stressors 
are intrinsic to the human condition, but people have internal and external resources they can use in the face of stressful situations, and thus to maintain health. According to Antonovsky (1993), a person's sense of coherence (SOC) is a global orientation that expresses the extent to which the person has a pervasive, enduring but dynamic feeling of confidence enabling the person to apply general resistance resources (GRRs). These GRRs can be found in both the immediate and the distant environment of every person. They may include coping strategies, social support, religion, cultural identity, preventive health orientation and even money (Eriksson \& Lindtröm, 2006). A person's SOC consists of three dimensions, namely comprehensibility (cognitive), manageability (behavioural) and meaningfulness (motivational). The stronger an individual's SOC, the more adequately he or she will cope with stressors and maintain his or her health.

The SOC has recently received significant empirical research support as a determinant of oral health behaviour in adults (Savolainen et al., 2004; Savolainen et al., 2005). However, so far, only two studies on SOC in relation to adolescents' oral health have been published. One showed that adolescents' SOC was associated with children's dental attendance pattern (Freire, Sheiham \& Hardy, 2001). The other demonstrated that mothers' SOC was associated with their children's oral health and dental attendance pattern (Freire, Hardy \& Sheiham, 2002). The latter study's findings suggest that the SOC construct may also provide insights into life-course influences on oral health (Nicolau et al., 2003).

The studies reported on in Chapters 1 and 4 of this dissertation provide for the first time, information on the application of the SOC construct in a South African adolescent population. There was also evidence to suggest that the influence of SOC on adolescent tooth brushing may be partly mediated through the adolescents' intention state. This finding is consistent with cognitive-behavioural models and supports a previous suggestion that there is a pathway that connects SOC with the concept of self-efficacy (McSherry \& Holm, 1994). However, unlike self-efficacy measures, which are of necessity tailored to specific domains of functioning and possibly to specific population characteristics (Maibach \& Murphy, 1995), SOC could be considered a general construct of self-efficacy with crosscultural applications (Antonovsky, 1993).

Findings from a determinant study (Chapter 4) presented in this dissertation also demonstrated that the social environment, in particular the presence of the mother in a family, may be an important determinant of a change in tooth brushing behaviour. This supports a previous suggestion that if health promotion was to make a difference to the lives of South Africans, it had to provide strategies that would not only place responsibility on the individual to make choices (Watt, 2002), but would have to involve strategies that would have an impact on the political, economic, environmental, social and cultural aspects of all South Africans (Reddy, 1999). Expanding on the health promotion matrix proposed for a tobacco control model, a multilevel framework for integrating oral health promotion with tobacco control can be summarized as depicted in Figure 6 . 
Figure 6: A multilevel intervention framework for integrated action: Tobacco control and oral health promotion (adapted from Reddy, 1999)

\begin{tabular}{|c|c|c|c|}
\hline \multirow{2}{*}{$\begin{array}{l}\text { Health } \\
\text { promotion } \\
\text { strategies }\end{array}$} & \multicolumn{3}{|l|}{ Levels of health promotion impact } \\
\hline & Primary Prevention level & Early Detection level & Patient Care level \\
\hline $\begin{array}{l}\text { Health } \\
\text { education and } \\
\text { information }\end{array}$ & $\begin{array}{l}\text { Training to improve knowledge about } \\
\text { the adverse effects of tobacco use and } \\
\text { the development of tobacco refusal } \\
\text { skills. } \\
\text { Mass communication programme } \\
\text { Improve knowledge of adverse effects } \\
\text { of poor oral health and the development } \\
\text { of effective and frequent tooth brushing }\end{array}$ & $\begin{array}{l}\text { Identify smokers and } \\
\text { promoting the development } \\
\text { and uptake of smoking } \\
\text { cessation programmes } \\
\text { involving both adolescents } \\
\text { and their caregivers }\end{array}$ & $\begin{array}{l}\text { Education for recognition of } \\
\text { being a passive smoker } \\
\text { Education and skills to cope } \\
\text { with: } \\
\text { - } \quad \text { Stress } \\
\text { - } \quad \text { Cardiovascular disease } \\
\text { - } \quad \text { Respiratory disease } \\
\text { - } \quad \text { Cancer } \\
\text { - } \quad \text { Periodontal disease }\end{array}$ \\
\hline $\begin{array}{l}\text { Provisions and } \\
\text { facilities }\end{array}$ & $\begin{array}{l}\text { Provision of smoke-free environment for } \\
\text { the general public }\end{array}$ & $\begin{array}{l}\text { Access to: } \\
\text { - Stop-smoking } \\
\text { medication } \\
\text { - } \quad \text { Alternative healing } \\
\text { - School dental screening }\end{array}$ & $\begin{array}{l}\text { Provision of support, } \\
\text { primary treatment (e.g. } \\
\text { scaling and polishing) and } \\
\text { rehabilitation facilities } \\
\text { (prosthetic replacement of } \\
\text { missing teeth) }\end{array}$ \\
\hline $\begin{array}{ll}\text { Legislation } \\
\text { - } & \text { International } \\
\text { - } & \text { Regional } \\
\text { - } & \text { National } \\
\text { - } & \text { Local }\end{array}$ & $\begin{array}{l}\text { International } \\
\text { - Consensus on tobacco trade } \\
\text { agreements for developed and } \\
\text { developing countries } \\
\text { - Implement the WHO Framework for } \\
\text { Tobacco Control (FCTC). } \\
\text { Regional } \\
\text { Legislation to support consensus on } \\
\text { tobacco trade agreements to } \\
\text { promote health in neighboring } \\
\text { countries } \\
\text { National anal } \\
\text { - Legislation on water fluoridation } \\
\text { - Legislation to protect public health } \\
\text { such as banning tobacco } \\
\text { advertising, promotion and } \\
\text { sponsorship } \\
\text { Legislation on smoking in public } \\
\text { places and work sites. } \\
\text { Special legislation to protect } \\
\text { children } \\
\text { Legislation to regulate all tobacco } \\
\text { products. } \\
\text { Policies to restrict sale of free-sugar } \\
\text { containing foods on school } \\
\text { premises. } \\
\text { Local } \\
\text { Local legislation to ensure } \\
\text { enforcement of tobacco laws }\end{array}$ & 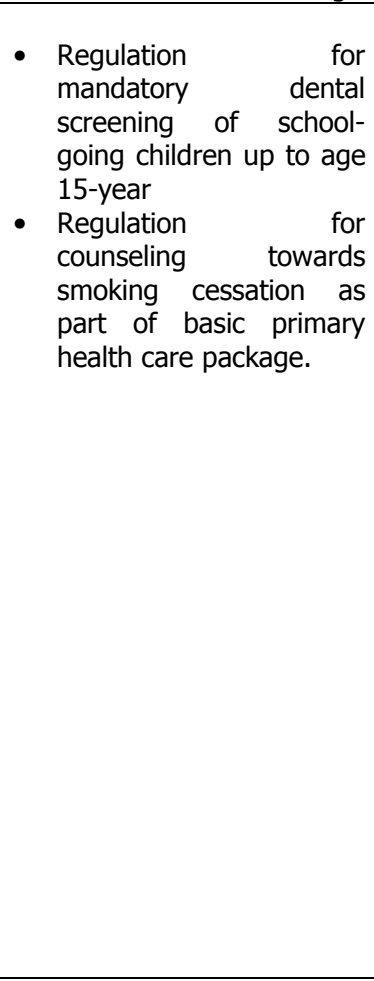 & $\begin{array}{l}\text { Basic dental and medical } \\
\text { care and, psycho-social } \\
\text { support mandated as } \\
\text { minimum benefit for medical } \\
\text { insurance/schemes }\end{array}$ \\
\hline $\begin{array}{l}\text { Economic } \\
\text { intervention } \\
\text { - } \quad \text { Taxation } \\
\text { - } \quad \text { Pricing } \\
\text { Alternative } \\
\text { livelihood } \\
\text { for those } \\
\text { dependent } \\
\text { on tobacco } \\
\text { faring or } \\
\text { products } \\
\text { retails } \\
\end{array}$ & $\begin{array}{l}\text { - Proportion of cigarette taxes should } \\
\text { be increased annually } \\
\text { - Annual price of cigarettes should be } \\
\text { above inflation }\end{array}$ & $\begin{array}{l}\text { Use tobacco tax to } \\
\text { reimburse the public health } \\
\text { sector for screening } \\
\text { programmes }\end{array}$ & $\begin{array}{l}\text { Use tobacco tax to } \\
\text { reimburse the public health } \\
\text { sector for primary care and } \\
\text { rehabilitation, including oral } \\
\text { rehabilitation. } \\
\text { Use tax revenue for capacity } \\
\text { building in alternative crop } \\
\text { farming }\end{array}$ \\
\hline
\end{tabular}




\section{Methodological limitations of the studies}

In addition to the brief mention of the study limitations outlined in the various Chapters, this section addresses several methodological limitations of the studies presented in the three parts of this dissertation. The issues highlighted here are potential threats to the internal validity of the studies as for example, the question of whether the results that were obtained can indeed be attributed to the factors or intervention evaluated or the external validity of the studies (for example, the question of whether the results that were obtained can be generalized to other populations and settings).

\section{Part 1: Health problems: tobacco use as a common risk behaviour associated with poor oral health and systemic health in South Africa}

Self-report of gingivitis was used in Chapter 1 of this study. This may not have sufficient validity for screening individuals, but it has been demonstrated to be a useful method for monitoring the gingival health of adolescent populations (Kallio, 1996; Taani \& Alhaija, 2003). Another factor that related to the study design used in Chapter 1 that could have influenced the outcome measure is that the initiation of this longitudinal study might have had a temporary effect on the participants' oral self-care behaviour, but we expect that this effect would have occurred at random and therefore believe that it is not likely to have had a significant influence on the conclusions reached in this study. Furthermore, the use of self-reporting of gingivitis is reasonably unlikely to have changed the conclusions reached in the study presented in Chapter 1 significantly, considering that a previous adolescent study demonstrated that the same factors that were associated with selfreported gingival health were associated with the objective measure of gingival health in the studied adolescent cohort (Kallio et al., 1994). This is particularly relevant as the aim of this investigation was to promote the oral health of a particular population.

Chapter 2 presents an analysis of quantitative data gathered by means of a crosssectional study that suggests that preventing the end-stage of poor oral health is important for general health promotion (preventing hypertension). Methodologically, this study was a cross-sectional study carried out using a national representative sample of South African adults. The results can be generalized to all provinces in the country, but because we did not have the information on the temporal order of events, we are cautious about making a causative attribution between poor oral health and hypertension. Similarly we cannot deduce causality from the results obtained from the cross-sectional studies reported in Chapters 2 and 3.

Complete tooth loss was most common among those in the lowest socioeconomic class. Although the significant association observed between complete tooth loss and hypertension remained even after controlling for socioeconomic class, the observed association may still be explained by an as yet unmeasured social factor for which tooth loss is a proxy. Indeed, complete tooth loss, which usually occurs over time, is more likely to support the underlying hypothesis of chronic nutritional deficiency and/or cumulative adverse effects of several bouts of dental infection on the integrity of the arterial system. 
Furthermore, as noted in Chapter 2, the measures of tooth loss used were too limited to establish a valid graded response with regard to hypertension. This measure was, however, also employed in the WHO STEPwise questionnaire used in the World Health Survey, which was conducted in 72 countries during 2003 (Bonita, 2004). It would indeed have required large numbers of oral health personnel and additional resources to examine the over 13,000 participants of the 1998 South African Demographic Health Survey if we were to record a more objective measure of the extent of tooth loss. Furthermore, given that we were mainly interested in the effect of complete tooth loss (edentulousness) on systemic health, such additional information would not have changed the conclusion reached in the current analysis, as the field workers involved in this study were trained to observe complete tooth loss as reported.

The studies reported in Part 1 of this dissertation also relied on respondents' selfreporting of tobacco use. The participants' responses are therefore potentially subject to reporting bias, especially in respect of smoking, which is generally regarded as a social taboo among black women. It is therefore possible that such reporting bias may have weakened the association reported between smoking and chronic bronchitis (CB), for instance. Furthermore, the responses to questions used for $\mathrm{CB}$ diagnosis may be subject to recall bias. Nevertheless, the criteria used for CB diagnosis and for the classification of current smokers are similar to those used in many other national surveys with which our results are therefore comparable. Moreover, in our study, CB diagnosis was cross-validated with an objective measure of compromised airflow as determined by the peak expiratory flow rate (PEFR).

Lastly, the data that were used in the studies reported in Chapters 2 and 3 are somewhat dated. However, considering that the biological relationship hypothesized between snuff and bronchitis is not time-dependent, this is not likely to have influenced the study findings significantly.

\section{Part 2: Determinants of regular oral self-care and adolescent smoking behaviour}

The methodological strength of the two studies reported in this part of this dissertation lies in its longitudinal approach.

A major limitation of the study reported in Chapter 4 is the reliance on self-reported tooth brushing behaviour, creating potential reporting bias, as respondents may have given answers that they believe are socially preferred. However, an attempt was made to limit the possibility of the respondents' giving what they saw as socially desirable responses by (1) stressing the confidentiality of the respondents' answers; (2) stressing that there were no right or wrong answers; (3) using a five-point scale instead of dichotomous scales, so that respondents would be more inclined to give answers that are suitable for their situation; and (4) applying the most conservative definition for brushing twice daily in our analysis, as informed by the results from a pilot study testing this question among adolescents. Moreover, the fact that those who reported a transition to more regular brushing experienced a $40 \%$ greater reduction in bleeding gums provides some support for the validity of the measure used.

It is possible that respondents could also have been misclassified in terms of their stage of change, but, given that the distribution of the study population in the different 
stages closely matched that reported as a rule of thumb for at-risk populations (Prochaska \& Velicer, 1997), we are fairly confident that our stage classification is fairly reflective of the true stage.

The internal consistency of the SOC- $6(a=0.63)$ used in the current study was lower than the benchmark of 0.70 (Eriksson \& Lindström, 2006). However, considering that only six items were used and this questionnaire performed better than the 0.42 obtained using the SOC-13 scale in a recent study among a South African adult population (Corless et al., 2006), the SOC-6 scale could be considered fairly reliable for the studied population. Nevertheless, we acknowledge that the scale could still be significantly improved, for example by using a 5-point instead of the original 7-point scale used. Our field experiences suggest that it is easier for this population of South African adolescents to comprehend a 5 -point scale than a 7-point scale.

Another limitation of the model reported in Chapter 4 is that the validity of the construct used for the motivation for tooth brushing is not known in the studied population. Moreover, it may well be that the adolescents that have selected preventive reasons as their main reason for brushing may also be motivated by aesthetic reasons. The construct we used to measure the adolescents' motivation for brushing, was also used in previous adolescent studies (Macgregor et al., 1996; Källestål et al., 2000), thus making our results comparable. In particular, because this construct of motivation for tooth brushing has been used in a previous study examining the relationship between adolescents' oral health behaviour and personal resources such as self-esteem (Källestål et al., 2000), the use of this construct in this study also provided an opportunity to examine its relationship with another construct related to personal resources, namely SOC.

The model used to predict regular tooth brushing behaviour contained a limited set of factors. It specifically omitted direct measures of self-efficacy and social influence. The number of questionnaire items included took into account the varying level of literacy in the studied population. The number of items was specifically reduced (after a pilot study) to allow time for the completion of the questionnaire within the time slot, which was strictly allocated by the participating schools to the research team for this project.

Furthermore, there are no validated self-efficacy constructs for tooth brushing as envisaged by the manner in which self-efficacy is measured in the integrated behaviour change model proposed by De Vries et al. (2003). However, we do not think we would have reached a different conclusion if we had also included the constructs of self-efficacy and several other factors included in the I-change model. This is because the focus of our explanatory model was to provide a salutogenic framework for an integrated model that includes the SOC, which has in turn been related to the concept of self-efficacy, social support and attitude. Indeed, the I-change presupposes that both self-efficacy and other motivational variables influence behaviour change through their influence on intention. This study has also established that the effect of SOC was partly mediated by behavioural intention. Nevertheless, we recommend that future investigations should explore the impact of including situational self-efficacy and other related motivational variables on the influence of SOC on tooth brushing behaviour. 
One of the limitations of the study reported in Chapter 5 is that it used one-item cigarette refusal self-efficacy, as opposed to a battery of items, to document an individual's perceived capability to perform the behaviour in question under different circumstances or situations (De Vries et al., 2003). The one-item option used was, however, much like that used in similar national youth tobacco surveys in South Africa (Swart et al., 2004).

The attitude construct was operationalised in Chapter 5 as the product of expectancy belief and outcome expectation, as suggested by Ajzen (2001). However, we do not know the reliability of this construct in the studied adolescent population. The low variance explained by the final model as reflected by the model $\mathrm{R}^{2}$ might suggest that several other relevant variables might not have been included in this model. Nevertheless, it should be noted that the $\mathrm{R}^{2}$ reported for the logistic regression models are not a true reflection of the variance explained, as is the case with linear regression (Tabachnick \& Fidell, 2007). Thus, a better diagnostic measure for model fit is the likelihood ratio test, which was statistically significantly different compared to the null model or the model without the inclusion of the smoking-related attitude to oral health. It is also pertinent to note that the standardized betas for oral health attitude (a better reflection of the strength of the contribution of ordinal variables than the odds ratio) were $21.7 \%$ and $30.4 \%$ higher than those obtained for the influence of peer-smoking and binge-drinking respectively. However, there is a need for further studies that include more behavioural constructs in addition to the current limited model in order to explore the association between adolescents' attitude towards oral health and smoking onset further; and thus provide a better understanding of the determinants of smoking in South Africa.

Another limitation of the study reported in Chapter 5 is its reliance on adolescents' selfreporting of tobacco use. An objective measure of tobacco use status was not applied due to logistic and financial constraints. However, as this was part of a study measuring oral health status, participants were told that subsequent oral examinations carried out would be able to confirm smoking status. This thus served as a 'bogus' pipeline procedure, which has been shown to improve the reliability of self-reports of substance use among adolescents (Murray \& Perry, 1987). Moreover, several studies have suggested that adolescent self-report of tobacco use is generally reliable and valid (Patrick et al., 1994; Dolcini et al., 2003).

A further limitation of the current study is that due to the relatively small sample size (relatively low smoking rates), only a limited set of variables that focused on smoking consequences have been assessed. Nevertheless, other variables of established theoretical relevance to the onset of smoking were included in the current analysis. Lastly, because the study sample was primarily a non-random sample of school-going black African adolescents, and because some significant behavioural differences between those followed-up on and those lost to follow-up were found, it may not be possible to generalize the results that were obtained to all other adolescent populations.

\section{Part 3: Implementing and evaluating an integrated educational intervention}

A major strength of this study is the use of a randomized controlled trial that allowed rigorous evaluation of the intervention's impact, while using multilevel analysis to take into 
account the randomisation done at school level (Murray \& Short, 1997). Nevertheless, because the intra-cluster correlation obtained in the current study population for smoking was higher than expected, the statistical power of the study to detect a difference even if there was one was reduced (a Type II error). This may account for the lack of statistical significance observed with the smoking outcome measured, despite the magnitude of the difference that was detected.

Similarly, one of the limitations in the study outcomes reported in Chapter 6 is that it used a self-efficacy measure as a binary variable. However, the one item of cigarette refusal self-efficacy used was similar to that used in similar teen surveys in the US and in past national youth tobacco surveys in South Africa, thus making are results comparable. In addition to the reasons given in the preceding section (in the discussion of Part 2) for using a limited number of items for self-efficacy measure, the responses to the single-item used were highly skewed. We therefore transformed the 5-point scale to a binary variable. Sensitivity analysis using the original 5-point scale item, did not produce a different result from the one we obtained using the transformed data. Nevertheless, we propose that future studies include self-efficacy items that could capture self-efficacy under varying situations.

Another limitation of this study, as with the determinant studies reported in Part 2 of this dissertation is the reliance on the self-reported outcome measures of tobacco use and oral health. The influences of these potential reporting biases were, however, limited by applying methods as previously described in the preceding section. Another limitation of the current study is that it implemented an already developed smoking prevention programme (LST). However, the programme was adapted for the South African educational system and culture through rigorous research and pilot studies by a research team at the Medical Research Council of South Africa (MRC, 2007). Furthermore, the LST matched with the theoretical underpinning derived from the determinant studies presented in this dissertation. The LST curriculum was designed to be taught as part of Life Orientation (LO). LO is a separate mandatory subject in South African schools that includes learner outcomes for health behaviours and social skills development, thus maximizing the potential for the implemented intervention to be widely adopted in South African schools. In relation to this, it is a limitation of the current report that we did not evaluate the implementation process - thus the current dissertation is not able to fully inform the potential for its effective adoption through diffusion.

Finally, because those who dropped out of the intervention study were more likely to be older adolescents the results may be subject to selection bias and, by implication, we may not be confident in generalizing the results to all adolescents, especially those out of school. The differential attrition of older adolescents may be related to legislation in South Africa which makes it mandatory for children to attend school only until the age of 15 (Republic of South Africa, Education Act 84 of 1996). Indeed field observation suggests that most of the drop-outs appeared to have either moved out of the locality or had gone to seek employment. The Limpopo Province in fact has the lowest rate of high school completion in South Africa (Statistics South Africa, 2001). 


\section{Implications}

The results of the studies presented in this dissertation have several implications for future research and oral health education.

\section{Implications for research}

Tooth loss must still be confirmed as a true risk factor for hypertension. Snuff use as a true risk for chronic bronchitis also needs further investigation using longitudinal studies that take into account the temporal order of events.

With the additional benefit of having to administer fewer survey questions, this study's findings (Chapter 4) suggest that in examining the determinants of other health behaviours it may be useful to include the SOC- 6 in the I-Change model (that is, an Integratedsalutogenic model), instead of function-specific self-efficacy measures that require several items for measurement (De Vries et al., 2003). It nevertheless remains important to examine the effect of including a wider range of motivation factors in the prediction model to determine their influence on SOC. This implies that future research should be directed at developing and validating self-efficacy and social influence constructs for tooth brushing among the South African adolescent population.

Considering that this life skills training intervention may be prone to a delay in impact (in other words, a "sleeper effect"), future research should include several more follow-up assessments to determine whether the results are affected by a possible sleeper effect or even whether the current positive impacts are sustained in the longer term. The effects of an additional booster intervention in the tenth grade (LST year 3) would also need to be tested for its effectiveness in maintaining or increasing the programme's effects. Furthermore, given that we estimated only a $61 \%$ implementation rate, it would also be particularly important that future research includes students' and teachers' evaluation of the impact of the programme. This may provide insight into factors that may have supported or impeded the implementation of the present programme.

\section{Implications for practice}

The findings that $\mathrm{SOC}$ and smoking were significant modifiable risk factors associated with gingivitis suggests that considerations should be given to stress management and smoking cessation as additional measures to the usual clinical periodontal care.

In the past three years, major transnational tobacco product manufacturers from Sweden and the US have made unprecedented inroads into the smokeless tobacco (ST) market in South Africa. However, these new ST products also carry the names of popular cigarette brands (Peter Stuyvesant, Lucky Strike, etc.). Indeed, the Peter Stuyvesant cigarette brand is popularly known among black South African youths as the 'school boy cigarette' (Rocha-Silva, De Miranda \& Erasmus, 1996). These products may therefore be intended to augment the cigarette market or substitute cigarettes when smoking is not possible (dual use), offsetting regulatory strategies such as those aimed at reducing the country's population exposure to SHS. While further studies are needed, the results presented in this dissertation suggest that caution must be applied in considering allowing the promotion of smokeless tobacco as an alternative to smoking in South Africa, as 
promoting smokeless tobacco may compromise smoking prevention among adolescents and smokeless tobacco may not be much less harmful among the adult women who mostly use these products in South Africa.

The influence of the family environment as a determinant of smoking and oral selfcare should also not be underestimated. With an increasing proportion of South African households with at least one maternal orphan (Madhavan \& Schatz, 2007); the implication for the promotion of adolescents' oral and general health becomes apparent from our proposed integrated-salutogenic model. There is a need to investigate the effect of involving the family, especially mothers, in future interventions, as this has been shown to be effective in promoting oral health among younger children (Vachirarojpisan, Shinda \& Kawaguchi, 2005) and preventing smoking onset among adolescents (Centers for Disease Control and Prevention, 1994). The fact that those in the intervention also experienced an increase in plaque levels along a non-statistically significant reduction in smoking rates indeed suggests that the LST should only be seen as part of a comprehensive programme for oral health promotion and tobacco control that goes beyond educational interventions.

We also recommend a more detailed process analysis in order to identify implementation challenges that may need to be addressed before considering diffusion of this programme.

\section{General conclusions}

In spite of the increasing expenditure on oral health services, the periodontal health of South African adolescents remains below expectation. Similarly, despite the implementation of comprehensive tobacco control legislation in South Africa, the prevalence of adolescent smoking and the related disease burden among adults remains unacceptably high. Within the limitations of the current study, namely a cross-sectional study design, the study findings, supported by the existing literature, suggest that tobacco use is a common risk factor for poor oral and general health. Considering that periodontal diseases and not dental caries was identified a priority oral disease among the adolescents in the Limpopo Province, and smokers were found to be less likely to brush regularly, tobacco control and the promotion of tooth brushing with fluoridated tooth paste should form an important part of oral health promotion programmes in the Limpopo Province.

A school-based oral health promotion programme integrated with smoking prevention was implemented to encourage adolescents to improve their oral health and avoid tobacco use by reinforcing the value they attach to fresh breath and providing them with general and substance-use specific skills, including stress management and peer resistance skills. It can be concluded that this adapted life skills training curriculum failed to demonstrate statistical significance with regard to efficacy, despite the magnitude of the effect demonstrated (a 14\% relative reduction in smoking rates). However, the programme tested was demonstrated to be very effective in promoting regular tooth brushing and subsequent improvement in oral hygiene and reduction of periodontal disease (gum bleeding/gingivitis). Nevertheless, a more detailed process analysis is still needed to identify implementation challenges in order to further elucidate why the effect of intervention on smoking reduction was not significant. It may also be worthwhile to investigate whether involving families and 
extending the education programme to parents and other family members will increase the effectiveness of the LST in promoting oral health and reducing smoking prevalence. Further studies with improved statistical power calculated based on the ICC determined in the current study would be useful in further elucidating the effectiveness of LST in tobacco use prevention. 


\section{References}

Ajzen, I. (1991). The Theory of Planned Behaviour. Organisational Behaviour and Human Decision Processes, 50, 179-211.

Ajzen, I. (2001). Nature and Operation of Attitudes. Annual Rev Psychology, 52, 27-58.

Albandar, J.M. (2002). Global risk factors and risk indicators for periodontal diseases. Periodontology 2000, 29: 177-206.

Albandar, J.M., Streckfus, C.F., Adesanya, M.R. and Winn, D.M. (2000). Cigar, pipe, and cigarette smoking as risk factors for periodontal disease and tooth loss. Journal of Periodontology, 71: 1874-1881.

Antonovsky, A. (1993). The structure and properties of the sense of coherence scale. Social Science \& Medicine, 36: 725-733.

Antonovsky, H. and Sagy, S. (1986). The development of a sense of coherence and its impact on responses to stress situations. Journal of Social Psychology, 126: 213-225.

Attwood, D., West, P. and Blinkhorn, A.S. (1993). Factors associated with the dental visiting habits of adolescents in the west of Scotland. Community Dental Health, 10: 365-373.

Axelsson, P., Paulander, J. and Lindhe, J. (1998). Relationship between smoking and dental status in 35-, 50-, 65-, and 75-year-old individuals. Journal of Clinical Periodontology, 25: 297-305.

Ayo-Yusuf, O.A, Reddy, P.S. and Van den Borne, B.W. Longitudinal association of adolescents' sense of coherence with tooth brushing using an integrated-behaviour change model. Community Dentistry \& Oral Epidemiology (in press).

Ayo-Yusuf, O.A., Swart, T.J. and Ayo-Yusuf, I.J. (2000). Prevalence and pattern of snuff dipping in a rural South African population. South African Dental Journal, 55: 610-614.

Bandura, A. (1986). Social foundations of thoughts and action. Englewood Cliffs, NJ: Prentice Hall.

Bandura, A. (1997). Self-efficacy: The exercise of control. New York: W.H. Freeman and Company.

Bartholomew, L.K., Parcel, G.S., Kok, G. and Gottlieb, N.H. (2006). Planning health promotion programs: an intervention mapping approach ( $\left.2^{\text {nd }} \mathrm{Ed}\right)$. New York: John Wiley \& Sons.

Bonita, R. (2004). Indicators in Health. The WHO Stepwise approach - a framework for surveillance. In D.M. Bourgeois \& J.C. Llodra (Eds.), European Global Oral Health Indicators Development Project (pp. 23-24). Paris, France: Quintessence International.

Botvin, G.J., Baker, E., Dusenbury, L., Botvin, E.M. and Diaz, T. (1995). Long-term follow-up results of a randomised drug abuse prevention trial in a white middle-class population. Journal of the American Medical Association, 273: 1106-1112. 
Brandon, T.H., Herzog, T.A., Irvin, J.E. and Gwaltney, C.J. (2004). Cognitive and social learning models of drug dependence: Implications for the assessment of tobacco dependence in adolescents. Addiction, 99: 51-77.

Brown, L.F. (1994). Research in dental health education and health promotion: a review of the literature. Health Education Quarterly, 21: 83-102.

Cabrera, C., Hakeberg, M., Ahlqwist, M., Wedel, H., Björkelunde, C., Bengtsson, C., et al. (2005). Can the relationship between tooth loss and chronic disease be explained by socio-economic status? A 24-year follow-up from the population of women in Gothenburg, Sweden. European Journal of Epidemiology, 20: 229-236.

Centers for Disease Control and Prevention. (1994). Guidelines for school health programs to prevent tobacco use and addiction. Centers for Disease Control and Prevention. Morbidity and Mortality Weekly Report. Recommendations and Reports, 43(RR-2), 1-18.

Chassin, L., Presson, C.C., Sherman, S.J. and Edwards, D.A. (1991). Four pathways to young-adult smoking status: Adolescent social-psychological antecedents in a Midwestern community sample. Health Psychology, 10: 409-418.

Corless, I.B., Nicholas, P.K., Wantland, D., McInerney, P., Ncama, B., Bhengu, B., et al. (2006). The impact of meaning in life and life goals on adherence to a tuberculosis medication regimen in South Africa. International Journal of Tuberculosis and Lung Disease, 10: 1159-1165.

Deinzer, R., Granrath, N., Spahl, M., Linz, S., Waschul, B. and Herforth, A. (2005). Stress, oral health behaviour and clinical outcome. British Journal of Health Psychology, 10: 269-283.

De Vries, H., Mudde, A., Leijs, I., Charlton, A., Vartiainen, E., Buijs, G., et al. (2003). The European Smoking Prevention Framework Approach (EFSA): an example of integral prevention. Health Education Research, 18: 611-626.

Dolcini, M.M., Adler, N.E., Lee, P. and Bauman, K.E. (2003). An assessment of the validity of adolescent self-reported smoking using three biological indicators. Nicotine \& Tobacco Research, 5: 478-483.

Eriksson, M. and Lindström, B. (2006). Antonovsky's sense of coherence scale and the relation with health: a systematic review. Journal of Epidemiology \& Community Health, 60: 376-381.

Fazio, R. and Zanna, M. (1981). Direct experience and attitude-behaviour consistency. Advances in Experimental Social Psychology, 14: 161-202.

Fishbein, M., Triandis, H. C., Kanfer, F. H., Becker, M. H., Middlestadt, S. E. and Eichler, A. (2001). Factors influencing behaviour and behaviour change. In A. Baum, T. R. Revenson, \& J. E. Singer (Eds), Handbook of health psychology (pp. 3-17). Hillsdale, NJ: Lawrence Erlbaum.

Flay, B (1985). Psychosocial approaches to smoking prevention: A review of the findings. Health Psychology, 4: 449-488. 
Freire, M.C.M., Hardy, R. and Sheiham, A. (2002). Mothers' sense of coherence and their adolescent children's oral health status and behaviours. Community Dental Health, 19: 2431.

Freire, M.C.M., Sheiham, A. and Hardy, R. (2001). Adolescents' sense of coherence, oral health status, and oral health-related behaviours. Community Dentistry \& Oral Epidemiology, 29: 204-212.

Glanz, K., Maskarinec, G. and Carlin, L. (2005). Ethnicity, sense of coherence, and tobacco use among adolescents. Annals of Behavioral Medicine, 29: 192-199.

Glynn, T. (1989). Essential elements of school-based smoking prevention programs. Journal of School Health, 59: 181-187.

Gollwitzer, P. (1993). Goal achievement: The role of intentions. In W. Stroebe \& M. Hewstone (Eds), European Review of Social psychology (pp. 141-185). Chichester, England: Wiley.

Gollwitzer, P. and Brandstätter, V. (1997). Implementation intentions and effective goal pursuit. Journal of Personality and Social Psychology, 73: 186-199.

Goodall, C. and Appiah, O. (2008). Adolescents' perceptions of Canadian cigarette package warning labels: Investigation the effects of message framing. Health Communication, 23: 117-127.

Hollister, M.C. and Anema, M.G. (2004). Health behaviour models and oral health: a review. Journal of Dental Hygiene, 78: 1-8.

Källestål, C., Dahlgren, L. and Stenlund, H. (2000). Oral health behaviour and self-esteem in Swedish children. Social Science \& Medicine, 51: 1841-1849.

Källestål, C., Mattson, L. \& Holm, A.K. (1990). Periodontal conditions in a group of Swedish adolescents. (I). A descriptive epidemiologic study. Journal of Clinical Periodontology, 17: 601-608.

Kallio, P. (1996). Self-assessed bleeding in monitoring gingival health among adolescents. Community Dentistry \& Oral Epidemiology, 24: 128-132.

Kallio, P., Nordblad, A., Croucher, R., and Ainamo, J. (1994) Self-reported gingivitis and bleeding gums among adolescents in Helsinki. Community Dentistry \& Oral Epidemiology, 22: 277282.

Kurer, J.R., Watts, T.L., Weinman, J. and Gower, D.B. (1995). Psychological mood of regular dental attenders in relation to oral hygiene behaviour and gingival health. Journal of Clinical Periodontology, 22: 52-55.

Macgregor, I.D.M, Balding, J. and Regis, D. (1996). Tooth brushing schedule, motivation and 'lifestyle' behaviours in 7,770 young adolescents. Community Dental Health, 13: 232-237. 
Macgregor, I.D.M., Regis, D. and Balding, J.W. (1997). Self-concept and dental health behaviours in adolescents. Journal of Clinical Periodontology, 24: 335-339.

Madhavan, S. and Schatz, E.J. (2007). Coping with change: household structure and composition in rural South Africa, 1992-2003. Scandinavian Journal of Public Health Supplement, 69: 85-93.

Maibach, E. and Murphy, D.A. (1995). Self-efficacy in health promotion research and practice: conceptualization and measurement. Health Education Research, 10: 37-50.

McSherry, W.C. and Holm, J.E. (1994). Sense of coherence: its effects on psychological and physiological processes prior to, during, and after a stressful situation. Journal of Clinical Psychology, 50: 476-487.

Medical Research Council of South Africa (MRC) (2007). South African tobacco and substance use prevention school based study - the effectiveness of 2 curricula. Retrieved 11 December 2007, from

http://www.mrc.ac.za/healthpromotion/tobaccostudy.pdf

Murray, D.M. and Perry, C.L. (1987). The measurement of substance use among adolescents: when is the 'bogus pipeline' method needed? Addictive Behaviors, 12: 225-233.

Murray, D.M. and Short, B.J. (1997). Intra-class correlation among measures related to tobacco use by adolescents: estimates, correlates, and applications in intervention studies. Addictive Behaviors, 22: 1-12.

Nicolau, B., Marcenes, W., Hardy, R. and Sheiham, A. (2003). A life-course approach to assess the relationship between social and psychological circumstances and gingival status in adolescents. Journal of Clinical Periodontology, 30: 1038-1045.

Offenbacher, S. and Weathers, D.R. (1985). Effects of smokeless tobacco on the periodontal, mucosal and caries of adolescent males. Journal of Oral Pathology, 14: 169-181.

Panday, S. (2005). Smoking: prevention and cessation among adolescents in South Africa. PhD dissertation (Chapter 2; pp. 50). Maastricht University, Netherlands.

Parcel, G., Kelder, S. and Basen-Engquist, K. (2000). The school as setting for health promotion. In B. Poland, L. Green, \& I. Rooman (Eds), Settings for Health Promotion (pp. 86-137). Thousand Oaks: Sage Publications.

Patrick, D.L., Cheadle, A., Thompson, D.C., Diehr, P., Koepsell, T. and Kinnes, S. (1994). The validity of self-reported smoking: a review and meta-analysis. American Journal of Public Health, 84: 1086-1093.

Pincus, D.B. and Friedman, A.G. (2004). Improving children's coping with everyday stress: transporting treatment interventions to the school setting. Clinical Child and Family Psychology Review, 7: 223-240. 
Prochaska, J.O. and Velicer, W.F. (1997). The trans-theoretical model of health behaviour change. American Journal of Health Promotion, 12: 38-48.

Prochaska, J.O., Redding, C.A. and Evers, K.E. (2002). The trans-theoretical Model and Stages of Change. In K. Glanz, C.E. Lewis, \& B.K. Rimer (Eds), Health behaviours and health education: Theory, research, and practice ( $3^{\text {rd }}$ ed., pp.99-120). San Franscisco: Jossey-Bass.

Reddy, P. (1999). Tobacco control as a model of health promotion in South Africa. Health Promotion: Global Perspective. Retrieved on 14 February 2008 from http://www.healthpromotionjournal.com/publications/global/2000-09/\#SouthAfrica

Reddy, S.P., Panday, S., Swart, D., Jinabhai, C.C., Amosun, S.L., James, S. et al. (2003). Umthnte Uhhaba Usamila - The South African Youth Behaviour Survey 2002. Cape Town: South African Medical Research Council.

Redmond, C.A., Blinkhorn, F.A., Kay, E.J., Davies, R.M., Worthington, H.V. and Blinkhorn, A.S. (1999). A cluster randomized controlled trial testing the effectiveness of a school-based dental health education program for adolescents. Journal of Public Health Dentistry, 59: 1217.

Republic of South Africa. Education Act 84 of 1996. Pretoria: Government Printer.

Resnicow, K., Reddy, P.S., James, S., Omardie, R.G., Kambaran, N.S., Langner, H.G. et al. Comparison of two school-based smoking prevention programs among South African high school students: results from a randomized trial. Annals of Behavioral Medicine (in press).

Rocha-Silva, L., De Miranda, S. and Erasmus, R. (1996). Alcohol, Tobacco, and Other Drug Use Among Black Youth. Pretoria: HSRC Publishers.

Rodu, B. and Godshall, W.T. (2006). Tobacco harm reduction: an alternative cessation strategy for inveterate smokers. Harm Reduction Journal, 3: 37.

Savolainen, J., Knuuttila, M., Suominen-Taipale, L., Martelin, T., Nordlad, A., Niskanen, M., et al. (2004). A strong sense of coherence promotes regular dental attendance in adults. Community Dental Health, 21: 271-276.

Savolainen, J.J., Suominen-Taipale, A.L., Uutela, A.K., Martelin, T.P., Niskanen, M.C. and Knuuttila, M.L. (2005). Sense of coherence as a determinant of tooth brushing frequency and level of oral hygiene. Journal of Periodontology, 76: 1006-1012.

Sheeran, P. (2002). Intention-behaviour relations: A conceptual and empirical review. In W. Stroebe \& M. Hewstone (Eds), European Review of Social psychology (pp. 1-36). Chichester, England: Wiley.

Sheeran, P. and Orbell, S. (1999). Using implementation intentions and repeated behaviour: augmenting the predictive validity of the theory of planned behaviour. European Journal of Social Psychology, 29: 349-369. 
Sheeran, P. and Silverman, M. (2003). Evaluation of three interventions to promote workplace health and safety: evidence for the utility of implementation intentions. Social Science and Medicine, 56: 2153-2163.

Statistics South Africa (2001) Census in brief. Pretoria: RSA Government printers.

Stokes, E., Ashcroft, A. and Platt, M.J. (2006). Determining Liverpool adolescents' beliefs and attitudes in relation to oral health. Health Education Research, 21: 195-205.

Strecher, V., Wang, C., Derry, H., Wildenhaus, K. and Johnson, C. (2002). Tailored interventions for multiple risk behaviours. Health Education Research, 17: 619-626.

Swart, D., Reddy, P., Panday, S., Phillip, J.L., Naidoo N. and Ngobeni, N. (2004). The 2002 Global Youth Tobacco Survey (GYTS): The $2^{\text {nd }}$ GYTS in South Africa - A comparison between GYTS (SA) 1999 and GYTS (SA) 2002. Cape Town: South African Medical Research Council.

Taani, D.Q., and Alhaija D.S. (2003). Self-assessed bleeding as an indicator of gingival health among 12-14-year-old children. Journal of Oral Rehabilitation, 30: 78-81.

Tabachnick, B.G and Fidell, L.S. (2007). Using Multivariate Statistics. (5 $5^{\text {th }}$ Ed). Boston: Pearson Education, Inc.

Taguchi, A., Sanada, M., Suei, Y., Ohtsuka, M., Lee, K., Tanimoto, K., et al. (2004). Tooth loss is associated with an increased risk of hypertension in postmenopausal women. Hypertension, 43: $1297-1300$.

Unger, J.B., Rohrbach, L.A., Howard-Pitney, B., Ritt-Olson, A. and Mouttapa, M. (2001). Peer influence and susceptibility to smoking among Californian adolescents. Substance Use \& Misuse, 36: 551-571.

Vachirarojpisan, T., Shinda, K. and Kawaguchi, Y. (2005). The process and outcome of a programme for preventing early childhood caries in Thailand. Community Dental Health, 22: 253-259.

Van Wyk, P.J. (2003). National Children's Oral Health Survey South Africa, 1999-2002. Pretoria. UPrinters.

Watt, R.G. (2002). Emerging theories into the social determinants of health: implications for oral health promotion. Community Dentistry \& Oral Epidemiology, 30: 241-247.

Watt, R.G. and Marinho, V.C. (2005). Does oral health promotion improve oral hygiene and gingival health? Periodontology 2000, 37: 35-47. 


\section{Summary}

Common oral conditions and diseases such as stained teeth, bad breath, dental caries, periodontal diseases and oral cancer have a negative effect on people's overall quality of life, self-esteem and social confidence. The continuing high social and economic burden of oral diseases also has implications for the use of scarce resources in South Africa and therefore calls for novel approaches to oral health promotion.

Poor diet, tobacco use, inadequate hygiene and stress are risk factors commonly linked to the development of several chronic oral and systemic diseases. Hence, the 'commonrisk approach' to oral health promotion, which suggests directing actions towards these common risks and their underlying determinants as a way to improve the efficiency and effectiveness of public oral health interventions, is becoming increasingly popular worldwide. However, although this approach was adopted by the World Health Organization (WHO) as a formal resolution at its 2007 world health assembly, thus far, only limited empirical evidence is available on the effectiveness of such an integrated approach at a programmatic level.

Given the high disease burden (including oral diseases) associated with smoking in South Africa, the present thesis therefore evaluated the effectiveness of a school-based oral health promotion intervention integrated with a smoking prevention programme. Evidence in support of the adoption of the LifeSkills training (LST) programme concerned is also presented in the thesis.

The introductory section of the dissertation provides an overview of the oral health status, tobacco use prevalence and prevention in South Africa. This section of the dissertation also provides an overview of the theoretical grounding for the studies conducted and reported in this thesis.

The individual studies in Part 1 of this dissertation (Chapters 1 to 3 ) confirm that smoking is a modifiable common-risk factor in poor oral health, gingivitis in particular (Chapter 1), and for systemic diseases that impose a significant health-related burden in South Africa, namely hypertension (Chapter 2) and chronic bronchitis (Chapter 3). In Chapter 1 , adolescents' predisposition to cope adequately with stress, as indicated by a higher sense of coherence (SOC), not living in a poor household and having adequate dental plaque control were all associated with good gingival health. The study reported in Chapter 2 not only demonstrates that smoking is significantly associated with tooth loss, but also suggests that complete tooth loss is a risk indicator for hypertension. Furthermore, the study in Chapter 3 reports the first demonstration of an association between smokeless tobacco (snuff) use and chronic bronchitis in South Africa. It was therefore concluded in Chapter 3 that the use of snuff in South Africa as an alternative to smoking may be as harmful to health as smoking itself.

The results from the studies reported in the first part of this dissertation therefore provide motivation for understanding why South African adolescents smoke and why they develop irregular tooth brushing behaviour, as well as the impact of tobacco use on oral health and related effects. 
In the second part of this dissertation two longitudinal studies were conducted to identify determinants of regular tooth brushing (Chapter 4) and smoking onset among adolescents (Chapter 5).

The findings of the study reported in Chapter 4, consistent with the salutogenic theory, demonstrate that a predisposition to adequately coping with stress was associated with regular tooth brushing behaviour among adolescents (aged 12 to 19 years). The study reported in Chapter 4 showed that adolescents who did not live with their mother and who were regular smokers were less likely to brush regularly. The study findings reported in Chapter 5, consistent with outcome expectancy theory, suggest that a negative smokingrelated attitude to oral health, in addition to peer influence, was associated with smoking onset among adolescents. Smoking onset was least likely when youth strongly believe that smoking causes bad breath and that bad breath has negative social consequences, such as peer rejection.

The results from the determinant studies reported in Part 2 of this dissertation provide the evidence base for the implementation and evaluation of an intervention integrating oral health promotion with a social skills-based smoking prevention curriculum - LifeSkills Training (Chapter 6). Where information about the health consequences of smoking was included, the focus was on salient short-term health consequences (such as bad breath and stained teeth) and their subsequent influence on social interaction, especially as it relates to the adolescents' romantic aspirations.

Based on the results of this part of the dissertation, it was concluded that the Life Skills Training curriculum that was evaluated was significantly effective in promoting adolescents' regular tooth brushing behaviour and good gingival health. However, the intervention did not significantly reduce smoking prevalence, even though the intervention increased baseline non-smokers' cigarette-offer refusal self-efficacy (Chapter 6).

The last section of the dissertation discussed the results of the different studies presented, including their theoretical and practical implications, and their methodological limitations. It also made suggestions for future research. 


\section{Samenvatting}

Het vaak voorkomen van bruine tanden, slechte adem en aandoeningen als cariës, periodontale ziekten en kanker in de mondholte, hebben een negatieve invloed op de algemene kwaliteit van leven, op het gevoel van eigenwaarde en op zelfvertrouwen in sociale situaties. De blijvend hoge maatschappelijke en economische lasten als gevolg van ziekten in de mondholte, doen ook een aanslag op de beperkte middelen voor de gezondheidszorg in Zuid Afrika en vragen om nieuwe benaderingen in de bevordering van de mondgezondheidszorg.

Ongezond eten, tabaksgebruik, slechte hygiëne en stress zijn factoren die vaak samengaan met het ontstaan van verschillende chronische aandoeningen van de mondholte zoals cariës en periodontale ziekten, en met vaak voorkomende ziekten als chronische bronchitis, hoge bloeddruk en kanker. Het identificeren van algemene risicofactoren voor de mondgezondheid, het bepalen van de determinanten van die factoren en het op basis daarvan ontwikkelen van interventies ter bevordering van de efficiency en effectiviteit van openbare mondgezondheidszorg, is steeds gebruikelijker. Hoewel deze aanpak in de openbare mondgezondheidszorg recent is aangenomen door de Wereld Gezondheidsorganisatie (WHO) en verwoord in een formele resolutie in haar jaarlijkse bijeenkomst in 2007, is er op programmaniveau nog slechts weinig wetenschappelijk bewijs voor de effectiviteit van deze geïntegreerde benadering.

Tegen de achtergrond van de hoge ziektelasten, waaronder ziekten van de mondholte, in Zuid Afrika als gevolg van roken, wordt in dit proefschrift de effectiviteit geëvalueerd van een mondgezondheidsprogramma voor scholieren dat was geïntegreerd in een rookpreventieprogramma. Resultaten die een bredere toepassing van dit "Life skills" programma ondersteunen, worden eveneens gepresenteerd. In het eerste deel van het proefschrift (hoofdstuk 1 tot en met 3) wordt een overzicht gegeven van de mondgezondheid en van het roken en de rookpreventie in Zuid Afrika evenals een overzicht van de theoretische achtergronden van de studies in dit proefschrift. Eveneens wordt in deel 1 vastgesteld dat roken een risicofactor is voor zowel een slechte mondgezondheid, in het bijzonder ontsteking van het tandvlees (hoofdstuk 1) alsook voor veel voorkomende ziekten die een grote belasting vormen voor Zuid Afrika, te weten hoge bloeddruk (hoofdstuk 2) en chronische bronchitis (hoofdstuk 3). In hoofdstuk 1 wordt eveneens vastgesteld dat adolescenten die goed konden omgaan met stress blijkend uit een hoge "Sence of Coherence (SOC) ", die niet uit een arm gezin kwamen en die een goede mondhygiëne beoefenden, minder tandvleesontstekingen vertoonden. Het onderzoek dat is gerapporteerd in hoofdstuk 2 laat niet alleen zien dat roken samenhangt met verlies van tanden, maar laat tevens zien dat het verlies van het hele eigen gebit een risicofactor vormt voor het krijgen van een hoge bloeddruk. Het onderzoek dat is gerapporteerd in hoofdstuk 3 laat voor het eerst een duidelijk verband zien tussen het gebruik van snuiftabak en chronische bronchitis in Zuid Afrika. Op basis daarvan wordt in hoofdstuk 3 geconcludeerd dat snuiftabak gebruikt als een alternatief voor roken, mogelijk even schadelijk is voor de gezondheid als het roken zelf. 
Naar aanleiding van de resultaten van de studies die zijn gerapporteerd in het eerste deel van dit proefschrift, werd verder onderzoek gedaan om te achterhalen waarom Zuid Afrikaanse adolescenten roken en waarom ze hun tanden niet regelmatig poetsen. In deel 2 van dit proefschrift worden daarom 2 longitudinale studies beschreven die werden uitgevoerd om relevante voorspellers van regelmatig poetsgedrag te bepalen (hoofdstuk 4) en om te bepalen wanneer deze adolescenten startten met roken (hoofdstuk 5).

Overeenkomend met de "salutogene" theorie laten de resultaten gepresenteerd in hoofdstuk 4, ook zien dat de capaciteit om adequaat om te gaan met stress samengaat met regelmatig tandenpoetsgedrag onder adolescenten in de leeftijd tussen 12 en 19 jaar. Het onderzoek in dit hoofdstuk laat eveneens zien dat adolescenten die in het gezin niet samenwoonden met hun moeder en die regelmatig rookten, een minder regelmatig tandenpoetsgedrag hadden. De onderzoeksresultaten die zijn gerapporteerd in hoofdstuk 5 wijzen erop dat een negatieve houding ten aanzien van roken in relatie tot mondgezondheid evenals het ervaren van sociale druk van medestudenten (peers), geassocieerd waren met het beginnen met roken door de adolescenten. Jongeren die van mening waren dat roken leidt tot een slechte adem en dat een slechte adem negatieve sociale gevolgen heeft zoals afwijzing door leeftijdsgenoten, begonnen minder snel met roken. Deze bevindingen zijn in overeenstemming met verwachtingen vanuit de "outcome expectancy" theorie.

De resultaten van de determinantenstudies die zijn gerapporteerd in hoofdstuk 4 en 5 van dit proefschrift, boden een empirische onderbouwing voor de ontwikkeling, implementatie en evaluatie van een curriculum waarin de bevordering van mondgezondheidszorg is geïntegreerd in een op sociale vaardigheden gebaseerd rookpreventieprogramma, een "social skills-based smoking prevention curriculum" (hoofdstuk 6). In dit programma werd weliswaar aandacht besteed aan de mogelijke gevolgen van roken voor de gezondheid op de langere termijn, maar er werd vooral aandacht besteed aan de korte termijn gezondheidseffecten van het roken zoals een slechte adem en bruine tanden en de gevolgen daarvan voor sociale interacties en wel in het bijzonder met betrekking tot de romantische aspiraties van adolescenten.

Op basis van de resultaten van het programma werd geconcludeerd dat het geëvalueerde Life-Style Curriculum zeer effectief was in het bevorderen van regelmatig tandenpoetsgedrag en gezond tandvlees bij adolescenten. Echter, de interventie bleek niet te leiden tot een significante vermindering van het roken, hoewel de interventie wel leidde tot een hogere self-efficacy in het afwijzen van aangeboden sigaretten (hoofdstuk 6).

In de algemene discussie en conclusies van dit proefschrift worden de resultaten van de verschillende studies gepresenteerd, terwijl tevens de theoretische en praktische implicaties worden besproken. Verder wordt daarbij ingegaan op de beperkingen van de studies en worden suggesties gedaan voor verder onderzoek. 


\section{Acknowledgements}

First to my God, I offer reverence to you for giving me the strength, character and wisdom to bring this task to completion.

I especially thank my colleagues at work that so kindly and patiently supported me through the entire time of this process by taking care of my clinical duties whenever I was away. I also extend a special thanks to Prof. AJ Ligthelm and Prof. PJ van Wyk - my Dean and Head of Department respectively - for their mentorship and support.

I thank my promoters, Bart van den Borne and Priscilla Reddy for their guidance, for reviewing numerous drafts of the manuscript and for so skillfully steering the completion of this project. Bart, I thank you for believing in me, for being a friend and for always being there, thus making Maastricht so close to home!

Thank you to Idette Noome for editing this manuscript. Marja Vissers, you were there when I needed the courage to complete this dissertation and I am grateful for that.

To Dehran Swart and Shegs James, thank you for facilitating the vital collaboration with the Life skills project under your directorship. My gratitude to Muhdni Grimwood for successfully working with tight timelines to produce the Limpopo edition of the educator's manual and learner workbooks of the Life skills training curriculum. My gratitude also goes to Max Petzold from the Nordic school of Public Health, Sweden and Roger Vaughan from Columbia University, USA, for sharpening my statistical skills.

To the dentists and hygienists in the Limpopo Department of Health, Department of Education, circuit managers, principals, Life Orientation teachers, parents and learners of the schools included in the study, thank you for your support.

And finally to my wife - Imade and my sons - Kolade and Laolu: there are no words to express my gratitude to you for unfailing support, love and care during this process. I have been an absent husband and father for the last few years and I really appreciate your tolerance and patience. Imade, this is as much your achievement as it is mine! 


\section{Curriculum Vitae}

Olalekan (Lekan) Ayo-Yusuf was born on the $11^{\text {th }}$ of May 1969 in Lagos, Nigeria. He matriculated from Eric More High School in Lagos, Nigeria. In 1992, he obtained a Bachelor of Dental Surgery (BDS) Degree from the University of Benin, Nigeria and in 1998 he obtained a Master of Science (MSc) degree in Restorative Dentistry (Cum laude) from the University of Pretoria. He then went on to complete a Master's degree in public health (MPH) in 2003 at the same University. From 1992 to 1994 he served as a dental officer at the University of Benin Teaching Hospital, Nigeria and went on to complete his National Youth Service working as a dental officer at the Randle Health Centre, Lagos, during 1994-1995. After a sting in private practice, he took up employment at the F.H. Odendal Hospital, Limpopo Province, South Africa where he worked as a senior dental officer from 1995-1998. During 1999, he was appointed, as the first dentist, to the position of Hospital Medical Superintendent (Chief Executive Officer) of this hospital. While managing the business of providing primary and secondary care at this 200-bed district hospital and attending to dental patients himself, he continued to study. He has published papers in the field of dental public health and tobacco control and has received several academic and fellowship awards. His continued interest in understanding why people use tobacco products despite knowing it would lead them to end up in hospital; the cost of which they can hardly afford in many underserved areas of South Africa, motivated him to pursue a $\mathrm{PhD}$ in health promotion, the outcome of which is the present dissertation. He is currently a senior lecturer at the Department of Community Dentistry of the University of Pretoria, a position he has held since April 2002. 


\section{Publications from this dissertation \& other related publications from the candidate}

1. Ayo-Yusuf OA, Reddy PS, van den Borne BW. Adolescents' sense of coherence and smoking as longitudinal predictors of self-reported gingivitis. Journal of clinical Periodontology 2008; 35: 931-937.

2. Ayo-Yusuf OA, Ayo-Yusuf IJ. Association of tooth loss with hypertension. South African Medical Journa/ 2008; 98: 381-385.

3. Ayo-Yusuf OA, Reddy PS, van den Borne B. Association of snuff use with chronic bronchitis among South African women: implications for tobacco harm reduction. Tobacco Contro/ 2008; 17: 99-104.

4. Ayo-Yusuf OA, Reddy PS, van den Borne BW. Longitudinal association of adolescents' sense of coherence with toothbrushing using an integrated-behaviour change model. Community Dentistry and Oral Epidemiology (in press).

5. Ayo-Yusuf OA, van den Borne B., Reddy PS, van Wyk PJ, Severson HH. Longitudinal association of smoking-related oral health attitude with adolescents' smoking onset. Journal of Public Health Dentistry 2008; Jul 22. [Epub ahead of print].

6. Postma TC, Ayo-Yusuf OA, PJ van Wyk. Socio-demographic correlates of early childhood caries in a developing country - South Africa. International Dental Journal 2008; 58: 91-97.

7. Postma TC, PJ van Wyk, Ayo-Yusuf OA. Empirical support for a fissure sealant placement timeframe protocol for black South Africans. South African Dental Journal 2008; 63: 344-347.

8. Ayo-Yusuf OA, Reddy PS, van Wyk PJ, van den Borne. Household smoking as a risk indicator for caries in adolescents' permanent teeth. Journal of Adolescent Health 2007; 41: 309-311.

9. Ayo-Yusuf OA, Ayo-Yusuf IJ and van Wyk PJ. Socio-economic inequities in dental caries experience of 12-year old South Africans: policy implications for prevention. South African Dental Journal 2007: 62: 8-11.

10. Ayo-Yusuf OA, Omole OB. Snuff use and the risk for hypertension among black South African women. South African Family Practice Journal 2008; 50: 64-64c.

11. Ayo-Yusuf OA, Peltzer K, Mufamadi J. Traditional healers' perception of smokeless tobacco use and health in the Limpopo Province of South Africa. Substance use \& Misuse 2006; 41: 211222.

12. Ayo-Yusuf OA. The WHO's framework convention on tobacco control and its relevance to the dental profession in South Africa. South African Dental Journa/2005; 60: 202-204.

13. Ayo-Yusuf OA, van Wyk C, van Wyk CW and de Wet I. Smokeless tobacco products on the South African market do not inhibit oral bacterial flora: a pilot study. Southern African Journal of Epidemiology and Infection 2005; 20: 136-139.

14. Ayo-Yusuf OA, Swart TJP, Pickworth WB. Nicotine delivery capabilities of smokeless tobacco and implications for control of tobacco dependence in South Africa. Tobacco Control 2004; 13: 186189.

15. Ayo-Yusuf, OA. Swart, TJP and Ayo-Yusuf IJ. Prevalence and pattern of snuff-dipping in a rural South African population. South African Dental Journal 2000; 55: 610-614.

16. Carpenter CM, Connolly G., Ayo-Yusuf OA, Wayne GF. Developing smokeless tobacco products for smokers: an examination of tobacco industry documents. Tobacco Control (in press). 
